NBSIR 76-1187

\title{
Interim Performance Criteria for Solar Heating and Cooling Systems in Commercial Buildings
}

Center for Building Technology Institute for Applied Technology National Bureau of Standards Washington, D. C. 20234

November 1976

Prepared for

Energy Research and Development Administration Division of Solar Energy Washington, D. C. 20545

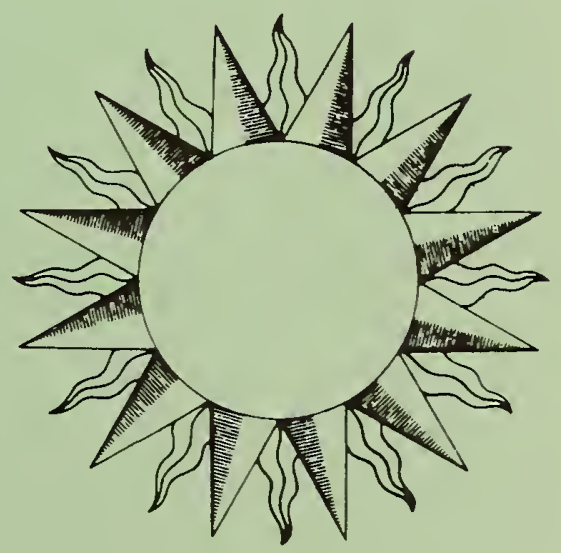





\section{INTERIM PERFORMANCE CRITERIA}

FOR SOLAR HEATING AND COOLING

SYSTEMS IN COMMERCIAL

BUILDINGS

Center for Building Technology Institute for Applied Technology

National Bureau of Standards

Washington, D. C. 20234

November 1976

Prepared for

Energy Research and Development Administration

Division of Solar Energy

Washington, D. C. 20545

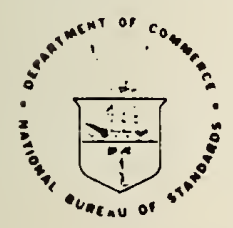

U.S. DEPARTMENT OF COMMERCE, Elliot L. Richardson, Secretary

Edward O. Vetter, Under Secretary

Dr. Betsy Ancker-Johnson. Assistant Secretary for Science and Technology

NATIONAL BUREAU OF STANDARDS. Ernest Ambler, Acting Director 



\section{ACKNOWLEDGMENTS}

The preparation of this interim document has been a joint effort of members of the Solar Energy Program Team at the National Bureau of Standards. Team members who participated in the preparation of this document include:

\begin{tabular}{ll} 
David Waksman & Robert Dikkers \\
Elmer Streed & John Holton \\
Larry Masters & James Harris \\
Leopold Skoda & Richard Crenshaw \\
Paul Brown & William Walton \\
\multicolumn{2}{c}{ Robert Beausoleil }
\end{tabular}

Typing and editing was performed by Leslie Suddueth and Mary Lou Miller.

Valuable comments regarding this document have also been received from Alwin Newton, P.E., Consulting Engineer; Andrew Parker, Mueller Associates, Inc.; and Richard Rittleman, Burt Hill and Associates.

The helpful suggestions and review comments received from Car1 W. Conner, ERDA, and William Freeborne, HUD, are also gratefully acknowledged. 
These interim performance criteria will be used for the design, development, technical evaluation and procurement of the solar heating and cooling systems to be used in commercial buildings during the solar heating and cooling demonstration program authorized by Public Law 93-409, the "Solar Heating and Cooling Demonstration Act of 1974".

This second edition of the "commercial criteria" document, prepared by the National Bureau of Standards (NBS), represents the first revision to the document prepared by the National Aeronautics and Space Administration (NASA) ${ }^{*}$ in February 1975. Major changes to the criteria and evaluation statements contained in the original NASA document are indicated by vertical lines in the margins. Where an entire section has been significantly changed or reorganized, a notation appears at the beginning of the section.

These interim criteria are intended primarily for use in the solar demonstration program. However, it is hoped that they will evolve into definitive performance criteria that can be used to develop provisions for model and local building codes as well as Federal specifications. Comments related to the usability of this document and suggested modifications are encouraged and should be sent to the following address:

Manager, Solar Energy Program

National Bureau of Standards

Building 225, Room A-114

Washington, D.C. 20234

* Interim Performance Criteria for Commercial Solar Heating and Combined Heating/Cooling Systems and Facilities, NASA, Marshal1 Space F1ight Center, Document No. 98M1001, February 28, 1975 
In view of the present accepted practice in this country for building technology, common U.S. units of measurement have been used throughout this document. In recognition of the position of the United States as a signatory to the General Conference of Weights and Measures, which gave official status to the metric SI system of units in 1960, assistance is given to the reader interested in making use of the coherent system of SI units by giving conversion factors applicable to U.S. units used in this document.

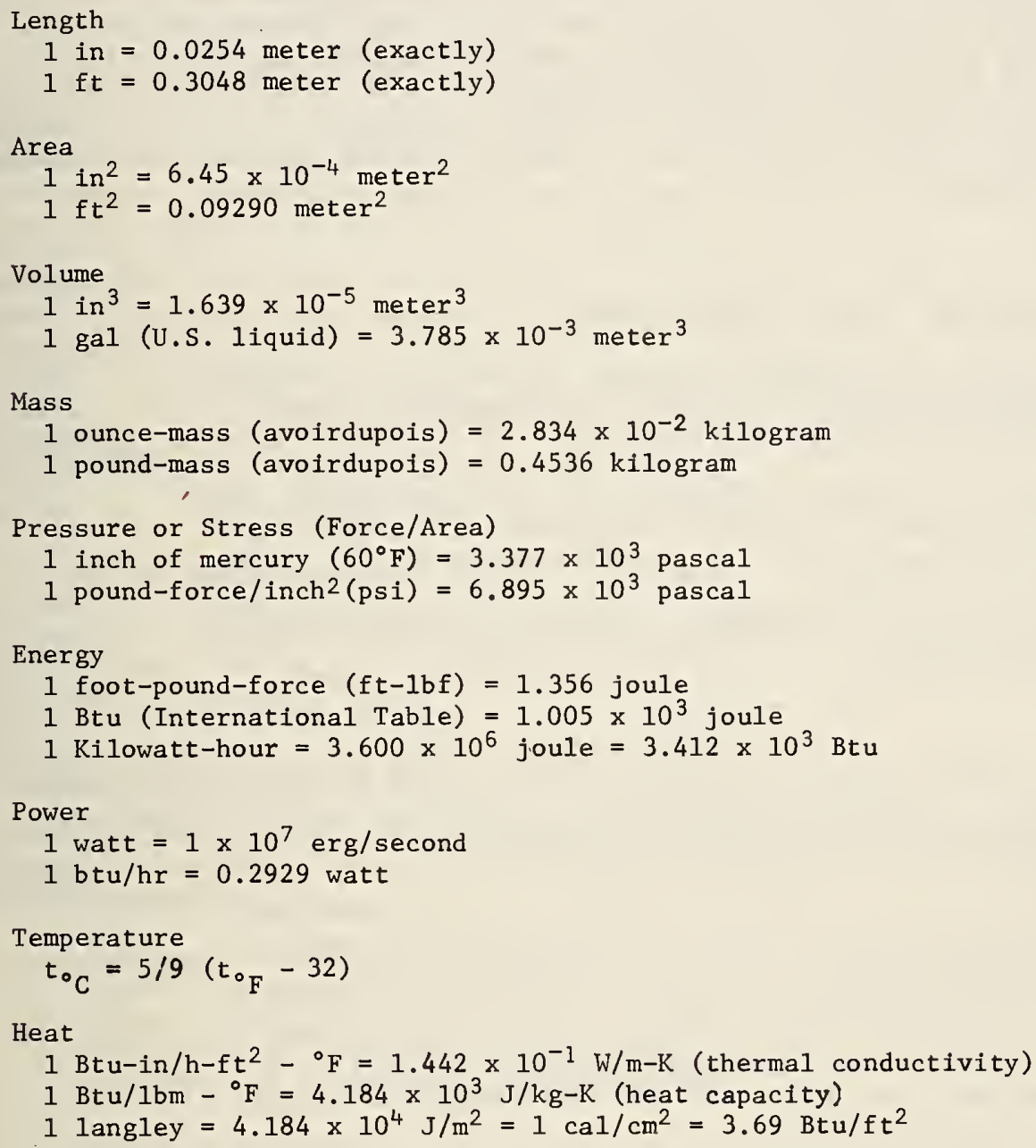

\section{Energy}

1 foot-pound-force $(\mathrm{ft}-\mathrm{lbf})=1.356$ joule

$1 \mathrm{Btu}$ (International Table) $=1.005 \times 10^{3}$ joule

1 Kilowatt-hour $=3.600 \times 10^{6}$ joule $=3.412 \times 10^{3} \mathrm{Btu}$ 


\section{Background}

Public Law 93-409, the Solar Heating and Cooling Demonstration Act of 1974, provides for "demonstration within a three-year period of the practical use of solar heating technology, and . . . the development and demonstration within a five-year period of the practical use of combined heating and cooling technology." Under the provisions of the Act, in February 1975, the NASA developed a first edition of this document containing interim performance criteria for the design and evaluation of solar heating and cooling systems to be demonstrated in commercial buildings. Since that time, responsibility for further development of the document has been assumed by the NBS. This second edition of the "commercial criteria" represents the first revision to the NASA document. It is expected that this document will be updated periodically as data and information are gained from the demonstration program.

\section{Objectives}

These interim criteria have the following objectives:

1. To provide designers, manufacturers and evaluators with the technical performance criteria that will be used for the commercial solar heating and cooling demonstration program.

2. To establish technical performance levels that will be used for the evaluation and procurement of systems, subsystems and components* for the commercial solar heating and cooling demonstration program.

3. To provide a basis for the development of more definitive performance criteria at a later date.

\section{Scope}

The interim performance criteria given for hardware related items including space heating systems, hot water systems, space cooling systems, or combinations thereof**, and their various subsystems, components, and materials are intended to:

1. establish minimum levels for health and safety that are consistent with those presently established for conventional systems used in commercial applications,

2. ensure that the proposed heating, cooling, and hot water systems, or combinations thereof, are capable of providing levels of performance consistent with those provided by conventional systems used in commercial applications.

3. verify that proposed systems, subsystems, and components are capable of providing their design performance levels, and

4. ascertain that the systems, subsystems, and components are durable, reliable, readily maintainable and generally constructed in accordance with good engineering practice.

*Definitions are given in the glossary to this document; see page 84.

**Although not specifically mentioned in PL 93-409, it is recognized in this document that not all cooling systems are combined with heating systems. 
The interim performance criteria are intended to be flexible in order to allow freedom of design and encourage innovation in keeping with the intent of Public Law 93-409.

Organization and Format

This interim document is organized on the basis of performance criteria dealing with heating and cooling systems and their integration into buildings.

Performance statement entries are presented in the Requirement, Criterion, Evaluation and Commentary format. The Requirement is a qualitative statement giving the user need or expectation for the item being addressed. It is a general statement of what the system or its subassemblies shall be able to do. The Criterion is generally a quantitative statement giving the level of performance required to meet the application or expectation for the $i$ tem being addressed. The one or more criteria associated with each requirement state those considerations which are necessary to meet the requirement. Due to limitations in the state-of-the-art, a quantitative statement is not always contained in each criterion in this document. In addition, quantitative statements have been intentionally omitted in some criteria where these values will be provided by the designer. The Evaluation sets forth the methods of test and/or other information upon which an evaluative judgment of compliance with a criterion will be based. It states the standards, inspection methods, analyses, review procedures, historical documentations, and/or methods which may be used in evaluating whether or not the system and its subassemblies as designed comply with the criterion. It is expected, in many cases, that the review of documentation of in-use performance, or professional judgment, will be used as evaluative tools in lieu of testing. The Commentary provides background for the reader and presents the rationale behind the selection of specific data presented in the Requirement, Criterion or Evaluation. The commentary is intended for information purposes, and is therefore not mandatory.

The document is divided into two parts. The first part, Systems and Components, deals with interim performance criteria for heating, cooling and hot water systems and their subassemblies. The second part, Building and Sites, presents performance criteria dealing with the interactions between the solar energy system and its surrounding environment, the building and site. These performance criteria provide for integrating the building and site with the system and its components without seriously degrading the environment or impairing the normal function of the building and its components.

Both parts of the document are organized on the basis of the first six performance attributes listed below. An additional attribute, Visual Characteristics, is considered under Building and Site.

1. Functional performance statements are used to evaluate the ability of systems and their subassemblies to operate and provide their rated output. The ability of the solar heating system to maintain the building at a specified temperature under a given set of outdoor conditions is an example of a functional consideration.

2. Mechanical performance statements treat the mechanical design and performance of the solar energy systems and their subassemblies. Factors such as the ability of the system to withstand normal design service conditions, e.g., pressure and temperature, are considered under this category.

3. Structural performance statements deal with the ability of systems and subassemblies to maintain their structural integrity under in-service and extreme conditions. Factors such as wind, snow and seismic loads are considered under this category. 
4. Safety deals with the mitigation of hazards that could result in property damage or infury and death. Hazards such as those due to fragile, toxic and/or flammable materials are considered under this category.

5. Durability/Reliability relates to the ability of systems and their subassemblies to perform designed functions for a specified interval under actual use conditions. Corrosion and thermal degradation are typical durability/reliability related items.

6. Maintainability deals with the ease with which systems and their subassemblies can be maintained in good operating condition for extended periods of time. Routine scheduled maintenance, corrective maintenance, replacements, and repairs are considered under this category. Accessibility is an important maintainability consideration.

7. Visual Characteristics deals with the relationship of the solar installation to the building and the site with regard to visual compatibility.

For the purposes of this document the various systems and subsystems treated in this document are defined as follows:

The heating (H) system is the complete assembly of subsystems and components necessary to convert solar energy into thermal energy and use this energy in combination with auxiliary energy, where required, for space heating purposes.

The cooling (C) system is the complete assembly of subsystems and components necessary to convert solar energy into thermal energy and use this energy in combination with auxiliary energy, where required, for space cooling purposes. (Where cooling is required, nocturnal radiation, evaporative cooling, and/or other means may be used in combination with, or in lieu of, heat actuated space cooling.)

The hot water (HW) system is the complete assembly of subsystems or components necessary to convert solar energy into thermal energy and use this energy in combination with auxiliary energy, where required, to provide hot water in the building. It may either be integrated directly into the $\mathrm{H}, \mathrm{C}$, or combined $\mathrm{H}$ and C (HC) systems or be completely separate from them. The term hot water as used in this document includes both domestic hot water (DHW) and commercial service hot water (SHW). The commercial service hot water may either be potable or nonpotable depending on its intended use.

The term $\mathrm{H} / \mathrm{C} / \mathrm{HW}$ system is used when a requirement or criterion is applicable to the individual $\mathrm{H}, \mathrm{C}$ or $\mathrm{HW}$ systems or any combination thereof.

The energy transport subsystem includes those portions of the $\mathrm{H} / \mathrm{C} / \mathrm{HW}$ systems which transport energy throughout the systems. Heat transfer from the collector to storage and from storage to the point of use is accomplished through the energy transport subsystem.

The control subsystem comprises all of the devices and their electrical, pneumatic or hydraulic auxiliaries used to regulate the processes of collecting, transporting, storing and utilizing energy in response to the thermal, safety and health requirements of the building occupants or building.

The auxiliary energy subsystem utilizes conventional energy sources to back up and/or supplement the output provided by the solar energy system.

The collector subsystem serves the primary function of absorbing solar energy, converting it into useful thermal energy, and transferring the thermal energy to a heat transfer fluid. It consists of the entire collector array, with its one or more collector units, together with associated manifolding and interconnections. 
The storage subsystem serves the primary function of storing thermal energy so that it can be used when required. Specific designs may utilize more than one heat storage temperature (e.g. dual temperature storage) and may also employ cold storage in all or part of the storage subsystem.

This document is not final in nature. With the present state-of-the-art, there will be a need for frequent updates to readjust levels of acceptability for both systems and components. A major reason for including a commentary in the presentation is to assure a workable process of updating these interim performance criteria by establishing the basis for selection of performance levels and methods of evaluation so that, when questions arise as to the basis for a particular criterion, the reader will have avallable the rationale behind the criterion. 
1. FUNCTION

$1.1 \mathrm{H}$ and $\mathrm{C}$ system performance. . . . . . . . . . . . . . . . . . . . . . 1

1.2 HW system/subsystem performance . . . . . . . . . . . . . . . . . . . . . . 2

1.3 Collector performance . . . . . . . . . . . . . . . . . . . . . . . 4

1.4 Thermal storage performance . . . . . . . . . . . . . . . . . . . . . 7

1.5 Component/system/space interactions . . . . . . . . . . . . . . . . . . . . 7

1.6 Energy transport performance. . . . . . . . . . . . . . . . . . . . . . . 7

1.7 Controls and instrumentation. . . . . . . . . . . . . . . . . . . . . . . 8

1.8 Auxiliary energy. . . . . . . . . . . . . . . . . . . . . . . . . . 9

\section{MECHANICAL}

2.1 System design conditions. . . . . . . . . . . . . . . . . . . . . . . 12

2.2 Mechanical stresses . . . . . . . . . . . . . . . . . . . . . 14

2.3 Leakage prevention. . . . . . . . . . . . . . . . . . . . . . . . . 16

2.4 Collector adjustments . . . . . . . . . . . . . . . . . . . . . . . 16

2.5 Heat transfer fluid quality . . . . . . . . . . . . . . . . . . . . 17

3. STRUCTURAL

3.1 Structural loading and resistance . . . . . . . . . . . . . . . . . . . 19

3.2 Function and operation. . . . . . . . . . . . . . . . . . . . . . . . 22

Appendix . . . . . . . . . . . . . . . . . . . . . . . . . . . 24

\section{SAFETY}

4.1 Health and safety . . . . . . . . . . . . . . . . . . . . . . . 31

4.2 Fail-safe controls. . . . . . . . . . . . . . . . . . . . . 31

4.3 Fire safety . . . . . . . . . . . . . . . . . . . . . . . . 32

4.4 Toxic and flamable fluids. . . . . . . . . . . . . . . . . . . . . . 34

4.5 Safety under emergency conditions . . . . . . . . . . . . . . . . . . 35

4.6 Protection of potable water and circulated air . . . . . . . . . . . . . 35

4.7 Excessive surface temperatures. . . . . . . . . . . . . . . . . . . . 37 
5. DURABILITY/RELIABILITY

5.1 Effects of external environment . . . . . . . . . . . . . . . . . . 39

5.2 Temperature and pressure resistance . . . . . . . . . . . . . . . . . . 42

5.3 Chemical compatibility of components. . . . . . . . . . . . . . . . . 44

5.4 Components involving moving parts . . . . . . . . . . . . . . . . . . . . 4 45

Appendix . . . . . . . . . . . . . . . . . . . . . . . . . 47

\section{MAINTAINABILITY}

6.1 Accessibility for maintenance and servicing . . . . . . . . . . . . . . . 64

6.2 Installation, operation, and maintenance manual . . . . . . . . . . . . . . 65

6.3 Repair and service personnel. . . . . . . . . . . . . . . . . . . 66

BUILDINGS AND SITES

7. FUNCTION

7.1 Design. . . . . . . . . . . . . . . . . . . . . . . . . 68

7.2 Adequate space. . . . . . . . . . . . . . . . . . . . . . . 68

7.3 Functioning of building and site. . . . . . . . . . . . . . . . . 69

8. MECHANICAL

8.1 Mechanical and electrical functioning of H/C/HW systems . . . . . . . . . . 72

8.2 Mechanical and electrical functioning of building and site. . . . . . . . . . 72

8.3 Mechanical and electrical functioning of connections. . . . . . . . . . . . 73

9. STRUCTURAL

9.1 Structural integrity of H/C/HW systems. . . . . . . . . . . . . . . . . 75

9.2 Structural integrity of building and site elements. . . . . . . . . . . . . . 75

9.3 Structural connections. . . . . . . . . . . . . . . . . . . . . 76

10. SAFETY

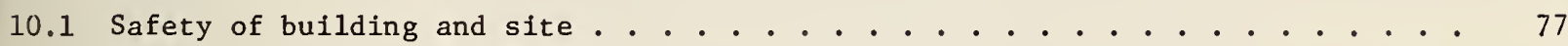

11. DURABILITY/RELIABILITY

11.1 Durability and reliability of $\mathrm{H} / \mathrm{C} / \mathrm{HW}$ systems. . . . . . . . . . . . . . . 79

11.2 Durability and reliability of building and site . . . . . . . . . . . . . 79

11.3 Durability and reliability of connections . . . . . . . . . . . . . . . 79 
12. MAINTAINABILITY

12.1 Maintainability of $\mathrm{H} / \mathrm{C} / \mathrm{HW}$ systems . . . . . . . . . . . . . 80

12.2 Maintainability of building and site . . . . . . . . . . . . 80

12.3 Maintainability of connections . . . . . . . . . . . . . . 81

13. VISUAL CHARACTERISTICS

13.1 Visual characteristics of building and site . . . . . . . . . . 82

GLOSSARY . . . . . . . . . . . . . . . . . . . . . . . 83

ABBREVIATIONS . . . . . . . . . . . . . . . . . . . . . . 88 
1.1

Requirement

1.1 .1

Criterion

Evaluation

Commentary

1.1 .2

Criterion

Evaluation

Commentary
$\mathrm{H}$ and $\mathrm{C}$ system performance. $\mathrm{H}, \mathrm{C}$, and $\mathrm{HC}$ systems shall be capable of collecting solar energy and converting it into useful thermal energy. This thermal energy and auxiliary energy, as required, shall be used to meet the total energy needs for building heating/cooling.

Heating design temperature. The heating system shall maintain the design indoor temperature for $971 / 2$ percent winter outdoor design conditions $[1]^{*}$ for the geographic area in which the system is to be operated.

Review of calculations and design parameters for compliance with ASHRAE Standard 90-75 [2]. The design load sha11 be evaluated and used on the same time basis as the solar energy system calculations (i.e., hourly, daily or monthly).

Heating equipment may be used in conjunction with the solar energy system in an assist or auxiliary mode. Passive techniques should be designed to collect, store, or distribute the thermal energy in a usable manner.

Occupied spaces for sedentary activities in normal dress are usually designed to maintain a recommended indoor temperature of $72^{\circ} \mathrm{F}\left(22^{\circ} \mathrm{C}\right)$ dry bulb [2]. Indoor design temperatures have not been specified in this criterion because they vary depending on when and how a space is used. Spaces intended to be used as part of a passive system may be designed for temperature fluctuations. Buildings with special functional requirements such as hospitals, housing for the elderly, laboratories, etc., may use other indoor design temperatures and design parameters. Additional details for design procedures utilizing energy conserving methods are available $[3,4,5]$.

Cooling design temperature. Where comfort air conditioning is required or used, the cooling system shall maintain the design indoor temperature for $21 / 2$ percent summer outdoor design conditions for the geographic area in which the system is to be operated.

Review of calculations and design parameters for compliance with ASHRAE Standard 90-75 [2]. The design load shall be evaluated and used on the same time basis as the solar energy system calculations (i.e., hourly, daily or monthly).

Air conditioning equipment may be used in conjunction with the solar system in an assist or auxiliary mode. The use of evaporation, nocturnal radiation, or other passive techniques should be designed to operate in conjunction with devices which collect, store, or distribute the converted thermal energy in a controllable manner.

Occupied spaces for sedentary activities in normal dress are usually designed to maintain a recommended indoor temperature of $78^{\circ} \mathrm{F}\left(25.5^{\circ} \mathrm{C}\right)[2]$. Indoor design temperatures have not been specified in this criterion because they vary depending on when and how a space is used. Spaces intended to be used as part of a passive system may be designed for temperature fluctuations compatible with their functional use. Buildings with special functional requirements such as hospitals, housing for the elderly, 
1.1.3 Criterion

Commentary

1.1.4 Criterion

Evaluation

Commentary

1.2 Requirement

1.2 .1

Criterion

Evaluation laboratories, etc., may use other indoor design temperatures and parameters. Additional details for design procedures utilizing energy conserving methods are available [3, 4, 5].

Relative humidity. If humidification is provided, it shall be designed to a maximum relative humidity of 30 percent. If dehumidification is provided, it shall be designed to a minimum relative humidity of 60 percent.

Review of design parameters and calculations made in accordance with ASHRAE Standard 90-75 to determine if the design relative humidity lies within the comfort evelope defined in ASHRAE Standard 55-74 [6].

Building spaces with special functional requirements may use other relative humidity design conditions. Design procedures have been establíshed to control relative humidity [1, 4]. This control should be achieved as much as possible utilizing energy that would otherwise be rejected.

Solar contribution. The average yearly contribution of solar energy to the operation of the H, C, or HC systems shall be specified in the design and shall result in a reduction in the average annual consumption of conventional energy for the total building heating/cooling needs.

Engineering review of analytical methods, drawings, test data and calculations. Analytical predictions or correlations based upon measured or simulated performance including the heating and cooling loads, solar subsystem or component performance and the climatic conditions shall be utilized to predict the percentage of average monthly and yearly total energy requirement to be provided by solar energy and auxiliary energy and to determine the operating energy and thermal losses. Hourly or daily input data intervals are required for simulation calculations. Predictions based upon correlation charts may be based upon monthly average climatic data for sites where at least 10 years of weather data are available.

Experimental verification of complete system performance is usually not practical for commercial size systems prior to installation; therefore, analytical methods employing empirical subsystem or component performance are used to calculate the performance over the full range of operating conditions. Examples of analytical methods are described in references [7, $8,9,10]$. Sources of insolation data and data reduction methods are described in references $[11,12,13,14,15]$. Performance factor definitions and evaluation procedures are presented in reference [16].

HW system/subsystem performance. The HW system shall be capable of collecting solar energy and converting it into thermal energy which shall be used in combination with storage, if provided, and auxiliary energy to supply an adequate amount of hot water at an acceptable temperature to meet the needs of the application.

Draw and temperature design output. The HW system shall be capable of providing hot water at the design temperature draw and recovery rate.

Engineering review of plans, specifications, and calculations. Total energy requirements should be based upon actual use, local water source temperature, and required hot water discharge temperatures. 
Typical methods for estimating potable hot water requirements have been described by ASHRAE [3]. The amount of hot water required will vary with climatic and application requirements. Potable hot water temperatures required can vary from $105^{\circ} \mathrm{F}$ to $180^{\circ} \mathrm{F}$ but a delivery temperature greater than $110^{\circ} \mathrm{F}$ must be used for domestic use and is recommended for calculations if the exact outlet temperature is not specified. Geographic and seasonal variations in source water temperature can be significant as shown in Table 1.2-1 and local values should be used.

Table 1.2-1

Source and Monthly Temperature $\left(t_{1}\right)$ in ${ }^{\circ} \mathrm{F}$ at Source for City Water in 14 Selected Cities (Data is for 1973) Unless Otherwise Noted

\begin{tabular}{|l|c|c|c|c|c|c|c|c|c|c|c|c|}
\hline City & Jan & Feb & Mar & Apr & May & Jun & Jul & Aug & Sep & Oct & Nov & Dec \\
\hline 1. Phoenix & 48 & 48 & 50 & 52 & 57 & 59 & 63 & 75 & 79 & 69 & 59 & 54 \\
2. Miami & 70 & 70 & 70 & 70 & 70 & 70 & 70 & 70 & 70 & 70 & 70 & 70 \\
3. Los Angeles & 50 & 50 & 54 & 63 & 68 & 73 & 74 & 76 & 75 & 69 & 61 & 55 \\
4. Albuquerque & 72 & 72 & 72 & 72 & 72 & 72 & 72 & 72 & 72 & 72 & 72 & 72 \\
5. Las Vegas & 73 & 73 & 73 & 73 & 73 & 73 & 73 & 73 & 73 & 73 & 73 & 73 \\
6. Denver & 39 & 40 & 43 & 49 & 55 & 60 & 63 & 64 & 63 & 56 & 45 & 37 \\
7. Ft. Worth & 56 & 49 & 57 & 70 & 75 & 81 & 79 & 83 & 81 & 72 & 56 & 46 \\
8. Nashville & 46 & 46 & 53 & 66 & 63 & 69 & 71 & 75 & 75 & 71 & 58 & 53 \\
9. Washington, DC & 42 & 42 & 52 & 56 & 63 & 67 & 67 & 78 & 79 & 68 & 55 & 46 \\
10. Salt Lake City & 35 & 37 & 38 & 41 & 43 & 47 & 53 & 52 & 48 & 43 & 38 & 37 \\
11. Seattle & 39 & 37 & 43 & 45 & 48 & 57 & 60 & 68 & 66 & 57 & 48 & 43 \\
12. Boston & 32 & 36 & 39 & 52 & 58 & 71 & 74 & 67 & 60 & 56 & 48 & 45 \\
13. Chicago & 32 & 32 & 34 & 42 & 51 & 57 & 65 & 67 & 62 & 57 & 45 & 35 \\
14. New York City & 36 & 35 & 36 & 39 & 47 & 54 & 58 & 60 & 61 & 57 & 48 & 45 \\
\hline
\end{tabular}

1.2.2 Criterion

Evaluation

Commentary
Non-tap temperature design output. Other commercial applications using potable (non-tap) or non-potable HW systems shall meet the temperature criteria as specified in ASHRAE [2] [3], as applicable.

Engineering review of plans, specifications, and calculations. Total energy requirements should be based upon actual demand and temperature requirements when available.

Tables estimating the demand at $140^{\circ} \mathrm{F}$ for various buildings and utilization temperatures have been prepared by ASHRAE [3] for use if the exact demand and the outlet temperature are not known. 


\subsubsection{Criterion}

Evaluation

Commentary

1.3 Requirement

1.3.1 Criterion

Evaluation

Commentary

\subsubsection{Criterion \\ Evaluation \\ Commentary}

Solar contribution. The average yearly contribution of solar energy to the operation of the HW system shall be specified in the design and shall result in a reduction in the average annual consumption of conventional energy for hot water heating.

Engineering review and analysis of drawings, test data, and calculations. Analytical predictions or correlations based upon measured or simulated performance including at least the source water temperature, hot water requirements, HW system performance, and the climatic condtions shall be utilized to predict the percentage of average monthly and yearly total energy requirements to be provided by solar energy and auxiliary energy from conventional energy sources. Hourly or daily input data intervals are required for simulation calculations. Predictions based upon correlation charts may be based upon monthly average climatic data for sites where at least 10 year weather data is available. Examples of analytical and design methods are described in references $[10,15,17,18]$.

The effectiveness of solar hot water systems is influenced by the correlation between the daily withdrawal schedule and the availability of solar energy. These parameters should be considered during the design when known.

Collector performance. The solar collectors sha11 absorb solar energy and convert it into useful thermal energy. The collectors shall be capable of dissipating thermal energy (i. e., nocturnal reradiation) where this function is included in the design.

Thermal performance of discrete collectors. The solar collectors shall collect or dissipate energy at their design values.

Engineering review of drawings, calculations, and test data. Solar collector panel performance data shall be generated using the method described in ASHRAE Standard 93-P (in preparation) [19] or any other comparable method demonstrated to have an overall limit of error of less than $\pm 5 \%$.

Typical slope intercept curves for flat black and selective coated absorber panels with one and two covers are shown in Figures 1.3-1 and 1.3-2 for air and water heat transfer fluids, respectively.

The 93-P test method will provide the efficiency as a function of operating temperature, ambient temperature, and insolation for collectors with a definable aperture or interception area. The collector must have a single heat transfer fluid inlet and outlet and must be separate from the thermal storage device. Collectors with other geometric, optical, or thermal characteristics may require additional or other tests to fully describe their thermal performance for all environmental and operating conditions. Additional information on collector design, performance, and operation is presented in reference $[10,15,20,21]$.

Thermal performance of combined active collector-storage units or passive collectors. Combined active or passive collectors shall collect or dissipate energy at their design values.

Engineering review of calculations, drawings, and test data.

Consensus methods to calculate or experimentally determine the performance of combined or integral systems do not currently exist. 


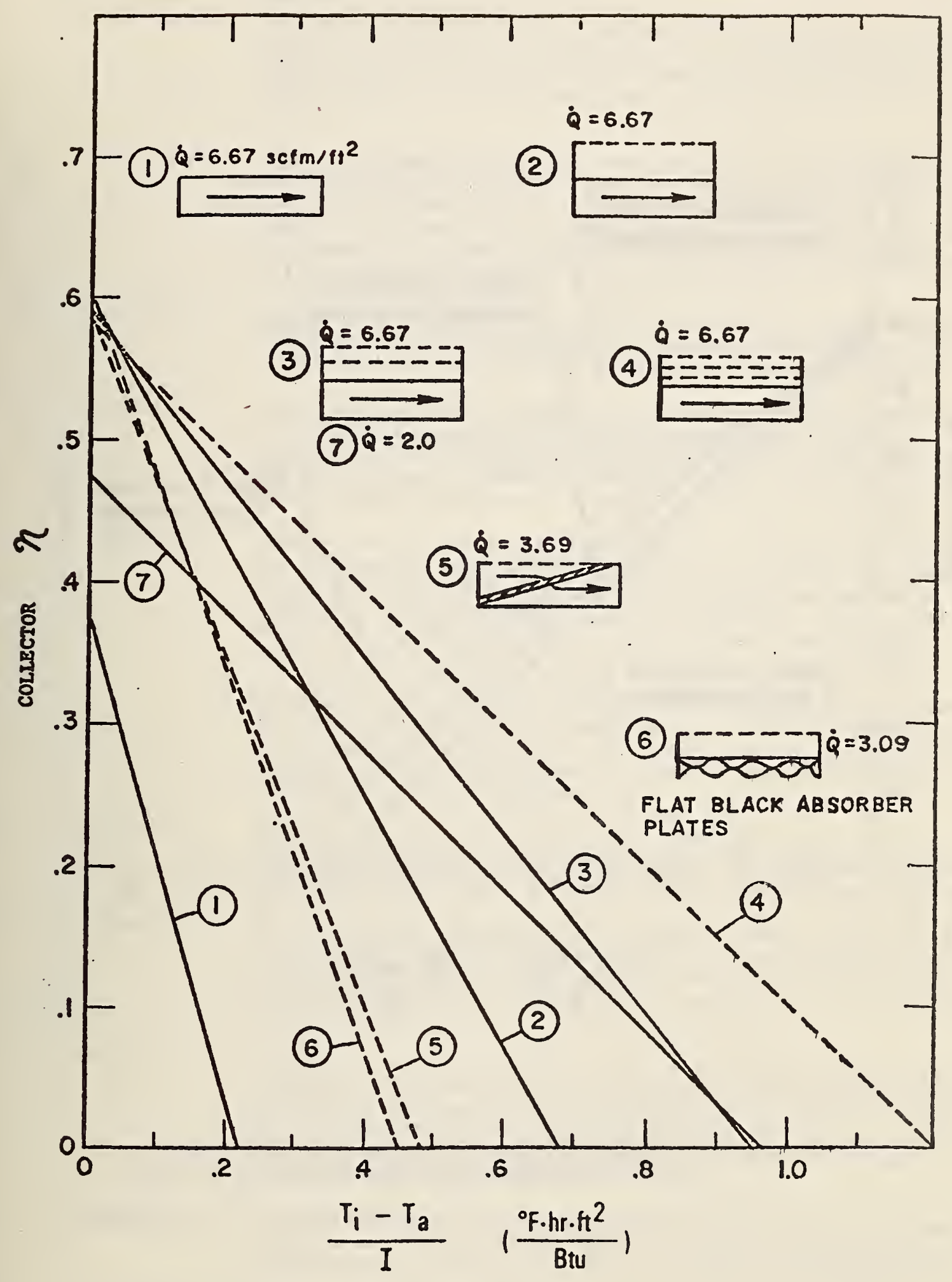

-Figure 1.3-1 Thermal Efficiency Curves For Typical Flat Plate Collectors Using Air As The Working Fluid [20] 


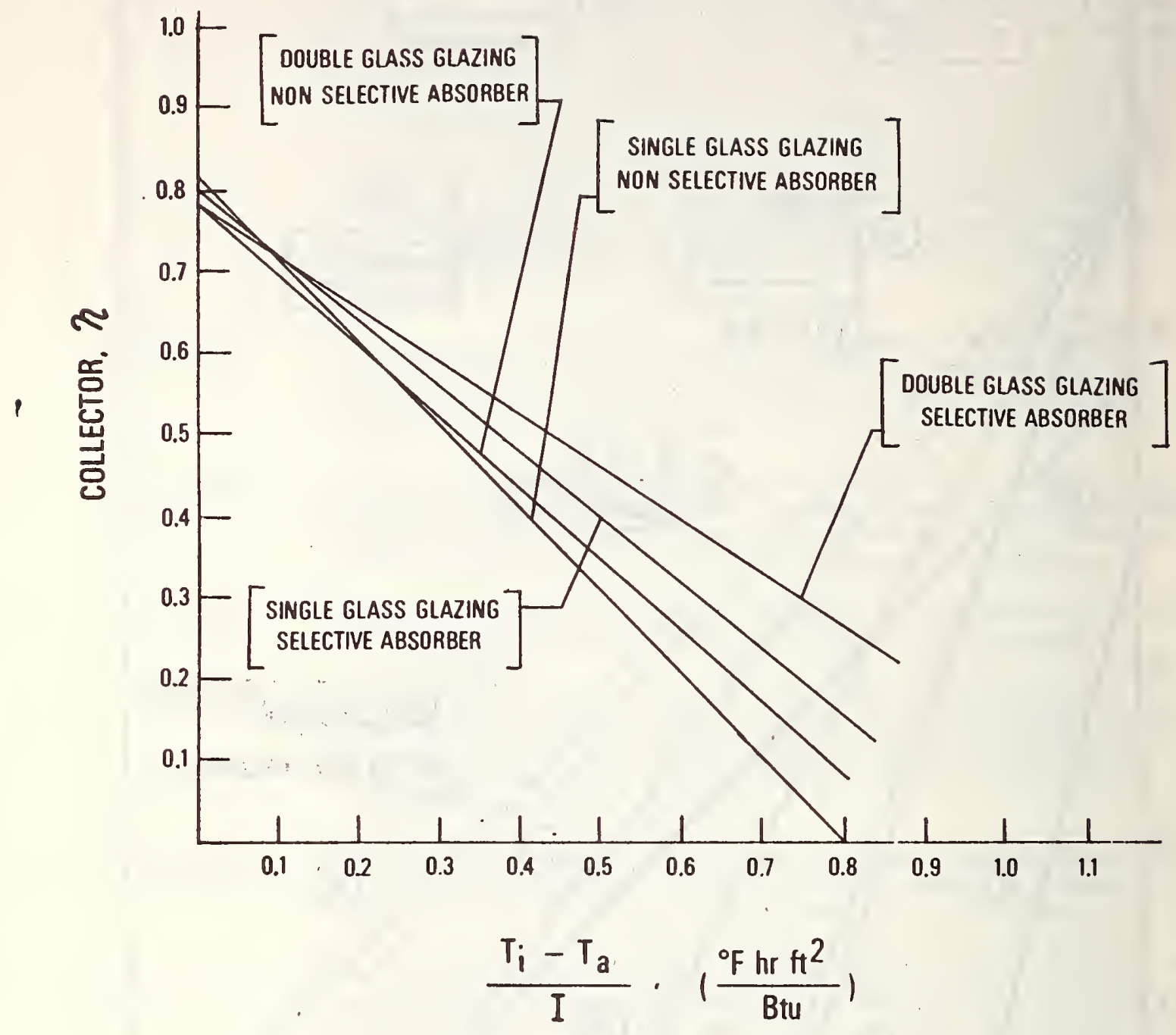

Figure 1.3-2 Thermal Efficiency Curves For Typical Flat Plate Collectors Using A Liquid Heat Transfer Fluid [19] 
1.4

Requirement

\subsubsection{Criterion}

Evaluation

Commentary

1.5

1.5.1 Criterion

Evaluation

Commentary
However, combined system performance can be predicted using the analytical methods cited in Paragraph 1.1 .4 and preliminary procedures or approaches to predicting the solar fraction of the total energy supplied by passive systems have been described [22] Comprehensive coverage of collector technology has been published [21].

Thermal storage performance. When included in the design, the storage subsystem shall be capable of providing its rated output under design loads and the required output for all part load conditions during which the solar energy system contributes heat. The storage of thermal energy from sources other than solar may be utilized when feasible.

Storage capacity and rate. The storage subsystem shall provide sufficient heat transfer rates and thermal energy capacity to absorb and store energy at the maximum design collection rate.

- Engineering review of drawings, calculations, and/or test data. The thermal storage design shall be evaluated using the procedure prescribed in NBSIR 74-635 [23] (currently under revision for publication as ASHRAE Standard 94-P [24]), or a comparable method demonstrated to have an error of $\pm 5 \%$ or 1 ess.

Criteria for thermal losses from liquid storage tanks and piping are presented in ASHRAE Standard 90-75 [2]. Thermal energy lost within the building envelope during the heating season may be credited to the solar energy system. Conversely, thermal losses during the cooling season must be considered in the design as adding to the cooling load.

Thermal storage can be provided for hot or cold applications and at a range of 'temperature in more than one container. The use of thermal storage in conjunction with heat recovery, electrical peak shaving, and dampening of time and weather dependent loads on machines should be considered.

Component/system/space interactions. The presence of system components shall not significantly affect the efficient operation of the $\mathrm{H} / \mathrm{C} / \mathrm{HW}$ systems or the habitability of the occupied spaces.

Heat or humidity transfer effects. Heat or humidity transfer from the collector, thermal storage, piping, or other elements shall not interfere with the efficient operation of the $\mathrm{H} / \mathrm{C} / \mathrm{HW}$ systems or cause loss of control of temperature, humidity, or other controlled conditions.

Engineering review of drawings, specifications, calculations, and test data. A thermal analysis including calculations of the heat transfer and condensation rates from storage containers, piping, and other thermally insulated components or test data on equivalent material and configurations may be necessary in designs where test data does not exist.

It is realized that some heat transfer from insulated piping and storage containers will occur within or under a building structure. Over-heating and condensation can create adverse conditions.

Energy transport performance. The energy transport subsystem shall transfer the required thermal energy between the operating subsystems at or above the design efficiency under full load conditions. 


\subsubsection{Criterion}

Evaluation

Commentary

\subsubsection{Criterion}

Evaluation

Commentary

1.7 Requirement

1.7.1 Criterion

Evaluation

Commentary

\subsubsection{Criterion}

Evaluation

Commentary
Thermal losses. Thermal losses for the energy transport subsystem shall not exceed the design values throughout the operating range.

Engineering review of drawings, specifications, calculations, and test data.

Criteria for thermal losses in piping and ducts are presented in ASHRAE Standard 90-75 [2]. Variations in the thermal conductivity, specific heat, and viscosity of the heat transfer medium with temperature should be considered in the design. Design data and analytical procedures for thermal insulation and heat transfer in building systems are available in the literature [1, 2, 4]. Thermal energy lost within the building envelope during the heating season may be credited to the solar energy system. Conversely, thermal losses during the cooling season must be considered in the design as adding to the cooling load.

Electrical operating energy. The use of electrical operating energy for the energy transport subsystem shall not exceed the design values throughout the operating range.

Engineering review of drawings, specifications, calculations and test data.

The electrical operating energy required for fans, pumps, controls, or valves can significantly influence the overall system efficiency. These energy requirements should be accounted for in the evaluation of overall system performance.

Controls and instrumentation. The control subsystem shall provide for the safe and proper operation of the $\mathrm{H} / \mathrm{C} / \mathrm{HW}$ systems.

Installation and maintenance. The control subsystem shall include such provision for manual bypass, adjustment, or over-ride of automatic controls as is required to facilitate installation, startup, operation, shutdown, and maintenance.

Review of drawings, specifications, and operating procedures.

Provision of manual controls may be needed during installation, startup, and operation to balance or adjust the system for proper operation. Other manual controls may be required for tests or maintenance after the system has been in operation or for seasonal shutdown. Control considerations have been discussed [10]. Controls should be considered for collector-to-storage, storage-to-load and collector protection from overheating or freezing.

Manual adjustment. If manual control adjustments are required during normal operation of the system/subsystem, the control subsystem shall ensure that the safety and durability of the system and the building in which they are installed are not compromised by failure to perform these manual control adjustments for a reasonable period of time. The time period, as well as any contingent environmental conditions, shall be stipulated by the designer.

Review of drawings, specifications, and operating procedures.

These provisions are not intended to restrict appropriate seasonal shutdown manual controls. Control considerations for solar $H$ and $C$ applications [10] and for HVAC equipment in general are discussed in references $[3,4,25]$. 
1.7.3 Criterion

1.7 .4

Criterion

Evaluation

Commentary

1.8 Requirement

1.8.1 Criterion

Evaluation

Commentary

1.8.2 Criterion

Evaluation

Commentary
Demonstration systems may require various degrees of attention for periodic adjustments. The use of main valves and duct dampers with visual position indicating devices is encouraged.

Inhabited space temperature contro1. Each H, C, or HC system shall be capable or providing occupied space temperature regulation by at least one adjustable automatic control or combination of controls and sensors set to control within the range from $55^{\circ} \mathrm{F}$ to $85^{\circ} \mathrm{F}$.

Review of drawings and specifications.

In certain multizone or multisystem applications, a priority control may be needed to avoid simultaneous heating and cooling of a common conditioned space. Localized controls for building heating and cooling are discussed in reference [3].

Hot water temperature. Potable water storage tanks providing hot domestic water directly to the hot water distribution system shall be equipped with instantaneous automatic temperature controls capable of adjustment from the lowest to the highest acceptable temperature settings for the intended use.

Review of drawings and specifications.

Location and adjustment of the HW controls can influence the use of auxiliary energy.

Auxiliary energy. The auxiliary energy subsystem shall be integrated into the systems to the extent necessary to automatically provide the designed heating, cooling, and hot water.

Design heat loads. The auxiliary energy subsystem shall be designed to meet the peak heating and hot water loads as specified in Criteria 1.1 .1 and 1.2 .1 .

Engineering review of plans, specifications, calculations, and test methods.

The purpose of this criterion is to back up the systems used in the Demonstration Program with 100 percent operating capability with the auxiliary energy subsystem when energy derived from solar radiation is not available. Design heat loads are discussed by ASHRAE $[1,2,3]$.

Design cooling load. The portion of the yearly total (latent and sensible) cooling load provided by the auxiliary energy subsystem shall not exceed the design values specified in Criteria 1.1.2 and 1.1 .3 .

Engineering review of drawings, specifications, calculations, and test data.

The design of the cooling system must carefully consider the type and amount of auxiliary energy used to ensure that a saving in conventional energy is realized with the solar cooling system. 


\section{References}

1. ASHRAE Handbook of Fundamentals - 1972.*

2. ASHRAE Standard 90-75, Energy Conservation in New Building Design, 1975.*

3. ASHRAE Handbook and Product Directory - 1973 Systems.*

4. ASHRAE Handbook and Product Directory - 1974 Applications.*

5. Energy Conservation Design Guidelines for New Office Buildings, Second Edition, July 1975, General Services Administration (3F1), Washington, D.C. 20407.

6. ASHRAE Standard 55-74, Thermal Environmental Conditions for Human Occupancy, 1974.*

7. Solar Heating and Cooling of Buildings - Phase 0, National Science Foundation Reports, NSF/RA/N-74-021B, NSF/RA/N-74-022B, and NSF/RA/N-74-023B, Washington, D.C., May 1974.t

8. Duffie, J. A. and Beckman, W. A., Solar Energy Thermal Process, Wiley-InterScience Publication, John Wiley and Sons, New York, 1974.

9. Klein, S. A., etal, "A Method of Simulation of Solar Processes and Its Applications," Solar Energy, Vol. 17, p. 29, 1975.

10. Extended Abstracts, International Solar Energy Congress and Exposition (ISEC\&E), Los Angeles, California, July 1975.

11. Liu, B. Y. H. and Jordan, R. C., "Availability of Solar Energy for Flat-Plate Solar Heat Collectors," Chap. 1, Low Temperature Engineering Application of Solar Energy, 1967 (revised edition being prepared by ASHRAE see reference 15).*

12. Bennett, I., "Monthly Maps of Mean Daily Insolation for the United States," Solar Energy, Vo1. 9, p. 145, 1965.

13. Climatic Atlas of the United States, U.S. Department of Commerce, June 1968.t

14. Climatological Data - National Summary, published monthly, National Climatic Center, Federal Building, Asheville, North Carolina 28801.

15. ASHRAE Publication, "Applications of Solar Energy for Heating and Cooling of Buildings," (in preparation).*

16. Streed, E. R., etal, "Thermal Data Requirements and Performance Evaluation Procedures for the National Solar Heating and Cooling Demonstration Program," NBSIR 76-1137, August 1976, National Bureau of Standards, Washington, D.C. 20234.

17. Gutierrez, G., Hincapie, F., Duffie, J. A. and Beckman, W. A., "Simulation of Forced Circulation Water Heaters; Effects of Auxiliary Energy Supply, Load Type and Storage Capacity," Solar Energy, Vo1. 15, p. 287-298, 1974.

18. Chinnery, D. N. W., Solar Water Heating in South Africa, NBRI Bulletin 44, Council for Scientific and Industrial Research Report 248, p. 1-79, UDC 694, 4.551.521.1 (680), Pretoria, South Africa, 1967.

19. ASHRAE Standard 93-P, "Method of Testing for Rating Solar Collectors Based on Thermal Performance," (in preparation).*

*American Society of Heating, Refrigerating and Air-Conditioning Engineers, Inc., 345 East East 47th Street, New York, N.Y. 10017.

+Superintendent of Documents, U.S. Government Printing Office, Washington, D.C. 20402. 
20. Hill, J. E., Streed, E. R., Kelly, G. E., Geist, J. C. and Kusuda, T., "Development of Proposed Standards for Testing Solar Collectors and Thermal Storage Devices," NBS Technical Note 899, February 1976, Catalog No. C13.46:899.+

21. Workshop on Solar Collectors for Heating and Cooling of Buildings, Proceedings, National Science Foundation, NSF/RA-N-75-019, May 1975.+

22. Balcomb, J. D. and Hedstrom, J. C., "Simulation Analysis of Passive Solar Heated Buildings - Preliminary Results," Report No. LA-UR-76-89, Los Alamos Scientific Laboratory, Los Alamos, New Mexico 87544.

23. Kelly, G. E. and Hill, J. E., "Method of Testing for Rating Thermal Storage Devices Based on Thermal Performance," NBSIR 74-635, National Bureau of Standards, Washington, D. C. May 1975 .

24. ASHRAE Standard 94-P, "Method of Testing Thermal Storage Devices for Thermal Performance," (in preparation).*

25. ASHRAE Handbook and Product Directory - 1975 Equipment.*

*American Society of Heating, Refrigerating and Air-Conditioning Engineers, Inc., 345

East 47th Street, New York, N.Y. 10017

+Superintendent of Documents, U.S. Government Printing Office, Washington, D.C. 20402. 
$2.1 \quad$ Requirements

2.1.1 Criterion

Evaluation

Commentary

\subsubsection{Criterion}

Evaluation

Commentary

2.1.3 Criterion

Evaluation

Commentary

2.1.4 Criterion
System design conditions. The H/C/HW systems shall be capable of functioning at their design flow rates, pressures and temperatures.

Equipment capabilities \& applicable standards. Pumps, fans, or other components shall be sized to move the heat transfer fluid through the collector, piping, and/or ducts at design flow rates. All mechanical components shall conform to applicable local and nationally recognized codes and standards.

Review of drawings, specifications, historical performance, previous test data, and design calculations. Systems or applications that do not lend themselves to engineering analysis may require prototype tests to demonstrate compliance.

In order to transfer heat through the system/subsystem, a number of different transfer approaches such as gravity circulation, combined forced and gravity circulation, or forced circulation may be used.

Noise or erosion-corrosion. The piping or ducts and associated fittings shall be sized to carry the heat transfer fluid at design flow rates without excessive noise as prescribed by reference [1] or erosion-corrosion.

Review of drawings, specifications, historical performance, previous test data and design calculations.

Reference [2] provides organized design practices for transfer fluid limit velocities in piping systems. In air ducts, the velocities normally should not exceed the recognized values of ASHRAE or Sheet Metal and Air Conditioning Contractors National Association (SMACNA).

Operating conditions. Collectors, space heaters, water heaters, pumps, valves, regulating orifices, pressure regulators and other fluid handling components shall be capable of being operated over the pressure and temperature ranges anticipated in actual service without breakage, rupture, binding, galling, or significant loss or gain in pressure that could impair their intended function.

Review of drawings, specifications, historical performance, previous test data and design calculations. Systems or components that do not lend themselves to engineering analysis shall be tested at the maximum and minimum service temperatures with anticipated fluid pressures. To show compliance with this criterion it is desirable that the design consist of components that are covered by recognized standards, where available, and are specified by the manufacturer to be suitable for the pressure, temperature, and flow application.

Available codes and standards are listed by ASHRAE [3].

Fluid flow in collectors. When an array of collectors is connected by manifolds, provision shall be incorporated in the manifolds and/or collectors to maintain the design flow rate of the heat transfer fluid through each collector. 
Evaluation

Commentary

2.1.5 Criterion

Evaluation

Commentary

2.1.6 Criterion

Evaluation

Commentary

\subsubsection{Criterion}

Evaluation

Commentary
Review of drawings, specifications, historical performance, previous test data, and design calculations or testing to determine that each collector will receive its design flow rate.

Because of friction and variation in velocity head in manifolding, flow rates may be inadequate through collectors remote from the pump or other fluid supply source. This can result in inefficient collector operation. The provision of flow regulating devices is one means of correcting for this problem. Another method is the use of reversed supply and return headers for parallel arrays of collectors with graduated header sizes to compensate for changes in flow rate [4].

Consideration should be given to the effect of header arrangement on collector array $\Delta \mathrm{T}$.

Entrapped air. When liquid heat transfer fluids are used, the system shall provide suitable means for air or gas removal from high points in the piping system.

Review of drawings and specifications.

Except for expansion tanks and air chambers where trapped air is required, trapped air in piping systems and collectors can impede the flow of liquids through piping, reduce heat transfer potential and otherwise reduce overall system efficiency. The freezing of exposed air vent fittings has been known to occur and create trapped air conditions in solar piping systems. The potential bulldup of vapor which could create air pockets and thus block or restrict the flow of heat transfer fluids should be considered.

Thermal expansion of fluids. Adequate provisions for the thermal expansion of heat transfer fluids that can occur over the service temperature range shall be incorporated into the system design. Expansion tanks shall be sized in accordance with the recommendations of ASHRAE.

Review of drawings, specifications, and design calculations.

Water expands about $4 \%$ in volume when heated from $40^{\circ} \mathrm{F}$ to $200^{\circ} \mathrm{F}$, Other heat transfer fluids will have different coefficients of volume expansion. Means should be provided in the system design to contain this additional fluid volume without exceeding the operating pressure of the system or resulting in spillage.

Pressure drops. Pressure drops shall not exceed the limits specified in the design. Pipe sizing shall be in accordance with recognized methods.

Review of drawings, specifications, and design calculations.

Since the energy requirements of pumps and fans are a function of the system flow resistance, pressure drops should be kept as low as practical. The unnecessary use of fittings such as bends, tees, globe valves, reducers, or obstructions to flow should be avoided by careful arrangement of piping runs. Accepted practices for plumbing design are discussed in standard plumbing guides [5] [6]. It is possible to design solar energy systems that consume more conventional energy than the systems that they replace because of high operating power requirements. 
2.1.8 Criterion Alr transport system. Design of all air heating and air conditionIng systems shall be in accordance with applicable recommendations of ASHRAE, National Environmental Systems Contractors Association (NESCA), or Air-Conditioning and Refrigeration Institute (ARI). Installation shall comply with National Fire Protection Association (NFPA) standards $90 \mathrm{~B}, 31$ and 54.

Evaluation Review of plans and specifications.

Commentary Duct work should be designed for the shortest practical run and elbows should be kept to a minimum. Constrictions should be avoided.

\begin{tabular}{|ll} 
2.1.9 & Criterion \\
& Evaluation \\
& Criterion \\
& Evaluation \\
& Commentary \\
2.1 .10 & Requirement \\
& \\
2.2 .1 & Criterion
\end{tabular}

Evaluation

Commentary

2.2.2 Criterion
Air discharge openings. Alr discharge openings through roofs or exterior walls shall not be located such that their exhaust will cause the deposttion of grease, lint, condensation or other deleterious materials on solar optical components.

Review of plans and specifications.

Thermosyphoning losses. Means shall be provided to prevent undesired loss of thermal energy from storage through thermosyphoning action.

Review of drawings and specifications.

Significant losses of energy from storage can occur through this mechanism. Some designs may use thermosyphoning of energy from storage as a means of protection from freezing.

Mechanical stresses. Mechanical stresses that arise within the system shall not cause damage to or malfunction of the system or its components

Vibration stress levels. Vibrations in piping, ducts, instrumentation lines, and control devices shall be controlled to reduce stress levels below those that could cause fatigue and subsequent component damage.

Review of drawings, specifications, historical performance, and previous test data for adequate piping and equipment supports.

Examples of possible vibration sources in piping are as follows:

a. Lengths of piping and connecting equipment that are resonant with pressure pulsation frequency.

b. Vibration resulting from motors, pumps, fans, and compressors which are not properly mounted.

c. Water hammer and quick closing valves.

d. Expansion and contraction of piping on hangers.

e. Wind pulsations on certain lengths and diameters of piping supported by loose hangers or supports.

Vibration from moving parts. Pumps, fans and compressors or other components involving moving parts shall be balanced and/or mounted in a manner that will avoid vibration that could cause damage or excessive noise. 
Evaluation

\section{2 .3}

Criterion

Evaluation

Commen tary

\subsubsection{Criterion}

Evaluation

Commentary
2.2 .5
Criterion

Evaluation

Commentary

2.2.6 Criterion

Evaluation

Comment ary

2.2.7 Criterion

Evaluation
Review of drawings and specifications. Prototype inspection and testing if deemed necessary. The equipment supporting structure shall not have natural frequencies within \pm 20 percent of the operating speeds. The equipment when mounted and placed in operation should not exceed a self-excited vibration velocity of 0.10 inches per second when measured with a vibration meter on the bearing caps of the machine in the vertical, horizontal, and axial directions or measured at the equipment mounting feet if the bearing caps are concealed [7].

Water hammer. When a liquid is used as the transfer fluid and cuick closing valves are employed in the design, the piping system shall be able to control or withstand potential "water hammer". Water hammer arresters shall be in compliance with applicable codes.

Review of drawings, specifications, and/or design calculations.

Pressure rises resulting from water hammer may damage piping and equipment. It can be minimized by piping system design, or the use of water hammer arresters $[8,9]$.

Vacuum relief protection. Closed storage tanks and piping located at elevations above the system served shall be protected agalnst collapsing pressure if subjected to vacuum. Such components shall be designed to withstand such pressures or have vacuum relief protection.

Review of drawings and specifications.

Possible collapse of large diameter tanks and piping from atmospheric pressure is an important design consideration [10].

Thermal changes. The system components and assemblies shall be designed to allow for the thermal contraction and expansion that will occur over the service temperature range.

Review of drawings, specifications and calculations.

Piping and other components may experience changes in dimensions as a result of temperature changes. Such changes can result in excessive stresses within the piping, piping supports, structure, pumps, compressors, and solar collectors if means are not incorporated in the piping system design to allow for the thermal movement.

Pipe and duct hangers. Pipe and duct hangers used to support insulated pipes or ducts shall be designed to avoid damaging the insulation material.

Review of drawings and specifications.

If pipe or duct hangers are installed over the insulation material, plates should be used to avoid damaging the insulation.

Flexible joints. All systems employing heat transfer fluids shall be designed to be capable of accommodating flexing of plumbing and fittings.

Review of drawings and specifications. 
2.3 Requirement Leakage prevention. System assemblies containing heat transfer fluids shall not leak to an extent greater than specified in the design when operated at all conditions within the design operating range.

\subsubsection{Criterion}

Leak testing. Those portions of installed $\mathrm{H} / \mathrm{C} / \mathrm{HW}$ systems which contain liquid heat transfer fluids and are not directly connected to the potable water supply shall not leak when pressures of not less than 1-1/2 times their design pressure are imposed for a minimum of 15 minutes.

Evaluation

Review of specifications and testing. The test pressure shall be applied for a period of time necessary to inspect each joint for leakage. The temperature of the water shall be within $5^{\circ} \mathrm{F}$ of the ambient atmosphere. A pressure gage would be observed for this period to determine whether the pressure drop is within allowable limits.

Commentary

A hydrostatic test pressure of $11 / 2$ times the design pressure is considered a standard test pressure [11]. For most applications, clear water is used. If the water temperature is not approximately that of the ambient atmosphere, sweating will result and proper examination will be difficult. In addition, the use of hot liquids can result in the swelling of packings and joint materials, thus concealing leaks. Some leakage in valve and pump stuffing boxes and packing glands may be desirable. Bleeder valves or petcocks should be provided at the highest point or points in the system to permit venting of all air in the piping during the filling operation.

\subsubsection{Criterion}

Pressure test: potable water. Those portions of installed $\mathrm{H} / \mathrm{C} / \mathrm{HW}$ systems that are directly connected to the potable water supply system shall not leak when tested in accordance with applicable local and nationally recognized codes and standards.

Evaluation Review of drawings and specifications.

Commentary

$2.4 \quad$ Requirement

See Commentary for 2.3.1.

Collector adjustments. The collector subsystem shall be capable of being located, oriented, and tilted as required by the design to capture sufficient solar energy to meet functional requirements.

\subsubsection{Criterion}

Evaluation

Orientation and tilt. The collector shall be installed on a mount capable of maintaining tilt and orientation to design conditions.

Commentary

Review of drawings and specifications.

Collectors can either be fixed, require seasonal adjustment, or be continuously movable. Detailed information concerning orientation and tilt is given by ASHRAE [3]. It is not the intent of this criterion that the collector necessarily be reoriented or tilted after initial installation. 


\subsubsection{Criterion}

Evaluation

Commentary

2.5

Requirement

2.5 .1

Criterion

Evaluation

Commentary

2.5.2 Criterion

Evaluation

Commentary

\subsubsection{Criterion}

Evaluation

Commentary

2.5 .4

Criterion

Evaluation

Commentary
Mutual shadowing. Collectors shall be installed so that mutual shadowing is minimized and does not exceed design limits.

Review of drawings (stte and system), specifications and calculations.

Data are available for calculating shading angles with respect to the time of day and year [12].

Heat transfer fluid quality. Provision shall be made to maintain the quality of the heat transfer fluid at a level that does not impair its heat transfer function.

Liquid quality. The systems shall have filters or other means to prevent contamination by foreign substances that could impair the flow and quality of the heat transfer fluid beyond acceptable limits.

When make-up water is of such a quality that excessive corrosion is known to exist, a suitable water treatment system as recommended by the Water Quality Association shall be provided [13].

Review of piping drawings and specifications.

The piping in some solar collectors and heat exchangers may have small cross sections in which blockage by dirt, scale, pieces of gasket material, pleces of packing, or other foreign matter in the heat transfer fluid could occur.

Air quality. Adequate means sha11 be provided to prevent the accumulation of deposits of dust or dirt that could result either in a reduction of system efficiency, or in the creation of a health hazard when air from the system is admitted into occupied spaces.

Review of drawings and specifications.

The gravel used for rockbed storage with air systems should be selected for size and freedom from dirt and dust. The use of smooth and washed material and of filtered air is desirable. The possibility of dirt buildup in collectors should also be considered.

Fluid treatment. Suitable devices and procedures shall be provided to assure that the chemical composition of the heat transfer fluid is maintained at levels adequate to prevent unacceptable deposits on the heat transfer surfaces or corrosion of the surfaces with which the heat transfer fluid comes in contact.

Review of drawings and specifications.

Problems can develop when fluids such as "hard" water are used.

Freezing protection. System components shall be protected from damage by the freezing of heat transfer liquids at the lowest amblent temperatures that will be encountered in actual use.

Review of drawings and specifications.

The purpose of this criterion is to insure that rupture or other damage to solar collectors and associated piping and equipment will not occur from expansion of water if it freezes. The intent of this criterion is not to restrict the designer to the use of antifreeze solutions. If automatic draindown is the freeze protection technique to be used, automatic air vents and/or vacuum rellef valves should also be protected from freezing. 
1. ASHRAE Handbook and Product Directory - 1973 Systems.+

2. National Standard Plumbing Code, as recommended by the National Association of Plumbing-Heating-Cooling Contractors, Appendix B, pp. 10-11, 1971.

3. ASHRAE Handbook and Products Directory, 1974 Applications.t

4. Duffie, John A., and Beckman, William A., Solar Energy Thermal Processes, John Wiley and Sons, New York, N.Y.., pp. 261-264, 1974.

5. King, R. C. and Crocker, S., Piping Handbook, 5th ed., McGraw-Hill Book Company, New York, Chapter 3, p. 130.

6. Marks, L. S., Mechanical Engineers Handbook, 6th ed., McGraw-Hill Book Company, Section 12, p. $102,1958$.

7. "Vibration Isolation," Section 1515, Public Bulldings Service Guide Specifications, April 1970, PBS: 401515, General Services Administration, Washington, D.C. 20405.

8. American National Standard, Water Hammer Arrésters, ANSI Al12.26.1, 1969, American Society of Mechanical Engineers.

9.

10. Windenburg, D. F., "Vesse1s Under External Pressure," Mechanical Engineering, pp. 601-607, January 1937.

11. King, R. C. and Crocker, S., Piping Handbook, 5th ed., Chapter 7, p. 291, McGraw-Hil1 Book Company, New York, 1967.

12. Tabor, H., "Stationary Mirror Systems for Solar Collectors," Solar Energy, Vol. II, pp. 3-4, July-October 1958.

13. Water Quality Association - 447 East Butterfield Road, Lombard, Illinois 60148, 1974. 
( Note: This chapter has been significantly reorganized)

The performance requirements and criteria in this chapter deal with the ability of systems and elements to maintain their structural integrity under in-service and extreme conditions. Factors such as thermal, operating, wind, snow and seismic loads are considered in this chapter. Typical fallures that are to be avoided might include the fracture of a glass collector surface due to restraint from incompatible thermal expansion, due to the impact of hail, or due to unequal stress caused by partial shading, or the collapse of a rack supporting solar collectors due to wind, snow, or earthquake.

Performance requirements for bullding structures and the interaction of solar systems with building structures are Included in Chapter 9.

There is an important distinction made between conventional elements, those elements for which design and construction procedures are contalned in common building regulatory documents, and non-conventional elements, those elements for which such procedures are not available. Elements made of materials documented in common bullding regulatory documents, such as structural steel, aluminum, timber, glass, masonry, concrete, etc., that will be exposed to service conditions that are normally considered in such documents are examples of conventional elements. New materials, such as a new alloy of aluminum, or conventional materials exposed to an environment not normally considered, such as welded steel subjected to unusually high or low temperatures, are examples of non-conventional elements.

3.1 Requirement Structural loading and resistance. The structural elements and connections of the $\mathrm{H} / \mathrm{C} / \mathrm{HW}$ systems shall support the ultimate loads expected during the service life of the systems without fallure.

3.1.1 Criterion Conventional elements, load and resistance. The resistance, $R$, of the conventional elements of the system shall exceed the required design load $U$.

The resistance, $R$, of conventional elements and systems shall be determined by reference to the local building code or to one of the three model codes [1, 2, 3] or the MPS [4] if no local code is in effect.

The design load, $U$, includes the following:

1. Dead loads (D) shall be the "Dead Loads" stipulated in Section 2 of ANSI A58.1 [5].

2. Live loads (L) shall include all applicable "Live Loads" stipulated in Section 3 and "Snow Loads" stipulated in Section 7 of ANSI A58.1, static and dynamic loads exerted by the operation of the solar energy system, ice loads as stipulated in Section 1 of the Appendix to this chapter on slender elements such as wires and slender pipes, vehicular loads as stipulated by AASHTO [6] on elements at or below grade subjected to traffic, and all soil and water pressures on burled elements in accordance with accepted principles of sol1 mechanics.

3. Wind Loads (W) sha11 be "Wind Loads" stipulated in Section 6 of the ANSI A58.1 [5].

4. Earthquake loads (E) shall be those stipulated in Section 8 of the ANSI A58.1 [5], or the provisions of the Uniform Building Code (UBC) [2]. For components and connections which cannot be evaluated within the scope of the referenced provisions, the value of " $C_{\mathrm{P}}$ " shall be taken as 1.0 . 
Evaluation

Commentary

3.1.2 Criterion
5. Constraint loads ( $\mathrm{T}$ ) caused by temperature changes, shrinkage, moisture changes, normal functioning of the system, time-dependent changes within the materials of the system, and by differential foundation settlement shall be taken as the most severe likely to be encountered during the service life.

The above loads shall be combined to obtain the total design load, U, as stipulated in Section 4 of ANSI A58.1 [5].

Review of design drawings, specifications, and calculations.

Conventional elements and systems are those for which design and construction procedures are currently specified in common building regulatory documents. The intent of this criterion is that such elements continue to be designed in accordance with these documents.

It is recognized that some elements will be designed using the ultimate resistance and factored loads while others will be designed using an allowable resistance and unfactored loads. The loads presented are those expected to occur in the projected lifetime of the installation. Particular attention should be given to the load caused by the thermal cycling of the system, both under normal conditions and "no-flow" conditions.

The value of $C_{p}$ supplied for elements that are not specified by the UBC is consistent with conservative values for elements appended to structures.

Nonconventional elements, resistance to maximum load. The resistance, $R$, of the nonconventional elements of the system or a portion thereof shall exceed the required ultimate load, U:

$$
\mathrm{U} \leq \mathrm{R}=\mathrm{R}_{\mathrm{m}} \emptyset \mathrm{C}_{\mathrm{u}}
$$

where:

$\mathrm{R}_{\mathrm{m}}=$ mean resistance

$\emptyset$ = variability factor as defined in Section 2 of the Appendix to this chapter

$\mathrm{C}_{\mathrm{u}}=$ ductility factor as defined in Section 2 of the Appendix to this chapter

$\mathrm{U}=\mathrm{a}_{1} \mathrm{D}+\mathrm{a}_{2}\left(\mathrm{a}_{3} \mathrm{~L}+\mathrm{a}_{3} \mathrm{Q}+\mathrm{a}_{4} \mathrm{~T}\right)$

$\mathrm{Q}=\mathrm{W}$ or $\mathrm{E}$

D, L, W, E, and T as defined in Criterion 3.1.1

$\mathrm{a}_{1}=1.3$ if $\mathrm{D}$ acts alone or adds to the effect of other loads or 0.9 if $D$ counteracts other loads

$\mathrm{a}_{2}=1.0$ if one of $\mathrm{L}, \mathrm{Q}$, or $\mathrm{T}$ is acting, or 0.75 if two of $\mathrm{L}, \mathrm{Q}$, or $\mathrm{T}$ are acting, or 0.6 if $\mathrm{L}, \mathrm{Q}$, and $\mathrm{T}$ all act

$a_{3}=1.7$ or 0

$\mathrm{a}_{4}=1.3$

Constraint loads ( $\mathrm{T}$ ) shall be explicity allowed for by considering a differential foundation settlement of 2 inches in any horizontal distance of 50 feet in addition to those conditions specified in 3.1.1, except that in cases where a particular foundation is specifically designed to control 
differential settlements, the differential settlements used for $T$ should be those consistent with the specified design. Uplift forces caused by a swelling of expansive soils shall be calculated assuming a level of 0.90 for gravity loads.

Evaluation

Commentary

3.1 .3

Criterion

Evaluation
Review of design drawings, specifications, calculations, and documentation of the resistance as described in section 2 of the Appendix to this chapter.

The intent of the criterion is to provide a minimum level of safety against loading situations which have a suitably low probability of occurrence during the service life. The load factors represent present day design practice of building structures and are simflar to the load factors proposed for use in the NBC of Canada [7]. These factors will also produce ultimate loads comparable to those presently used in the design of steel and concrete structures. Adoption of a similar level of performance requirements for the $\mathrm{H} / \mathrm{C} / \mathrm{HW}$ systems will permit the designer to explore the potential use of system components as structural elements in addition to their primary heating and/or cooling function.

Due to economic considerations in foundation design, the assumption is usually made that the conventional structures are capable of accommodating a reasonable amount of differential settlement. The prescribed foundation settlement is consistent with observed performance of conventionally designed foundations and represents the threshold at which structural damage occurs. This criterion is relaxed when special precautions are used in foundation design to control differential settlements.

Nonconventional elements, resistance to cyclic loads. Nonconventional structural elements shall be capable of resisting the following repeated loads without failure and without a residual deflection in excess of 25 percent of the maximum deflection measured in the first cycle of load application:

(1) 100 cycles from $1.0 \mathrm{D}$ to $1.0 \mathrm{D}$ to $+0.5 \mathrm{~L}$

(2) 1000 cycles from $1.0 \mathrm{D}$ to $1.0 \mathrm{D}+0.5 \mathrm{~W}$

(3) 1000 cycles from $1.0 \mathrm{D}$ to $1.0 \mathrm{D}+0.5 \mathrm{~T}$

Where $\mathrm{D}, \mathrm{L}, \mathrm{W}$, and $\mathrm{T}$ are as defined in 3.1 .1 , except that only thermal constraint loads need be included in $T$.

Physical simulation and testing or analysis based on available test data.

The cycle loading (1) and (2) shall be assumed to be applied after reducing system slack by the prior application of one preloading cycle of the following loads:
for (1) from (1D) to $(1 D+1 L)$
for (2) from (1D) to $(1 D+1 W)$
for (3) from (1D) to $(1 D+1 T)$ 
Commentary

3.1.4 Criterion

Evaluation

Commentary

\subsubsection{Criterion}

Evaluation

Commentary
3.2
Requirement

3.2.1 Criterion
Cyclic loading shall commence only after deflection recovery from the preloading cycle is substantially complete. The residual deflection shall be taken as the difference between the deflection measured 24 hours after removal of the superimposed cyclic load and the residual deflection, if any, not recovered from the preloading cycle.

Even though the service load history cannot be simulated, the imposition of the stipulated cyclic loads is intended as a conservative representation of service conditions. The residual deflection limitation assures preservation of structural integrity under cyclic loading.

Ponding. Horizontal surfaces of all elements exposed to the exterior environment shall be designed to prevent failure due to ponding.

Review of drawings and analysis based on documented strength and stiffness properties or physical simulation and testing.

Ponding is defined as the retention of water due to the deflection of horizontal, surfaces. Measures to resist ponding include providing sufficient stiffness to prevent failure, providing slope to carry excess water away, providing drains to remove water, or providing overflow locations to limit the depth of water.

Hail damage. All system components and supporting structural elements that will be exposed to the natural environment in service shall be designed to resist, without excessive damage or major impairment of the functioning of the system, the impact of falling hail as stipulated in Section 3 of the Appendix to this chapter.

Evaluation will be based on analysis using known structural information on the physical characteristics of the system components or on physical simulation and testing using the NBS hail resistance test described in the NBS Building Science Series $23[8]$.

In cases where protective measures are provided to prevent impact of hall on system components, such as the use of screens or deflectors, these protective measures shall be included in the test specimen.

It is not the intent of this criterion to prevent punching or local cracking of nonstructural element's such as glass cover plates of collector panels under hail impact, but rather to control damage by keeping it at a level which would not create a major curtailment in the functioning of the system, premature faflure or hazards created by excessive shattering of glazed elements.

Function and operation. The structural elements of the solar energy system shall not impair the function or operation of the solar energy system when exposed to service loads.

Resistance to damage. Under the effect of deflections caused by loads $\mathrm{D}, \mathrm{L}, \mathrm{W}$, and $\mathrm{T}$ as defined in Criterion 3.1.1, in addition to the anticipated creep deflections, the system as a whole or any component, connection or support thereof, shall not suffer permanent damage which would require replacement or repair, or which would impair its intended function during its service life. 
Evaluation

Commentary

3.2.2 Criterion

Evaluation

Commentary
Evaluation of documentation of data for design, tests, installations. Evaluation and/or testing of components and elements where deemed essential. Determination of compliance with generally accepted standards and engineering and trade practices, where applicable.

The criterion is deemed satisfactory if it can be demonstrated that deflections caused by the specified loads can be accommodated by suitable details or adequate flexibility.

The intent of this criterion is to provide for the proper functioning of the system under service loading conditions without breakdown or permanent impairment beyond levels comparable to conventional heating and cooling systems.

Nonconventional elements, deflection limitations. The deflection of nonconventional structural elements supporting the system components shall not exceed the following limitations:

(a) With the full dead load $(1.0$ D) in place, the maximum deflection due to a superimposed load of $0.2 \mathrm{D}+1.5 \mathrm{~L}$, sustained for 24 hours shall not exceed :

where $\mathbf{s}=$ span length

$$
\frac{1.25 \mathrm{~s}}{180} \cdot \frac{0.2 \mathrm{D}+1.5 \mathrm{~L}}{\mathrm{~L}}
$$

(b) The maximum residual deflection measured not more than 24 hours after removal of the superimposed load specified in (a) shall not exceed:

$$
\frac{0.25 s}{180}
$$

Analysis and/or physical simulation, including tests on prototype support structure. Deflections shall be measured in a direction normal to the span and shall include the deflection of the supporting members.

One preloading cycle is permitted, provided that loading in the actual test does not commence before deflection recovery from the preloading cycle is substantially complete.

Loads lower than required ultimate loads should not cause large, irrecoverable deformations. It is not unreasonable to require non-conventional structures to resist the stipulated superimposed loads without resulting in significant residual deformations. The limitations in part (a) implies deflection limitation of s/180 under service live load $(1.0 \mathrm{~L})$ with an additional 25 percent allowance for creep.

Part (b) requires 75 percent elastic recovery of deflection. This guards against significant residual deflection increases in each cycle of loading that may lead to incremental collapse. 
Section 1

Commentary

Section 2
Ice loads. The radial thickness of ice around the circumference of exposed wires, slender pipes, and similar members shall be based on the annual frequency of occurrence of glaze shown in Figure A-1 (see reference [9]) and shall be computed as follows:

Mean number of

days with glaze$$
\text { under } 1 \quad 1-4
$$$$
4-8
$$

over 8

Thickness of ice (inches)

$1 / 2$

$3 / 4$

1.0

The map of Figure A-1 with documented information of the accumulation of ice recorded for major ice storms [9] and ice loads considered in the design of steel transmission pole structures. [10] have been utilized to relate thickness of ice to frequency of occurrence of such storms. This assumption is made in view of a lack of statistical data on accumulation of ice and should result in a generally conservative practice even though it is recognized that thickness of ice cannot be solely expressed in terms of rate of occurrence.

Resistance of nonconventional elements. The resistance, $R$, of nonconventional elements is defined as follows:

$$
\mathrm{R}=\mathrm{R}_{\mathrm{m}} \emptyset \mathrm{C}_{\mathrm{u}}
$$

where:

$\mathrm{R}_{\mathrm{m}}=$ mean resistance

$\emptyset$ = variability factor which shall be such that approximately $95 \%$ of the system or portions thereof exceed $R_{m} \emptyset$ in resistance. For normal distribution of resistance, $\emptyset=1-1.65 \mathrm{v}$.

$v=$ coefficient of variation of resistance with respect to $R_{m}$.

$\mathrm{C}_{\mathrm{u}}=$ coefficient for ductility $=(\mathrm{u}+7) / 12$, but not more than 1.0 for loadings not including earthquake, and equal to 1.0 for loadings including earthquake.

$\mathrm{u}=$ ductility factor for loading condition $U$, as defined in the following paragraphs.

Where adequate existing test data on the various material properties comprising the system is available, evaluation of the resistance will be performed using engineering analysis. Where adequate test data is unavailable, system elements and subassemblies will be evaluated in the laboratory using simulated static load levels consistent with the specified load combinations. 


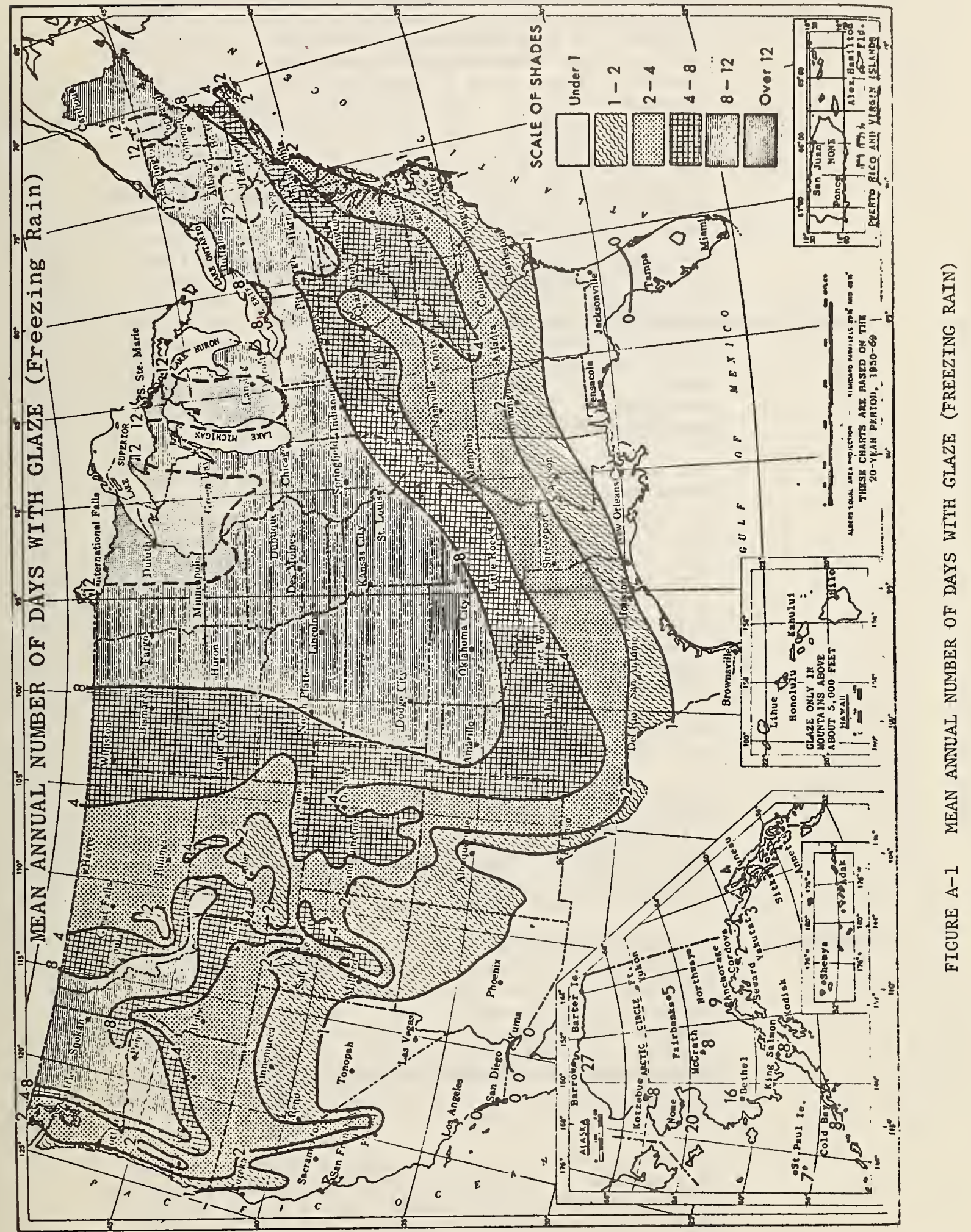


Section 3 Hail loads. The design hail load shall be taken from the perpendicular impact of falling hail particles with a diameter (in inches) equal to $0.3 \mathrm{~d}$ where $\mathrm{d}$ is the mean annul number of days with hail determined on the basis of the map shown in Figure $A-3$ and the velocity is the terminal velocity shown in Table $\mathrm{A}-1$.

Commentary The correlation of hall size with mean annual number of days with hail is based on studies on the probability of exceedance of a given particle size as a function of frequency of occurrence of hail, a twenty year recurrence interval reflecting the life expectancy of the system and observations of statistical data [11] indicating that a representative hail storm area is generally one order of magnitude smaller than the regions for which statistical information is compiled.

The impact from the vertical terminal velocity is used as a measure of the effect of hail falling with or without horizontal wind. It is possible that a larger impact could occur on surfaces sloped from $30^{\circ}$ to $60^{\circ}$ if the maximum particle diameter occurred simultaneously with a high horizontal wind velocity perpendicular to the 
surface. It may be overly conservative for particles over 1.5" impacting on near vertical surfaces. However, due to the lack of information on this phenomenon and the low probability of its occurrence, it is assumed that the terminal velocity gives the best measure of impart force consistent with the present state of the art.

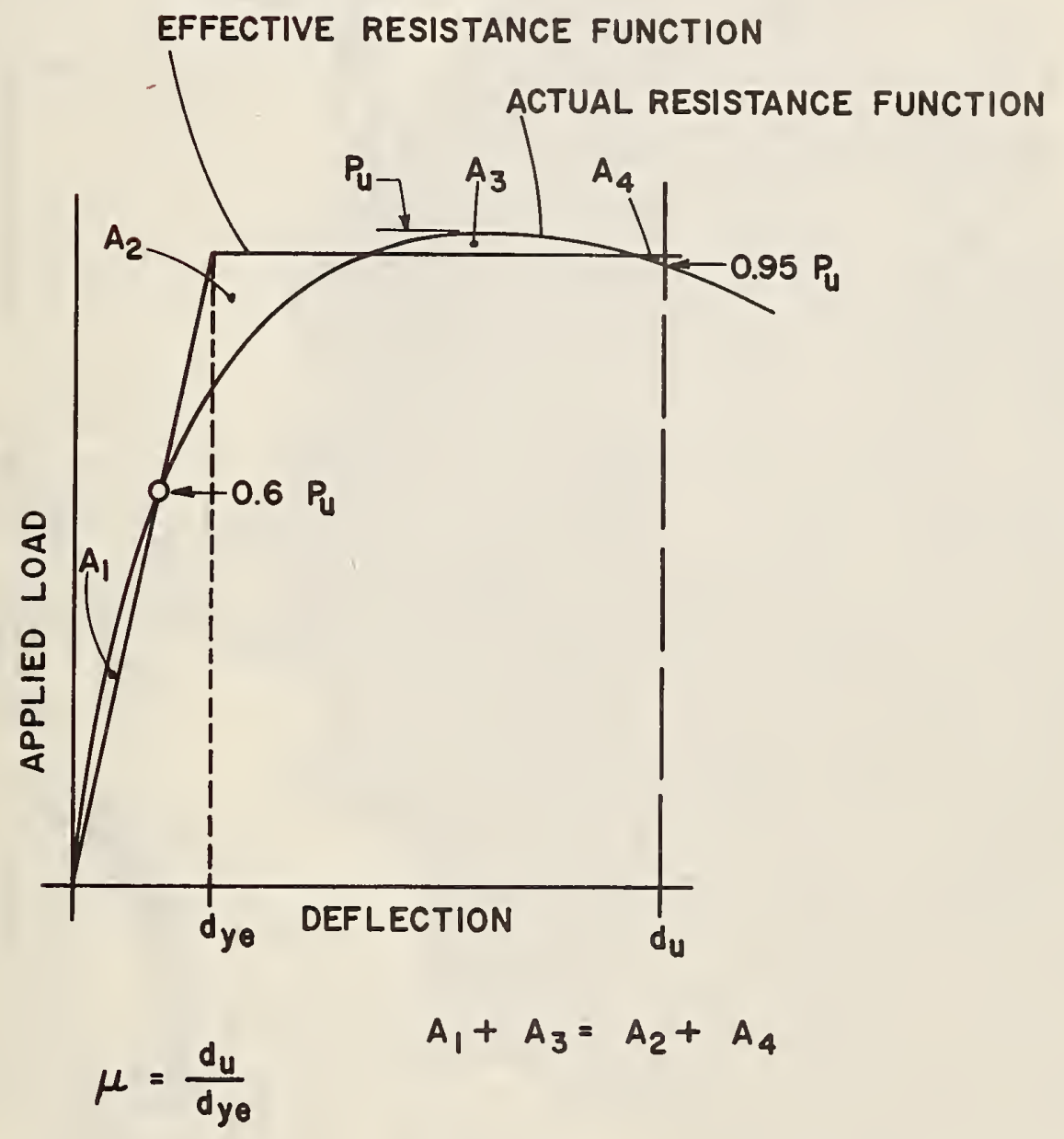

FIGURE A-2 DETERMINATION OF THE DUCTILITY FACTOR 
CHAPTER THREE - STRUCTURAL

Systems and Components

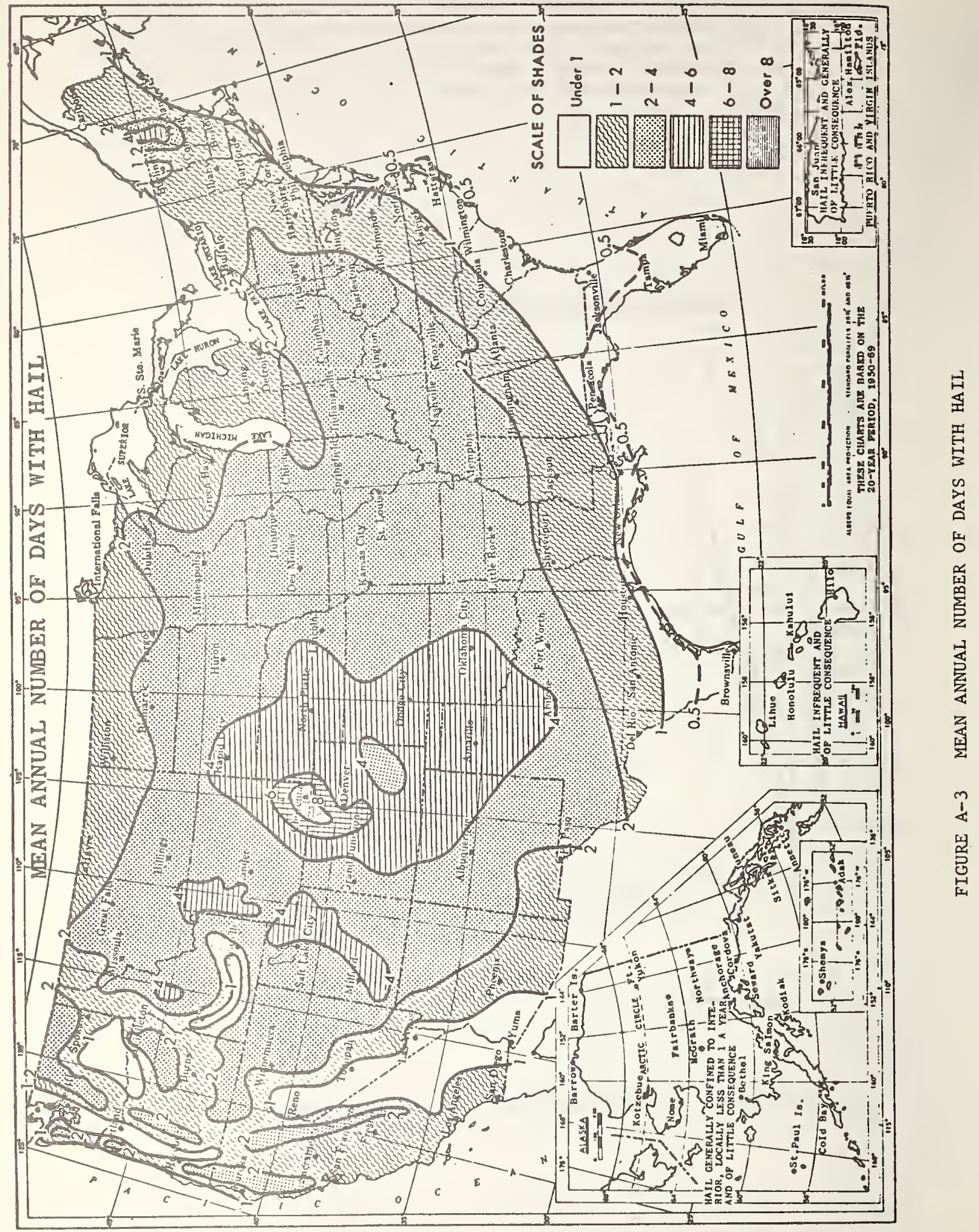


TABLE A-1

Values of weight and terminal velocity, computed for smooth ice spheres

\begin{tabular}{|c|c|c|c|}
\hline $\begin{array}{c}\text { Diameter } \\
\text { in }\end{array}$ & \multicolumn{2}{|c|}{ Weight } & \multirow{2}{*}{$\begin{array}{c}\begin{array}{c}\text { Terminal } \\
\text { Velocity } \\
\mathrm{ft} / \mathrm{sec}\end{array} \\
51\end{array}$} \\
\hline $1 / 2$ & 0.98 & 0.002 & \\
\hline $3 / 4$ & 3.30 & 0.007 & 62 \\
\hline 1 & 7.85 & 0.017 & 73 \\
\hline $11 / 4$ & 15.33 & 0.034 & 82 \\
\hline $11 / 2$ & 26.50 & 0.058 & 90 \\
\hline $13 / 4$ & 42.08 & 0.093 & 97 \\
\hline 2 & 62.81 & 0.138 & 105 \\
\hline $21 / 4$ & 89.43 & 0.197 & 111 \\
\hline $21 / 2$ & 122.67 & 0.270 & 117 \\
\hline $23 / 4$ & 163.28 & 0.360 & 124 \\
\hline 3 & 211.98 & 0.467 & 130 \\
\hline
\end{tabular}




\section{References}

1. Basic Building Code/1975, Building Officials and Code Administrators International, Inc., Chicago, Illinois 60637, 1975.

2. Uniform Building Code, 1976 Edition, International Conference of Building Officials, Whittier, California 90601, 1976.

3. Standard Building Code, 1976 Edition, Southern Building Code Congress International, Inc., Birmingham, Alabama 35222, 1976.

4. HUD Minimum Property Standards, One and Two Family Dwellings (No. 4900.1) (1973, revised 1974) and HUD Minimum Property Standards, Multi-Family Housing (No. 4910.0) (1973), U.S. Department of Housing and Urban Development, Washington, D.C.

5. Building Code Requirements for Minimum Design Loads in Buildings and Other Structures, American National Standards Institute, ANSI A58.1 - 1972.

6. Standard Specifications for Highway Bridges, AASHTO, Washington, D.C. 1973.

7. Allen, D. E., "Limit States Design - A Probabilistic Approach," Canadian Journal of Civil Engineering, Vo1. 2, 1975.

8. Greenfield, H., Hail Resistance of Roofing Products, Building Science Series 23, National Bureau of Standards, Washington, D.C., August 1969.

9. Baldwin, J. L., Climates of the United States, U.S. Department of Commerce, 1973.

10. "Design of Steel Transmission Pole Structures," Task Committee on Steel Transmission Poles of the Committee on Analysis and Design of Structures, Journal of the Structural Division, American Society of Civil Engineers, December 1974.

11. Mathey, R. G., Hail Resistance Tests of Aluminum Skin Honeycomb Panels for the Relocatable Lewis Building, Phase II, NBS Report 10193, 1970. 
4.1

Requirement

4.1 .1

Criterion

Evaluation

Commentary

4.1.2 Criterion

Evaluation

Commentary

Criterion

4.1 .3

Evaluation

Commentary

4.2

Requirement

4.2 .1

Criterion

Evaluation
Health and safety. The design and installation of the H/C/HW systems and their components shall be in accordance with applicable local and nationally recognized codes and standards for health and safety.

Plumbing codes and standards. Plumbing materials and equipment and their installation shall be in accordance with applicable local and nationally recognized plumbing codes.

Review of drawings and specifications. Testing to show compliance where necessary.

Suitable standards are available for conventional equipment. Unique, innovative installations may require special consideration.

Electrical codes and standards. Electrical materials and equipment and their installation shall be in accordance with applicable local and nationally recognized electric codes [1] and with applicable standards of American National Standards Institute (ANSI), National Electrical Manufacturer's Association (NEMA), and Underwriter's Laboratories (UL). Electrical components, wiring, switching, and protective devices shall be approved or listed by a nationally recognized testing laboratory.

Review of drawings and specifications. Testing to show compliance where necessary.

Suitable standards are available for conventional equipment. Unique installations may require special consideration.

Safety and health standards. The design and installation of the $\mathrm{H} / \mathrm{C} / \mathrm{HW}$ systems and their components shall comply with the Occupational Safety and Health Standards (OSHA) [2].

Review of drawings and specifications. Inspection of construction site.

The OSHA Standards apply to both construction practices and to the system as installed.

Fail-safe controls. The H/C/HW systems shall be fail-safe for operation under all anticipated conditions (normal and "no-flow") and in the event of damage to system components or a power failure.

System failure prevention. The control subsystem shall be designed so that, in the event of a power failure, or a failure of any of the components in the system, the temperatures and/or pressures developed in the $\mathrm{H} / \mathrm{C} / \mathrm{HW}$ systems will not damage any of the components of the system or the building or present a danger to the occupants. The safety devices shall meet the requirements of one or more of the following organizations: American Gas Association (AGA), American Society of Mechanical Engineers (ASME), Factory Mutual (FM), National Board of Boiler and Pressure Vessel Inspectors (NBBPVI), or Underwriter's Laboratories (UL).

Review of drawings, specifications, and design calculations. 
Commentary

\subsubsection{Criterion}

Evaluation

4.3 Requirement

4.3.1 Criterion

Evaluation
The excessive pressure and temperatures that can build up on collectors under "no-flow" conditions are an important consideration. Consideration should be given to the thermal shock which could occur when cool heat transfer fluids are introduced into collectors which have been exposed to solar radiation under "no-flow" conditions. Due to the possibility of large hydrostatic head pressure on tanks that may be greatly in excess of pressure elsewhere in the system, care should be taken in the selection of the location of safety devices. In systems which are not capable of withstanding the maximum temperatures to which they will be exposed (i.e. under "no-flow" conditions) it is essential that some means of protection such as energy dumping be provided.

Automatic pressure relief devices. Adequately sized and responsive automatic pressure relief devices such as valves and venting systems shall be provided in those parts of the energy transport subsystem containing pressurized fluids. Automatic pressure relief valves shall be set to open at not less than 25 percent in excess of working pressure and at not more than maximum pressure for which the subsystem is designed. Vented non-combustible, potable liquids shall be piped to suitable drains. Non-potable or combustible liquids shall be handled in accordance with Criterion 4.4.1.

Relief valves shall drain to locations acceptable to the local administrative code authority.

Review of drawings and specifications and/or determination that methods, devices, and materials to be used are approved by a recognized testing and evaluation agency as being suitable for the proposed use.

For large systems, special consideration should be given to venting the excessive pressures caused by exposure fires. Guidelines for calculating vent size are contained in NFPA 30 [3].

Fire safety. The design and installations of the H/C/HW systems and their components shall provide a level of fire safety consistent with applicable codes and standards.

Fire codes and standards. Assemblies and materials and their installations shall be in accordance with local and nationally recognized codes and standards for fire safety.

Review of drawings and specifications for conformance with the local and nationally recognized codes and standards for fire safety including but not limited to applicable sections of NFPA 89M [4], NFPA 90A and 90B [5], NFPA 211 [6], NFPA 54 [7], NFPA 30 [3], NFPA 31 [8], NFPA 256 [9], and the National Electric Code [1]. In cases where sufficient engineering information is not available, testing to show compliance may be required. Potential heat, rate of heat release, ease of ignition, and smoke generation will be considered in assessing the potential fire hazards. 
It is the intent of this criterion to (1) prevent the use of materials, equipment, and fluids which present a fire hazard greater than that allowed for conventional systems, (2) provide proper clearance and venting of heat build-up for those system components that operate at elevated temperatures, and (3) give consideration to the combustibility of materials adjacent to high temperature components in determining the clearance and/or insulation required.

Special consideration should be given to the fire safety features of innovative system designs particularly those utilizing insulation in a way which may present a greater hazard than with conventional designs.

\subsubsection{Criterion}

Evaluation

Commentary

4.3.3 Criterion

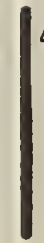

\section{Penetrations through fire-rated assemblies. Penetrations} through fire-rated walls, partitions, floors, roofs, etc. shall not reduce the fire resistance required by local codes and prdinances.

Review of drawings and specifications. Testing to show compliance in accordance with NFPA 251 [10].

It is the intent of this criterion to (1) prevent the passage of system components through fire-rated assemblies from adversely affecting the fire endurance rating of the assembly in terms of premature collapse of structural elements and (2) ensure that proper techniques are employed in constructing these components so that adequate protection can be provided.

Firestopping. $\mathrm{H} / \mathrm{C} / \mathrm{HW}$ system components that are integral parts of assemblies which normally require firestopping shall be firestopped on all sides. Firestopping shall be wood blocking of minimum two-inch nominal thickness or of non-combustible materials providing equivalent protection.

Evaluation Review of drawings and specifications.

Commentary It is the intent of this criterion to prevent $\mathrm{H} / \mathrm{C} / \mathrm{HW}$ system components from reducing the effectiveness of firestopping. For example, in the case where a solar collector is an integral part of a wood framed wall which would normally be firestopped between studs, firestopping shall be required in the wall above and below the solar collector.

Criterion Protection against auto-ignition of combustibles. Combustible solids used in solar equipment shall not be exposed to elevated temperatures which may cause ignition.

Evaluation Review of calculations, drawings, and specifications. Testing to show compliance where necessary.

Commentary Exposure of cellulosic materials as well as other combustible materials over an extended period of time result in the material reaching and surpassing its auto-ignition temperature. The most commonly accepted ignition temperature of wood is $392^{\circ} \mathrm{F}$. However, studies have indicated that wood may ignite when exposed to a temperature of $212^{\circ} \mathrm{F}$ for prolonged periods of time. The ignition temperatures of plastics may be above or below those of cellulosic materials. 
4.4 Requirement

4.4.1 Criterion

Evaluation

Commentary

4.4.2 Criterion

Evaluation

Commentary

4.4.3 Criterion

Evaluation

Commentary
Toxic and flammable fluids. Heat transfer fluids which require special handling because of their degree of toxicity, excessive pressure, high temperature, and/or flammability shall not be used unless the systems in which they are used are designed to avoid exposing the occupants of the building to hazards.

Fluids requiring special handling. Liquids defined as flammable according to NFPA 321 [11] and flammable gases shall not be used in $\mathrm{H} / \mathrm{C} / \mathrm{HW}$ systems. Liquids defined as combustible according to NFPA 321 [11] require special handling. Toxic fluids shall have a usage profile that precludes the possibility of evoking an adverse toxicological response in man as determined by the health authority having jurisdication. The use of toxic fluids shall comply with the Federal Hazardous Substances Act [12]. All toxic fluids require special handling.

When evaluating the toxicological properties of fluids, special consideration should be given to the effect of a system failure on the occupants. The evaluation should include the effects from contacting both the liquid directly and the vapor given off by the liquid. In addition, toxicological effects of the fluid should be evaluated at ambient temperature as well as the elevated temperatures expected during system operation.

Toxic fluids are those having the capacity to produce personal injury or illness to man through ingestion, inhalation, or absorption through any body surface [12].

Liquid flash point. Liquids used in solar-powered equipment shall not be heated to temperatures greater than $100^{\circ} \mathrm{F}$ below their flash points under either operating or "no-flow" conditions. The flash point of liquids used in industrial applications as defined by NFPA 101 [13] may be lower subject to the approval of the authority having jurisdiction.

Testing in accordance with NFPA 321, "Classification of Flammable Liquids" [11].

It is the intent of this criterion to minimize the possibility of ignition of hot heat transfer and thermal storage liquids when either leakage or intentional liquid release (e.g. pressure relief or drainage) occurs.

Detection of toxic and combustible fluids. If heat transfer fluids that require special handling are used, means shall be provided to indicate a failure of the fluid transfer system (e.g. leakage, pump fallure, or activation of relief valves) and the provision of warning when leaks occur. The extent of warning (i.e. whether solely maintenance personnel, or all of the occupants of a building) shall be determined on the basis of the degree of hazard presented by the fluid used and the type of occupancy.

Review of drawings and specifications. Testing of detection and warning system(s).

It is common practice to relate toxicity and flammability ratings to the level of hazard created at ambient temperatures. Heat transfer fluids which do not present a hazard at ambient temperatures may be hazardous at the temperatures developed in the system. 


\subsubsection{Criterion}

Evaluation

Commentary

4.5

Requirement

4.5.1 Criterion

Evaluation

Commentary

Criterion

4.5 .2

Criterion

Evaluation

Commentary

4.6 Requirement
Provision of catch basins. Adequately sized and protected catch basins shall be provided, when liquids requiring special handing are used, to collect and store the overflow from pressure relief valves, liquids drained from the system when it is being serviçed, potential leakage (i.e. leakage from components that would not normally be expected to last the life of the system), and accidental drainage.

Review of drawings and specifications.

The leakage of toxic liquids into the ground could contaminate ground water. In addition, leakage of some heat transfer liquids can damage roofing, sealants, and other building materials. Some components (for example, connector hoses) which have a shorter life than the system, but which are replaced on a scheduled replacement program which is more frequent than their design life may be considered in aggregate, to last the life of the system. The leakage of combustible liquids may pose a fire hazard when exposed to external ignition or heat sources.

Safety under emergency conditions. In the event of emergencies, the $\mathrm{H} / \mathrm{C} / \mathrm{HW}$ systems shall not unduly hinder the movement of occupants of the building or emergency personnel. Life safety hazards which could occur as a result of failures of the above systems shall not be greater than those imposed by conventional systems.

Emergency egress and access. The design and installation of the $\mathrm{H} / \mathrm{C} / \mathrm{HW}$ systems shall not impair the emergency movement of occupants of the building or emergency personnel to an extent greater than that allowed by NFPA 101 [13], where applicable.

Review of drawings and specifications.

The location of exits and passageways as related to the $\mathrm{H} / \mathrm{C} / \mathrm{HW}$ systems is an important consideration.

Identification and location of controls. Main shut of $f$ valves and switches should be conspicuously marked and placed in locations that are readily accessible to those personnel who would normally be expected to operate them in the event of an emergency. These valves and switches shall be located in the same manner as specified in 240.24 of NFPA 70 [1] for electrical panels.

Review of drawings and specifications.

In large facilities, accessibility would normally be limited to qualified personnel; however, in smaller commercial facilities, accessibility to the tenants should be provided.

Protection of potable water and circulated air. No material, form of construction, fixture, appurtenance or item of equipment shall be employed that will support the growth of micro-ogranisms or introduce toxic substances, impurities, bacteria or chemicals into potable water and air circulation systems in quantities sufficient to cause disease or harmful physiological effects. 


\subsubsection{Criterion}

Evaluation

Commentary

\subsubsection{Criterion}

Evaluation

Commentary

\section{$4 \cdot 6.3$ \\ Criterion}

Evaluation

4.6.4 Criterion

Evaluation

Commentary

\subsubsection{Criterion}

Evaluation

Commentary
Contamination by materials. Materials which come in direct contact with potable water shall not affect the taste, odor, or physical quality and appearance of the water in an undesirable manner.

Review of plans and specifications for compliance with the 1962 Edition of the Public Health Service Drinking Water Standards [14].

This criterion is not intended to preclude using dyes suitable for ingestion as a means for the detection and warning of leaks in the system.

Separation of circulation loops. Circulation loops of subsystems utilizing non-potable heat transfer liquids shall be separated from the potable water system in such a manner that a minimum of two walls or interfaces is maintained between the non-potable liquid and the potable water supply.

Review of drawings and specifications.

In double wall heat exchangers consisting of a heat exchange coil containing a non-potable liquid and a heat exchange coil containing a potable liquid immersed in an intermediary potable liquid intended to conduct heat between the two coils, leakage through one of the coil walls would result in a single wall configuration. There are several heat exchanger designs that avoid this problem.

Identification of non-potable and potable water. In buildings where dual 1iquid systems, one potable water and the other nonpotable 1iquid, are installed each system shall be identified either by color marking or metal tags as required in ANSI A13.11956 [15] or other appropriate methods.

Review of drawings and specifications.

Backflow prevention. Backflow of non-potable fluids into the potable water systems shall be prevented.

Review of drawings and specifications. Inspection of assembled systems.

Pollution of the potable water supply can occur by way of backflow caused by back pressure and/or backsiphonage within a cross connection between the potable supply and non-potable fluid in the system. The former type of backflow can occur, for example, from elevated tanks or pumps. The latter can occur when the potable water supply system is under vacuum such as might occur with a broken street water main.

Piping arrangements, backflow prevention devices, and/or air gaps are commonly used to prevent contamination of potable water systems.

Growth of fungi. Components and materials used in the $\mathrm{H} / \mathrm{C} / \mathrm{HW}$ systems shall not promote the growth of fungi, mold, or mildew.

The design shall be capable of withstanding exposure to fungus as defined by Method 508 of MIL-STD-810 [16].

Special consideration should be given to the presence of fungi in air handling systems since such micro-organisms are frequently allergenic. 


\subsection{Requirement Excessive surface temperatures. Contact with heated exterior surfaces of the $\mathrm{H} / \mathrm{C} / \mathrm{HW}$ systems shall not create a hazard to people.}

4.7.1 Criterion

Protection from heated components. Subassemblies of the $\mathrm{H} / \mathrm{C} / \mathrm{HW}$ systems that are accessible, located in areas normally subjected to public traffic and which are maintained at elevated temperatures shall either be insulated to maintain their surface temperatures at or below $140^{\circ} \mathrm{F}$ at all times during their operation or suitably isolated. Any other exposed areas that are maintained at hazardous temperatures shall be identified with appropriate warnings.

Evaluation Review of drawings and specifications. 


\section{References}

1. National Electric Code, NFPA, No. 70, 1975 * (also ANSI C1, 1975).

2. "Occupational Safety and Health Regulations," CFR Title 29, Chapter XVII, Part 1910 and Part 1926.

3. Flammable and Combustible Liquid Code, NFPA, No. 30, 1973.*

4. Clearances, Heat Producing Appliances, NFPA No. 89M, 1971.*

5. Air-Conditioning and Venting System, NFPA, No. 90A, 1975 and Warm Air Heating and AirConditioning, NFPA, No. 90B, 1973.*

6. Chimneys, Fireplaces and Vents, NFPA; No. 211, 1972.*

7. Gas App1iances and Gas Piping Installation, NFPA, No. 54, 1974 * (also ANSI Z 83.1, 1972).

8. Oil Burning Equipment, NFPA, No. 31, 1974* (a1so ANSI Z 95.1).

9. Fire Tests of Roof Coverings, NFPA, No. 256, 1970* (also ASTM E108 1975, American Society for Testing and Materials, 1916 Race Street, Philadelphia, Pa. 19103 and UL 790).

10. Standard Methods of Fire Tests of Building Construction and Materials, NFPA, No. 251, 1972* (a1so ASTM E119 and UL 263).

11. Classification of Flammable Liquids, NFPA, No. 30, 1973.*

12. "Federal Hazardous Substances Act," CFR Title 16, Part 1500.

13. Life Safety Code, NFPA, No. 101, Boston, Mass., 1973.*

14. The Public Health Service Drinking Water Standards, 1962, U.S. Department of Health, Education and Welfare.t

15. "Scheme for the Identification of Piping Systems," ANSI A13.1, 1975.

16. Military Standard, MIL-STD-810C, 10 March 1975, Military Standard for Environmental Test Methods.

*National Fire Protection Association (NFPA), 470 Atlantic Avenue, Boston, Mass. 02210. +Superintendent of Documents, U.S. Government Printing Office, Washington, D.C. 20402. 
5.1

Requirement

5.1.1 Criterion

Evaluation

I

Commentary

Criterion

5.1 .2

Criterion

Evaluation
Effects of external environment. The H/C/HW systems and their various subassemblies shall not be affected by external environmental factors to an extent that will significantly impair their function during their design life.

Solar degradation. Components or materials shall not be adversely affected by exposure to sunlight in service to an extent that will significantly impair their function during their design life.

a. When components or materials are exposed to UV radiation with or without an intermittent water spray at their maximum service temperature, there shall be no signs of excessive deterioration such as cracking, crazing, embrittlement, etching, loss of transmittance, loss of adhesion, changes in permeability, loss in flexural strength, or any other changes that would significantly affect the performance of the components in the system.

b. The collector shall be capable of providing its rated output after exposure to levels and intensities of solar radiation and temperatures that are equivalent to those that would be expected in actual use over the life of the collector.*

Documentation of satisfactory long-term performance under in-use conditions or engineering analysis. Where adequate existing information is unavailable, testing using either the methodology outlined in Section 03 of the Appendix given at the end of this chapter or other methods which can be shown to meet the intent of the criterion.

The transmittance, emittance, and absorptance data required to estimate the effects of degradation by solar radiation in reducing collector efficiency are available for most materials currently being used in collectors.

Moisture. Components or materials shall not be adversely affected by exposure to moisture in service to an extent that will significantly impair their function during their design life.

Documentation of satisfactory long-term performance under in-use conditions or engineering analysis. Where adequate existing information is unavailable, methods which can be shown to meet the intent of the criterion will be used.

*Use temperatures are defined in Sections 01 and 02 of the Appendix given at the end of this chapter. 
Moisture can exhibit itself in several forms, e.g. rainfall, melting snow and ice, or condensation. The intent of this criterion is to ensure adequate performance of components or materials that are expected to be exposed to moisture in service. Some components, such as collector insulation, are usually intended to be used in low moisture environments; however, it is still possible for them to be periodically exposed to moisture from condensation. Such components would not usually be expected to meet the intent of this criterion if moisture exposure could not occur, e.g. in collectors that are hermetically sealed. If flat plate collectors are not hermetically sealed, the likelihood of condensate forming on the underside of the cover plates is quite high. Dessicants in breather tubes or breather plugs can be used to maintain a dry environment. The dessicants should be located in such a way that they are not in contact with the collector plate and it is desirable that they be capable of regeneration by solar energy as the collector builds temperature.

One additional potential problem with collectors which are not hermetically sealed is that, in industrial atmospheres, the introduction of dilutants in condensate solution may cause permanent etching of the underside of the cover plates over a period of time. Such etching can permanently reduce the transmittance. When this possible condition exists, design considerations must be given to avoid the problem.

\subsubsection{Criterion}

Evaluation

Commentary

\subsubsection{Criterion}

Evaluation
Soil related degradation. Components that are intended to be buried in soils shall not degrade under in-use conditions to an extent that their function will be impaired during their design life.

Documentation of satisfactory long-term performance under in-use conditions or engineering analysis. Where adequate existing information is unavailable, testing using either the methodology outlined in Section 04 of the Appendix given at the end of this chapter or other methods which can be shown to meet the intent of the criterion will be used.

This criterion is primarily intended to protect metallic components from soll corrosion. It may be possible to protect some metallic components with the use of sacrificial anodes. Other components such as wood or plastics may also be degraded by contact with soil.

Airborne pollutants. Components that are exposed to airborne pollutants such as ozone, salt spray, $\mathrm{SO}_{2}$, NO ${ }_{\mathrm{x}}$, or $\mathrm{HCl}$ with or without the presence of moisture shall not be $x^{\prime}$ adversely affected by these factors to the extent that will significantly impair their function during their design life.

Documentation of satisfactory long-term performance under in-use conditions or engineering analysis. Where adequate existing information is unavailable, testing using either the methodology outlined in Section 05 of the Appendix given at the end of this chapter or other methods which can be shown to meet the intent of the criterion will be used. 
Commentary

5.1 .5

Criterion

Evaluation

Commentary

5.1.6 Criterion

Evaluation

Commentary

5.1.7 Criterion

Evaluation

Commentary
The maximum pollutant levels in the areas where the system will be installed shall be used to determine the pollutant levels required for testing. If components are to be used in areas where they are not exposed to any or all of these pollutants, tests that are not applicable need not be conducted.

Ozone concentrations in normal dry air have been reported to range from $1-5 \mathrm{pphm} / \mathrm{volume.} \mathrm{However,} \mathrm{concentrations} \mathrm{of} 100$ pphm/volume have been reported during very smoggy conditions. Ozone is known to degrade some organic materlals but it has iittle effect on inorganic materials other than metals.

The effects of solar radiation in combination with airborne pollutants may also be an important consideration.

Dirt retention on cover plate surface. The collector cover plate surface shall not collect and retain dift to an extent that would significantly impair the function of the collector during its design life.

Engineering analysis, documentation of satisfactory long-term performance under in-use conditions and review of plans and specifications.

The possible collection and retention of dirt by the cover plate and the effect of retained dirt on the collector performance may be significant. The retention of dirt may be affected by the tilt angle of the collector. Rainfall and snow melt are generally sufficient to keep the collector cover plates clean. In areas of low rainfall or because of the nature of the cover plate surface, periodic washing may be required to remove dirt.

Abrasive wear. The ability of the collector to function at its rated capacity shall not be significantly impaired by the abrasive wear to which its surface will be subjected during its design life.

Engineering analysis, documentation of satisfactory long-term performance under in-use conditions, and review of surface hardness specifications for cover plate materials.

Test methods which are currently available for measuring abrasion resistance are believed to be too stringent for testing organic collector cover plates. Abrasive wear is expected to present a possible problem in areas subject to wind driven sand. Also, abrasive wear of cover plates resulting from periodic cleaning or scrubbing may have a significant effect on the ability of the cover plates to transmit sunlight.

Fluttering by wind. Components that are subject to fluttering by wind shall not degrade under in-use conditions to an extent that will significantly impair their function during their design life.

Documentation of satisfactory long-term performance under in-use conditions, engineering analysis, or testing using an experimental verification procedure which can be shown to meet the intent of the criterion.

Thin films that increase in brittleness at low temperatures may be particularly susceptible to degradation by fluttering by wind. 
5.2 Requirement

\subsubsection{Criterion}

Evaluation

Commentary

\subsubsection{Criterion}

Evaluation

Commentary

\subsubsection{Criterion}

Evaluation
Temperature and pressure resistance. Components sha 11 be capable of performing their intended function for their design life when exposed to the temperatures and pressures that can be developed in the system.

Thermal degradation. Components shall not thermally degrade to the extent that their function will be reduced below design levels during their design life when exposed to in-use temperatures.

Documentation of satisfactory long-term performance under in-use conditions or engineering analysis. When adequate existing information is unavailable for collector components, the "no-flow" aging procedure described in Part B, Method 1 of Appendix Section 03, given at the end of this chapter, wil1 be used. When adequate existing information for other components is unavailable, testing using either the methodology outlined in Section 06 of the Appendix or other methods which can be shown to meet the intent of the criterion will be used.

Some organic components which may be used in the system may be particularly susceptible to thermal degradation under prolonged exposure. Collector components of particular concern include organic cover plates, absorptive coatings, insulation, sealants, and enclosure frames.

Deterioration of fluids. Except when such changes are allowed by the design of the system, fluids shall not freeze, give rise to excessive precipitation, otherwise lose its homogeneity, boil or change $\mathrm{pH}$. or viscosity beyond the design ranges when exposed to its intended range of service temperature and pressure.

Documentation of satisfactory long-term performance under in-use conditions or engineering analysis. Where adequate existing information is unavailable, testing using either the methodology outlined in Section 07 of the Appendix given at the end of this this chapter or other methods which can be shown to meet the intent of the criterion will be used.

Thermal cycling may cause precipitation to occur. Systems may be pressurized to prevent boiling. Although boiling can be prevented by pressurization, excessive temperatures can break down some constituents of the fluid to form organic acids. Buffers can counter the $\mathrm{pH}$ imbalance but only until they are exhausted. Changes in $\mathrm{pH}$ can be accepted but when the allowable range is exceeded, the transfer fluid or at least the buffers must be renewed. This can be an acceptable maintenance requirement.

Thermal cycling stresses. The H/C/HW systems and their various subassemblies shall be capable of withstanding the stresses induced by thermal cycling for their respective design lives.

Documentation of satisfactory long-term performance under in-use conditions or engineering analysis. Where adequate existing information is unavailable for collector components, the "no-flow" aging procedures, described in Part B, Method 1 of Appendix Section 03, given at the end of this chapter will be used. Where adequate existing information is unavailable for other components, testing using the methodology outlined in Section 08 of the Appendix given at the end of this chapter or other methods which can be shown to meet the intent of the criterion will be used. 
5.2.4 Criterion

Evaluation

Commentary

5.2 .5

Criterion

Evaluation

Commentary
Commentary This criterion is intended to identify potential problems that may occur as a result of differential thermal movement. Thermal compatibility is especially critical in the case of collectors which may contain large expanses of glazing. If thermal expansion is cumulative in the system or subsystem design, the tests must be designed to reflect this.

Physical restraints that will be imposed on the system in actual use shall be considered when testing is required.

Leakage. Those portions of systems which contain heat transfer fluids shall not leak when tested at a pressure equal to $150 \%$ of the working pressure of the system over the entire range of service temperatures.

Documentation of satisfactory long-term performance under in-use conditions or engineering analysis. Where adequate existing information is unavailable, testing using either the methodology outlined in Section 09 of the Appendix given at the end of this chapter or other methods which can be shown to meet the intent of the criterion will be used.

This criterion is intended to evaluate materials which may creep or become brittle within the range of expected service temperatures.

The joints near coupling hoses are a potential source of leakage. The selection of coupling hoses and clamps is quite critical. Many failures have been noted due to the clamping of hoses with screw or spring-type clamps, exposing the hose to high temperatures which tend to vulcanize the area beneath the clamp, causing it to lose resiliency and begin to leak. Further tightening of the clamps will temporarily stop leakage but further vulcanizing will occur with the end result being a hard non-resilient ring under the clamp which can no longer be tightened to prevent leakage. Silicone rubber hose is one of the few materials which have been tested and tend to maintain their resiliency with no tendency to take a thermal set. The silicone rubber hoses, however, tend to be so pliable that screw-type clamps with perforated bands should not be used as it is possible to extrude the material through the performations in the band. If this material is used, smooth band clamps should be utilized.

Transmission losses due to outgassing. Outgassing of volatiles that will reduce collector performance below specified design values shall not occur when the collector is exposed to the maximum service temperature and pressure that will occur in actual service.

Documentation of satisfactory long-term performance under in-use conditions or engineering analysis. Where adequate existing information is unavailable, testing using either the "no-flow" aging procedure described in Part B, Method 1 of Appendix Section 03 given at the end of this chapter or other methods which can be shown to meet the intent of the criterion will be used.

Outgassing from components inside the collector could lead to deposits on the underside of the collector cover plates which may reduce the transmissivity of the cover plates. 
5.3 Requirement

5.3.1 Criterion

Evaluation

Commentary

5.3.2 Criterion

Evaluation

Commentary

5.3.3 Criterion

Evaluation
Chemical compatibility of components. Materials used in the systems and their various subassemblies shall have sufficient chemical compatibility to prevent corrosive wear and deterioration that would significantly shorten the intended service life of components under in-use conditions.

Deterioration of gaskets, sealants, and polymeric coupling hoses. Gaskets, sealants, and polymeric coupling hoses in direct contact with fluids shall not be adversely affected by contact with these fluids to an extent that will significantly impair their ability to function during their design life.

Documentation of satisfactory long-term performance under in-use conditions or engineering analysis. Where adequate existing information is unavailable, testing using either the methodology outlined in Section 10 of the Appendix given at the end of this chapter or other methods which can be shown to meet the intent of the criterion will be used.

Gaskets, sealants, polymeric coupling hoses, and similar organic materials frequently swell when exposed to liquids and frequently lose their ability to function.

Materials/transfer fluid compatibility. Materials designed to be used in contact with heat transfer fluids shall not be corroded by these fluids to the extent that their function will be significantly impaired under in-use conditions during their design life.

Documentation of satisfactory long-term performance under in-use conditions or engineering analysis. Where adequate existing information is unavailable, testing using either the methodology outlined in Section 11 of the Appendix given at the end of this chapter or other methods which can be shown to meet the intent of the criterion will be used.

Corrosion of metals by heat transfer fluids could be a serious problem in solar energy systems. Society of Automotive Engineers (SAE)* Report J447a (1964), "Prevention of Corrosion of Metals," provides guidance in preventing corrosion.

Compatibility of dissimilar materials. Non-isolated dissimilar materials shall not be degraded to the extent that their function will be significantly impaired under in-use conditions during their design life.

Documentation of satisfactory long-term performance under in-use conditions or engineering analysis. Where adequate existing information is unavailable, testing using either the methodology outlined in Section 12 of the Appendix given at the end of this chapter or other methods which can be shown to meet the intent of the criterion will be used. Dissimilar materials used in contact with heat transfer or other fluids shall be tested to reflect this condition. Where protective finishes are normally provided, they shall be used on the specimens tested.

*Society of Automotive Engineers, Inc. Two Pennsylvania Plaza, New York, NY 10001. 
Commentary

5.3.4 Criterion

Evaluation

Commentary

5.3.5 Criterion

Evaluation

Commentary

5.4

Requirement

5.4.1 Criterion
The use of corrosion inhibitors or dielectric fittings that electrically isolate dissimilar materials may be desirable. In the case of plastics, plasticizer migration may be a concern. The presence of pinholes in protective coatings may drastically accelerate corrosive action.

Corrosion by leachable substances. Chemical substances that can be leached by moisture from any of the materials within the system shall not cause corrosive deterioration of any other components that would significantly impair the ability of those components to perform their intended function over their design life.

Documentation of satisfactory long-term performance under in-use conditions or engineering analysis. Where adequate existing information is unavailable, testing using either the methodology outlined in Section 13 of the Appendix given at the end of this chapter or other methods which can be shown to meet the intent of the criterion will be used.

Salts such as those that can be leached by moisture from some types of glass fiber and mineral wool insulation or from organic components may cause corrosion of system components that are in close proximity. Chlorides or sulfates that may be leached are of particular concern in regard to metallic corrosion.

Effects of decomposition products. Chemical decomposition products that are expelled from components under in-use conditions shall not cause the degradation of other components within the system to the extent that they would significantly impair their ability to perform their intended function over their design life.

Documentation' of satisfactory long-term performance under in-use conditions or engineering analysis. Where adequate existing information is unavailable, testing using either the methodology outlined in Section 14 of the Appendix given at the end of this chapter or other methods which can be shown to meet the intent of the criterion will be used.

Components and materials, such as gaskets, sealants, coatings, etc., may yield degradation products during their service life without impairing their function or aesthetic properties. These degradation products could significantly impair the performance of other components in the system.

Components involving moving parts. Components that involve moving parts shall, with normal maintenance, be capable of performing their intended function without excessive wear or deterioration for their design life.

Wear and fatigue. Check valves, pressure regulators, pumps, electrical switches and similar components shall be capable of operating under in-use conditions for their intended life spans without exhibiting wear or fatigue that would reduce their performance below specified levels. 
Evaluation

Commentary
Documentation of satisfactory long-term performance under in-use conditions, engineering analysis, or testing using an experimental verification procedure which can be shown to meet the intent of the criterion. Either the number of cycles that would be expected in actual service under in-use conditions or an accelerated procedure shall be used for experimental verification.

In some applications, less expensive components which are readily replaced but have shorter expected lifespans may be more desirable than more reliable but more costly components.

Inclusion of the heat transfer fluid during tests of components with moving parts may be helpful. In particular, very hard crystalline precipitates may be formed from some types of heat transfer fluids, and their additives. 
APPENDIX

\section{Section 01 - Temperature Conditions}

Many of the criteria given in this chapter contain references to the maximum or minimum service temperatures in specifying the temperature at which testing should be performed. The maximum service temperature is the maximum temperature to which a component will be exposed in actual service, either with or without the flow of heat transfer fluid. The minimum service temperature refers to the minimum temperature to which a component will be exposed in actual service, with or without the flow of heat transfer fluid.

The minimum service temperature to which a component in the system will be exposed will generally occur when 1) no solar radiation is falling on the collector, 2) the heat transfer is not flowing through the system, and 3) the ambient air temperature is at its lowest level. The no-flow condition mentioned above assumes the flow of the heat transfer fluid will be stopped when solar radiation is not falling on the collector to avoid pumping out heat energy. However, if the flow of fluid is not stopped at night, the minimum service temperature of some components may occur as nocturnal radiation and/or evaporative cooling takes place.

The maximum service temperature, to which the collector and components that are in intimate contact with it will be exposed, will generally occur when the collector is receiving its maximum level of solar radiation and the heat transfer fluid is not flowing through the collector component. Other components, such as those in the storage subsystem, will generally reach their maximum temperature when the collector is receiving its maximum level of solar radiation and the heat transfer liquid is flowing through the system. The maximum service temperature that will occur at various locations in the collector under no-flow conditions can be calculated if the ambient temperature, the intensity of insolation, the number of cover plates, the back and edge losses, and the absorptivity and emissivity of the absorbent surface and other related factors are known. The type of information that is required to determine the maximum service temperature in various locations of collectors under no-flow conditions is shown in Section 02 of this Appendix.

Section 02 - Typical Figures Showing the Maximum "No-Flow" Temperatures in Various Collector Locations of Specific Collector Designs

Figures $A-1$ through $A-4$ are intended to provide assistance in identifying the maximum service temperatures at various locations in the collector under no-flow conditions. The five curves on each figure represent the maximum service temperature for each side of two cover plates and the surface of the absorber. The calculations used to generate the graphs assumed: 1) a glass cover plate thickness of 0.125 inches, 2) air space thickness of 0.1875 inches both between cover plates and between the absorbent surface and the lower cover plate, 3) zero edge losses, and 4) the incident solar radiation is normal to the collector.

Section 03 - Test Methodology: Criteria 5.1.1.a and 5.1.1.b

$\underline{\text { Part A - Test Methodology: Criterion 5.1.1.a }}$

Components or materials shall be tested using at least one of the three aging procedures and appropriate evaluation procedures as described, beginning on page 52 .

The surfaces of components or materials shall be visually inspected before and after aging to ensure that no signs of excessive deterioration, such as dimensional changes, cracking, chalking, or other visually detectable changes which could significantly affect the performance of the components in the system, are present. In addition, other evaluation procedures shall be used, as necessary, to evaluate performance. 


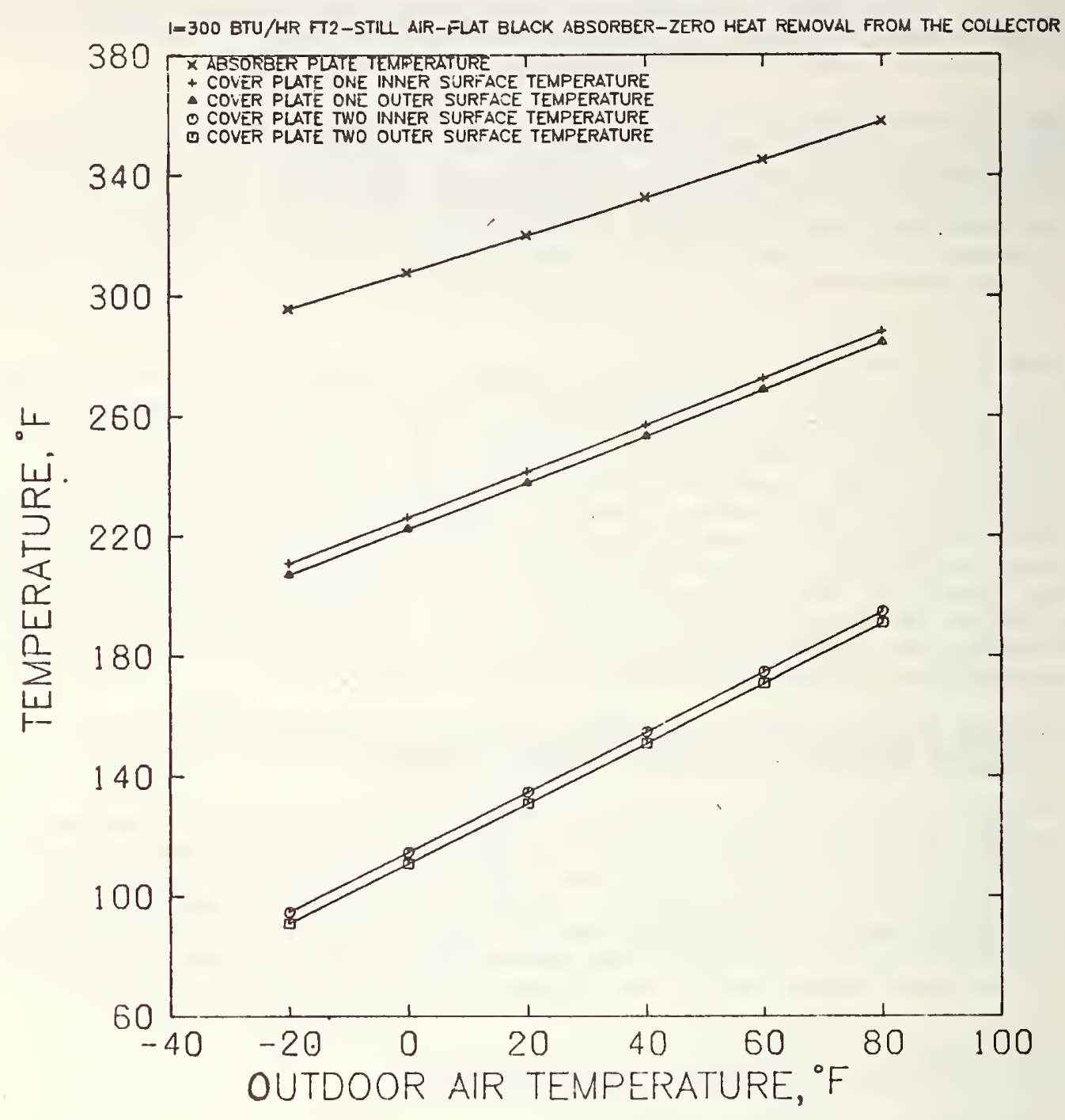

Figure A-1. Temperatures at Various Locations in a Collector with a Flat Black Absorber and Two Glass Cover Plates (Absorptivity $=0.9$, Emissivity $=0.9, I=300 \mathrm{Btu} / \mathrm{Hr} . \mathrm{ft} .{ }^{2}$ ) 


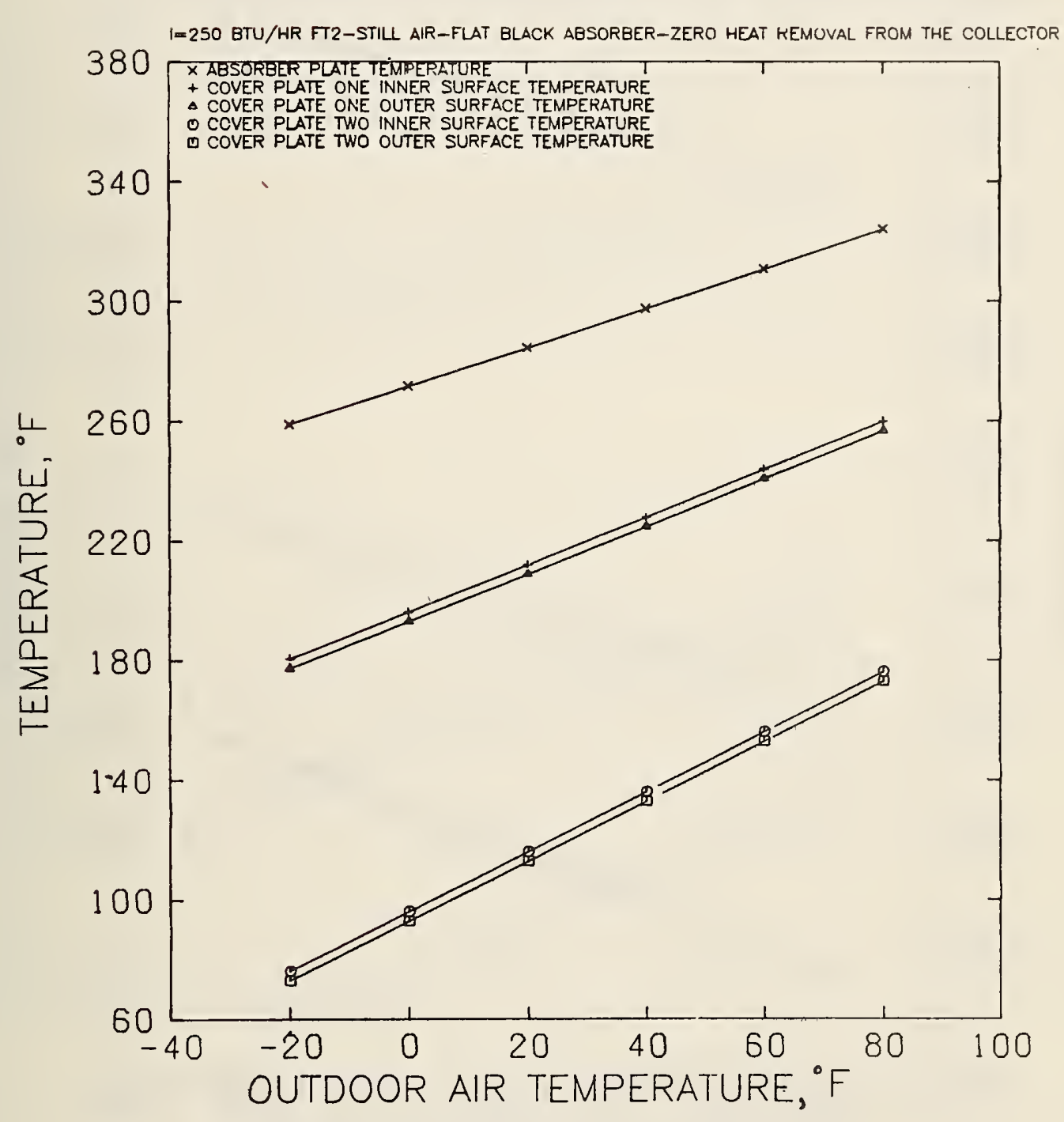

Figure A-2 Temperatures at Various Locations in a Collector with a Flat Black Absorber and Two Glass Cover Plątes (Absorpitivity = 0.9, Emissivity $=0.9, \mathrm{I}=250 \mathrm{Btu} / \mathrm{Hr} . \mathrm{ft}^{2}{ }^{2}$ ) 


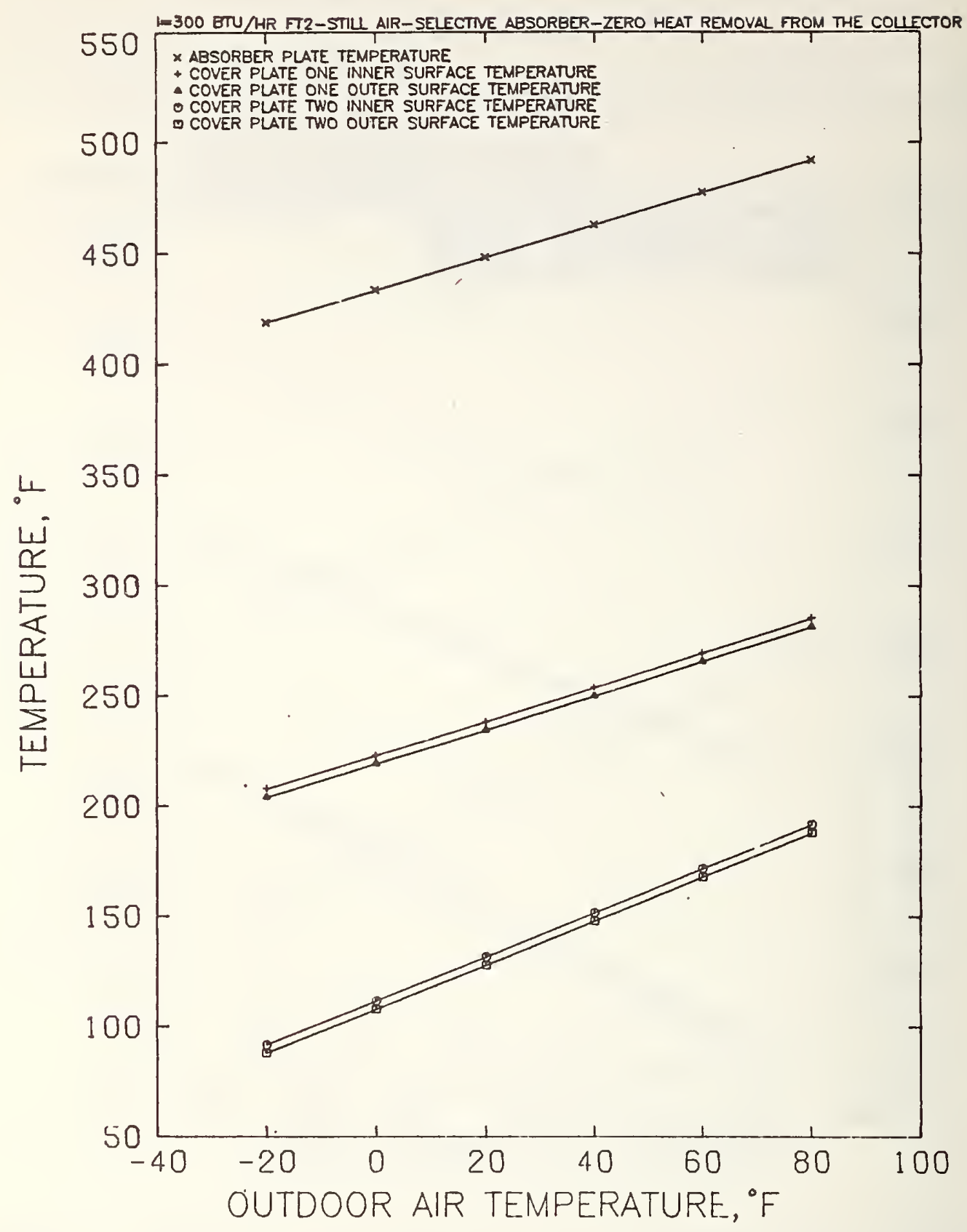

Figure A-3 Temperatures at Various Locations in a Collector with a Selective Absorber and Two Glass Cover Plates (Absorptivity $=0.9$, Emissivity $=0.1, \mathrm{I}=300 \mathrm{Btu} / \mathrm{Hr} . \mathrm{ft} .{ }^{2}$ ) 
CHAPTER FIVE - DURABILITY / RELIABILITY

Systems and Components

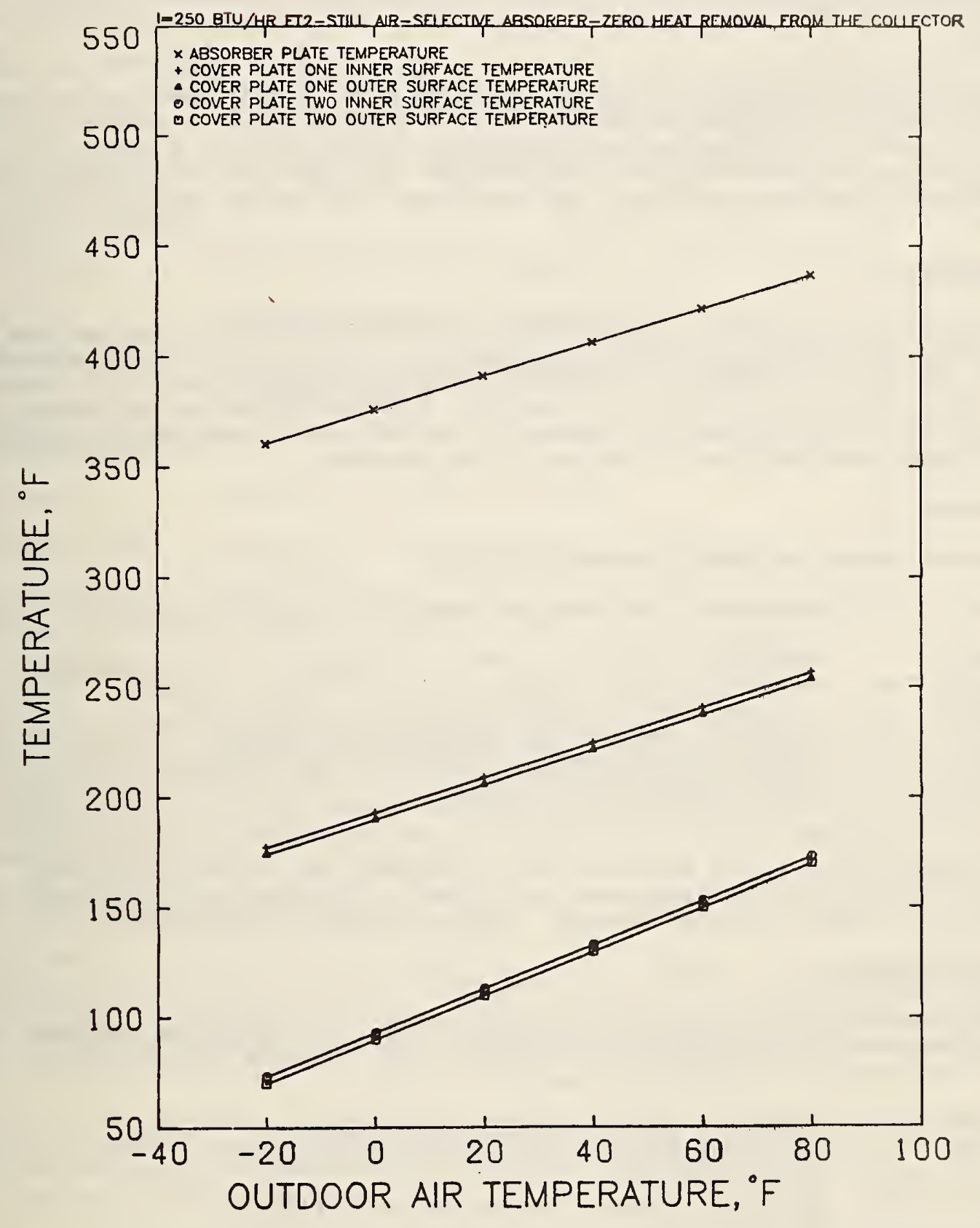

Figure A-4 Temperatures at Various Locations in a Collector with a Selective Absorber and Two Glass Cover Plates (Absorptivity $=0.9$,

Emissivity $=0.1, I=250 \mathrm{Btu} / \mathrm{Hr} . \mathrm{ft} .{ }^{2}$ ) 


\section{Aging Procedure 1}

ASTM reference methods for Aging Procedure 1 include G26-70 Operating Light and Water Exposure Apparatus (Xenon-Arc Type) for Exposure of Non-Metallic Materials, and D2565-75, Operating Xenon Arc-Type (Water-Cooled) Light and Water Exposure Apparatus for Exposure of Plastics.

Expose components or materials to simulated solar radiation (such as xenon arc radiation) for a period of 2,000 equivalent sun hours. The exterior surfaces of components which are exposed to rainfall in service shall be subjected to a water spray for a period of 5 minutes during each 60 minutes of the light exposure. For components not exposed to rainfall under normal operating conditions, the water spray shall not be included in the procedure.

\section{Aging Procedure 2}

Expose components or materials to concentrated natural solar radiation using machines such as those referenced in ANSI Z97.1-1975, paragraph 4.3.2, for a period of 2,000 equivalent sun hours. The exterior surfaces of components which are exposed to rainfall in service shall be subjected to a water spray for a period of 8 minutes during each 60 minutes of sunlight exposure. For components not exposed to rainfall under normal operating conditions, the water spray shall not be included in the procedure.

\section{Aging Procedure 3}

ASTM reference methods for Aging Procedure 3 include:
G7-69T
Atmospheric Environmental Exposure Testing of Non-Metallic
D1828-70 Materials
D1014-66
Atmospheric Exposure of Adhesive Bonded Joints and Structures
D1006-73
Conducting Exterior Exposure Tests of Paints on Stee1
G24-73
G11-72
Conducting Exterior Exposure Tests of Paints on Wood
Conducting Natural Light Exposures Under Glass
D1435-69
Effects of Outdoor Weathering on Pipeline Coatings
Outdoor Weathering of Plastics

Expose components and materials to solar radiation outdoors for twelve months. The average daily flux of the solar radiation, as obtained by averaging the daily fluxes over the twelve month period of outdoor exposure, shall be at least $1,500 \mathrm{Btu} / \mathrm{ft}^{2}$.

\section{Evaluation Procedures}

Evaluation procedures shall be selected to measure the effect of the aging procedures on important properties of the components or materials. The following ASTM evaluative techniques for organic coatings shall be used:
D714-56 (1974)
Evaluating Degree of Blistering of Paints
D659-74
Evaluating Degree of Resistance to Chalking of Exterior Paints
D660-44 (1970)
Evaluating Degree of Resistance to Checking of
Exterfor Paints
D661-44 (1975) Evaluating Degree of Resistance to Cracking of Exterior Paints. 
Evaluation techniques, in addition to those related to visual inspection, shall also be used. The methods below represent the types of evaluative techniques that should be used where applicable:

Vapor Transmission

E96-66 (1972) Water Vapor Transmission of Materials in Sheet Form

C355-64 (1973) Water Vapor Transmission of Thick Materials

Tensile Strength

D638-72

D897-72

C297-61 (1970)

Flexure Strength

D790-71

Flexural Properties of Plastics

C393-62 (1970)

Evaluations should be performed on both aged and unaged specimens to establish a basis of comparison.

Commentary

The test are intended to permit estimations to be made of the effect of solar radiation in degrading collector components and in reducing the collector efficiency. The 2,000 equivalent sun hours test time is considered to be equivalent to approximately 12 months of actual solar exposure with an average exposure time of 6 hours per day. The fact that the intensity of solar radiation varies with time of the day and time of the year should be considered in establishing the length of the exposure.

Part B - Test Methodology: Criterion 5.1.1.b

Method 1 involves the exposure of the collector to solar radiation at an actual test site and measuring the decrease in collector efficiency as a result of the exposure. State-ofthe-art collector test methods are referenced in Criterion 1.3.1. Method 1 also includes visually inspecting collector components after the aging procedure to ensure that undesirable changes have not occurred.

Method 2 involves measuring the deterioration of the windows and the absorbent surfaces separately by means of small scale laboratory tests and then incorporating this information into a model developed by ASHRAE which can be used to calculate collector efficiency. The test procedure for Method 2 is given below.

Method 1 for Evaluating the Effects of Solar Degradation on the Performance of the Collector

Test Specimens

The test specimen shall consist of the entire collector as it would be used in actual service. 


\section{Aging Procedure}

Expose the collector to solar radiation having an average daily flux of $1,500 \mathrm{Btu} / \mathrm{ft}^{2}$ at the tilt angle under "no-flow" conditions for 30 days. At least one 4 hour period during the 30 day exposure shall have a minimum solar flux of $300 \mathrm{Btu} / \mathrm{ft}^{2} / \mathrm{hr}$. The 30 day "no-flow" exposure must be performed on a complete collector without transfer liquid (if liquid is the transfer medium). The angle of collector exposure shall be $\pm 10^{\circ}$ of that used in service. For tracking collectors, the exposure angles shall be the same as those used in service.

\section{Evaluation Procedure}

Test the collector before and after aging for thermal efficiency. State-of-the-art test methods are referenced in Criterion 1.3.1.

The test specimens shall exhibit no significant change in performance as a result of the aging procedure. Components shall not exhibit changes that would significantly impair their function when visually inspected after the aging procedure.

Method 2 for Evaluating the Effects of Solar Degradation on the Performance of the Collector (Primarily for spectrally selective materials)

Test Specimens

Test specimens shall consist of specimens of the materials to be tested.

Specimens of window materials for aging and evaluating shall consist of the number of windows used in the collector spaced and aligned as they would be in the collector.

\section{Aging Procedure}

Specimens shall be exposed to simulated solar radiation* with the spectral intensity in the 300 to $450 \mathrm{~nm}$ wavelength range equivalent to the air mass 2 solar spectrum (such as Xenon arc radiation) for a period of 1,000 hours at the maximum temperature to which they will be subjected in actual service. For collector windows, the exterior surfaces of the components shall be subjected to a water spray for a period of 5 minutes during each 60 minutes of the light exposure. For components not normally exposed to rainfall as secondary collector windows and absorbent coatings, the water spray shall not be included in the procedure.

\section{Test Procedures**}

\section{Collector Windows}

1. Measure the total spectral transmittance (including both diffuse and normal radiation) of the windows from 300 to $1,820 \mathrm{~nm}$.

2. Expose the windows to the aging procedure described above.

3. Repeat step 1 .

4. Calculate the solar transmittance $(\tau)$ determined from transmittance measurements from 300 to $1,820 \mathrm{~nm}$ for both unaged and aged specimens using the procedure described under Calculations.

\footnotetext{
*Specimens shall be mounted perpendicular to the incident radiation.

**Other less sensitive test procedures which are directly integrating are given in ASTM E424-71 and E434-71.
} 


\section{Absorbent Surface}

$\underline{\text { Part A }}$

1. Measure the directional reflectance of the absorbent surface in the infrared spectral range from 3 to $20 \mu \mathrm{m}(3,000-20,000 \mathrm{~nm})$.

(Maximum of .5 $\mathrm{m}$ increments.)

2. Expose the absorbent surface to the aging procedure described above.

3. Repeat step 1 .

4. Convert the reflectance values to emittance $(\varepsilon$ ) assuming an opaque coating where: Emittance $=1$ - Reflectance.

5. Calculate the total emittance from 3 to $20 \mu \mathrm{m}$ for both unaged and aged specimens using the procedure described under Calculations.

$\underline{\text { Part B }}$

1. Measure the directional reflectance of the absorbent surface from 300 to $1,820 \mathrm{~nm}$. (Maximum 1,000 nm increments.)

2. Expose the abosrbent surface to the aging procedure described above.

3. Repeat step 1 .

4. Convert the reflectance values to absorptance assuming an opaque coating where: Emittance $=$ Absorptance $=1$ - Reflectance.

5. Calculate the solar absorptance $(\alpha)$ from 300 to $1,820 \mathrm{~nm}$ for both unaged and aged specimens using the procedure described under Calculations.

Calculations

$\underline{\text { Transmittance }}$

1. Multiply the measured value of transmittance of both aged and unaged window specimens over the wavelength range from 300 to $1,820 \mathrm{~nm}$ by the value of solar energy (watts $/ \mathrm{cm}^{2} / \mathrm{nm}$ ) at the same wavelengths as read from Figure A-5. (Maximum of $100 \mathrm{~nm}$ increments.)

2. Plot energy (watts $/ \mathrm{cm}^{2} / \mathrm{nm}$ ) versus wavelength curves for both aged and unaged specimens.

3. Integrate, from 300 to $1,820 \mathrm{~nm}$, the area under the curve of Figure $A-5$ and record the area $\left(\mathrm{E}_{\mathrm{T} 1}\right)$.

4. Integrate, from 300 to $1,820 \mathrm{~nm}$, the area under the energy versus wavelength curve for unaged specimens and record the area $\left(E_{\mathrm{T} 2}\right)$.

5. Integrate, from 300 to $1,820 \mathrm{~nm}$, the area under the energy versus wavelength curve for aged specimens and record the area ( $\left.\mathrm{E}_{\mathrm{T} 3}\right)$.

6. Divide $\mathrm{E}_{\mathrm{T} 2}$ by $\mathrm{E}_{\mathrm{T} 1}$ to obtain the solar transmittance, $\tau_{2}$, as measured for the unaged window specimen.

7. Divide $E_{\mathrm{T} 3}$ by $\mathrm{E}_{\mathrm{T} 1}$ to obtain the solar transmittance, $\tau_{3}$, as measured for the aged window specimen.

8. Incorporate $\tau_{2}$ and $\tau_{3}$ into the appropriate equations used in the method to determine the collector efficiency in Criterion 1.3.1. 


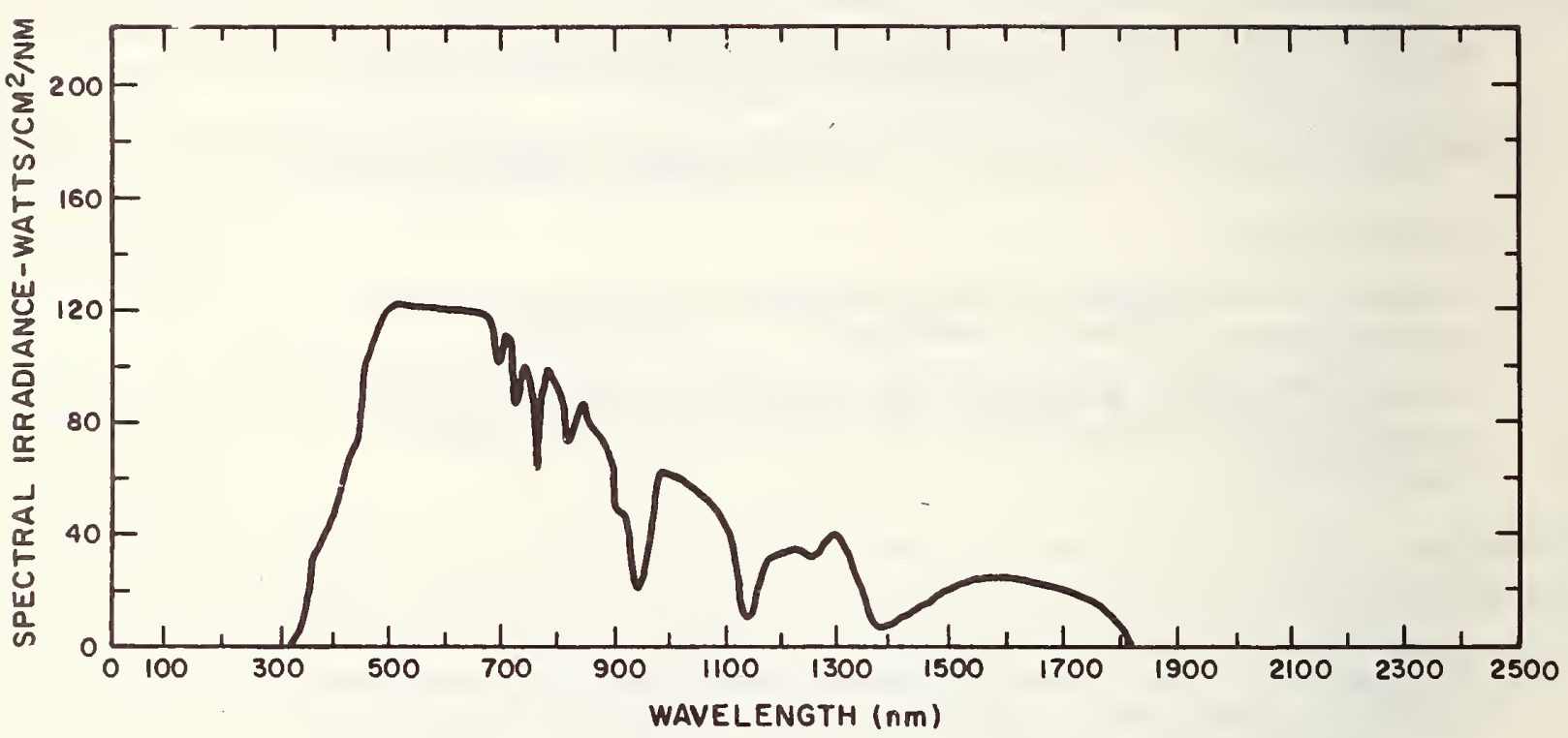

Figure A-5 Spectral Irradiation at Air Mass 2.0 


\section{Total Emittance*}

The total emittance of surfaces can vary with temperature because of the change in energy spectral distribution with temperature according to the Planck Radiation Law. The influence of environmental effects on the total emittance can be determined from spectral emittance data by the following procedure:

1. List the spectral emittance and the spectral energy (watts/cm $2 / \mu \mathrm{m}$ ) of a black body in at least $0.5 \mu \mathrm{m}$ wavelength intervals over the wavelength range of 3.0 to $20.0 \mu \mathrm{m}$ for each temperature. Use a maximum of $10^{\circ} \mathrm{C}$ temperature intervals over the temperature range of collector operation (nominally from 38 to $121^{\circ} \mathrm{C}\left(100\right.$ to $\left.250^{\circ} \mathrm{F}\right)$. Calculate the product of these two values for each wavelength interval.

2. Plot the data obtained from step 1 as a function of wavelength for both aged and unaged specimens and for each temperature. Plot the spectral energy distribution for a black body for each temperature used.

3. Integrate, from 3.0 to $20.0 \mu \mathrm{m}$, the area under the black body curve for each temperature and record the area $\left(E_{\varepsilon B}\right)$.

4. Integrate, from 3.0 to $20.0 \mu \mathrm{m}$, the area under each energy-emittance curve for unaged specimens and record the area $\left(E_{\varepsilon l}\right)$ for each temperature.

5. Integrate, from 3.0 to $20.0 \mu \mathrm{m}$, the area under each energy-emittance curve for aged specimens and record the area $\left(E_{\varepsilon 2}\right)$ for each temperature.

6. Divide $E_{\varepsilon l}$ by $E_{\varepsilon B}$ for each temperature to obtain $\varepsilon 1$ for each unaged specimen and $E_{\varepsilon 2}$ by $E_{\varepsilon B}$ to obtain $\varepsilon_{2}$ for each aged specimen.

7. Incorporate $\varepsilon 1$ and $\varepsilon 2$ into the appropriate equations used in the method to determine collector efficiency in Criterion 1.3.1.

\section{Absorptance}

1. Multiply the value of absorptance of both aged and unaged absorbent surface specimens at various wavelengths from 300 to $1,820 \mathrm{~nm}$ by the value of solar energy (watts $/ \mathrm{cm}^{2} / \mathrm{nm}$ ) at the same wavelengths as read from Figure A-5.

2. Plot energy (watts/ $\mathrm{cm}^{2} / \mathrm{nm}$ ) versus wavelength curves for both aged and unaged specimens.

*Total hemispherical emittance can be deterined by means of calorimetric techniques. Total normal emittance can be measured with a portable emissometer. 
3. Integrate, from 300 to $1820 \mathrm{~nm}$, the area under the curve of Figure A-5 and record the area $\left(E_{\alpha \beta}\right)$.

4. Integrate, from 300 to $1820 \mathrm{~nm}$, the area under the energy versus wavelength curve for unaged specimens and record the area $\left(E_{\alpha 1}\right)$.

5. Integrate, from 300 to $1820 \mathrm{~nm}$, the area under the energy versus wavelength curve for aged specimens and record the area $\left(\mathrm{E}_{\alpha 2}\right)$. 6. Divide $\mathrm{E}_{\alpha 1}$ by $\mathrm{E}_{\alpha \beta}$ to obtain the solar absorptance, $\alpha$, for the unaged window
specimen.

7. Divide $\mathrm{E}_{\alpha 2}$ by $\mathrm{E}_{\alpha \beta}$ to obtain the 'solar absorptance, $\alpha_{2}$, for the aged window
specimen.

8. Incorporate $\alpha 1$ and $\alpha 2$ into the appropriate equations used in the method to determine collector efficiency in Criterion 1.3.1.

Transmittance or Reflectance by ASTM Method E 424-71

An alternate calculation method to those presented above is presented in ASTM Method E 424 for transmittance and reflectance. In ASTM E 424, solar energy transmittance or reflectance is calculated by integration using the solar energy distribution for sea level and air mass 2.0 . Table A-1 contains twenty selected ordinates for use in the calculations.

Table A-1 Twenty Selected Ordinates for Evaluation of Solar Transmittance or Reflectance at Sea Leve1*

$\begin{array}{cccc}\begin{array}{c}\text { Ordinate } \\ \text { Number }\end{array} & \begin{array}{c}\text { Wavelength } \\ (\mathrm{nm})\end{array} & \begin{array}{c}\text { Ordinate } \\ \text { Number }\end{array} & \begin{array}{c}\text { Wavelength } \\ \text { (nm) }\end{array} \\ 1 & 390 & 11 & 745 \\ 2 & 444 & 12 & 786 \\ 3 & 481 & 13 & 831 \\ 4 & 511 & 14 & 877 \\ 5 & 543 & 15 & 959 \\ 6 & 574 & 16 & 1026 \\ 7 & 606 & 17 & 1105 \\ 8 & 639 & 18 & 1228 \\ 9 & 669 & 19 & 1497 \\ 10 & 705 & 20 & 1722\end{array}$

*Extracted from ASTM Method E 424. 
Section 04 - Test Methodology: Criterion 5.1.3

Testing of non-ferrous metals shall be performed for a period of 500 hours at the maximum service temperature to which the components will be subjected in actual use. During the duration of the test, coupon specimens shall be partially immersed in aqueous solutions having a $\mathrm{pH}$ equivalent to that found in soil specimens taken from the sites where the systems are intended to be used. ASTM G31-72 may be useful in performing immersion tests. Testing of ferrous metals shall be by either the four probe technique or the soil box technique [1]*. Both techniques measure soil resistivity. If the probe technique is used, probe spacing shall be adjusted to measure the soil resistivity at the depth at which the ferrous member is to be buried. Similarly, soil box samples shall be obtained from that depth. These tests shall not be carried out when the soil is frozen but shall be performed when the soil contains its maximum moisture content.

The resistivity values below give a rough indication of the relationship between soil corrosivity and resistivity.

$$
\begin{gathered}
\text { Resistivity, ohm-cm } \\
\hline \text { Below } 500 \\
500-1,000 \\
1,000-2,000 \\
2,000-10,000 \\
\text { Above } 10,000
\end{gathered}
$$

\section{Soil Corrosivity}

very corrosive very corrosive moderately corrosive mildly corrosive progressively less corrosive

The resistivity of the soil shall be $5,000 \mathrm{ohm}-\mathrm{cm}$ or greater if unprotected ferrous metals are to be buried in the soil. Wood to be buried in soil shall be resistant to natural decay when evaluated by ASTM D2017-71.

\section{Section 05 - Test Methodology: Criterion 5.1.4}

This section contains test methods to determine the resistance of components to airborne pollutants. Following the test, specimens shall exhibit no signs of deterioration that would significantly impair their performance.

\section{Resistance to Ozone}

Coupon specimens of components shall be exposed for 500 hours to an ozone atmosphere of $50 \pm 5 \mathrm{pphm} /$ volume in a test chamber at $23 \pm 2{ }^{\circ} \mathrm{C}\left(73.4 \pm 3.6^{\circ} \mathrm{F}\right)$. The specimens shalil be exposed under conditions which simulate in-use conditions. After the exposure, the surfaces of the specimens shall be visually examined for signs of deterioration such as cracking, blistering, or dimensional changes using a microscope with an eye-piece micrometer at 20X magnification. An ozone test chamber is described in ASTM D1149-64 (1970), "Accelerated Ozone Cracking of Vulcanized Rubber."

The extent of change of the specimens as a result of the exposure shall be determined by comparing the exposed specimens to control specimens or by comparing the characteristics of the same specimens before and after exposure.

[1] "Control of Pipeline Corrosion,"A. W. Peabody, National Association of Corrosion Engineers, 2400 South Loop West, Houston, Texas 


\section{Resistance to Salt Spray}

Coupon specimens of components shall be evaluated in accordance with ASTM Standard Method B117-73. After exposure for 500 hours, the specimens shall be visually examined for signs of deterioration such as cracking, crazing, blistering, or pitting. The extent of the change as a result of the exposure shall be determined by comparing the exposed specimens to control specimens or by comparing the characteristics of the same specimens before and after exposure.

Resistance to $\mathrm{SO}_{2}, \mathrm{NO}_{\mathrm{x}}$, and $\mathrm{HCl}$

Coupon specimens shall be immersed for 500 hours in aqueous solutions containing 100 ppm of $\mathrm{H}_{2} \mathrm{SO}_{3}, \mathrm{HNO}_{3}$ and $\mathrm{HCl}$ on a one component per test solution basis so that one half the specimen is in the solution. During the immersion, the temperature of the test specimen shall be cycled repetitively as follows: one hour at the maximum service temperature, one hour at $23 \pm 2{ }^{\circ} \mathrm{C}(73.4 \pm$ $3.6^{\circ} \mathrm{F}$ ), one hour at the minimum service temperature and one hour at $23+$ $2{ }^{\circ} \mathrm{C}\left(73.4 \pm 3.6^{\circ} \mathrm{F}\right)$. Sufficient time shall be provided between each of the above cycles to allow the specimens to equilibrate at the test temperature. Test solutions shall not be heated above their boiling points or cooled. below their freezing points during the tests and the concentrations of the solution shall be maintained at the desired levels. After exposure, the specimens shall be visually examined for signs of deterioration such as cracking, crazing, blistering, or pitting. The extent of change of the specimens as a result of the exposure shall be determined by comparing the exposed specimens to control specimens or by comparing the same specimens before and after exposure. ASTM D1654-74 may be useful in evaluating properties of coated metal specimens. Also ASTM G1-72 and G31-72 may be useful in performing tests.

\section{Section 06 - Test Methodology: Criterion 5.2.1}

Complete components or coupon specimens shall be subjected to heat aging for a period of 500 hours at the maximum service temperature to which they will be exposed in actual service. Components and materials stressed in normal use should be stressed during the exposure. They shall be visually inspected both before and after aging.

When visually evaluated after exposure at the maximum service temperatures, there shall be no significant signs of cracking, crazing, blistering, or other deterioration. Also, the specimens shall exhibit no significant loss of strength as a result of the aging.

Section 07 - Test Methodology: Criterion 5.2.2

All fluids shall be subjected to the three tests below:

Test 1 - Expose the fluids to their maximum service temperature for a period of 500 hours.

Test 2 - Expose the fluids to their minimum service temperature for a period of 500 hours.

Test 3 - Subject the fluids to 100 cycles of cooling and heating with each cycle consisting of the following steps:

a. Cooling to the minimum service temperature over a period of two hours.

b. Holding at the minimum service temperature for two hours. 

c. Heating to the maximum service temperature over a period of two hours.

d. Holding at the maximum service temperature for two hours.

Periodically, during each test and at the completion of each test, inspect the fluids visually for signs of undesired changes such as freezing, excessive precipitation, boiling, or formation of gas bubbles. Also, before and after each test, measure the $\mathrm{pH}$ and the viscosity of the fluid and evaluate the IR spectrum of the fluid to ensure fluid stability. Boiling tests shall be conducted at service pressures. After the tests, the fluids shall not exhibit changes that would significantly impair their ability to function.

\section{Section 08 - Test Methodology: Criterion 5.2.3}

Subject samples of each subassembly of the system, which would normally undergo or be affected by thermal cycling to 100 cycles of cooling and heating with each cycle consisting of the following steps:
a. Cooling to the minimum service temperature over a period of two hours.
b. Holding at the minimum service temperature for two hours.
c. Heating to the maximum service temperature over a period of two hours.
d. Holding at the maximum service temperature for two hours.

During the test, the specified minimum or maximum temperature shall be maintained only on the collector plate so that the plate will be the heat source. The temperature of other components shall be permitted to vary as the temperature of the plate changes. Strain induced into the specimens during the test shall be measured.

After every third cycle and at the end of the test, visually inspect the components for signs of thermal incompatibility.

After exposure to the repeated cycles at the maximum and minimum service temperatures, there shall be no significant signs of cracking, crazing, loss of adhesion, or other deterioration.

\section{Section 09 - Test Methodology: Criterion 5.2.4}

Joints and system components which contain heat transfer fluids shall be static pressure tested with the heat transfer fluids at a fluid pressure equal to $150 \%$ of the working pressure that would occur in the component. Testing shall be performed concurrently for a period of 500 hours at the minimum service temperature and a period of 500 hours at the maximum service temperature.

During and following the pressure tests, visual inspections shall be made to identify evidence of leaks. Also, the pressure of the fluid shall be monitored to detect changes due to leakage.

\section{Section 10 - Test Methodology: Criterion 5.3.1}

Test the components for 100 hours at the maximum service temperature using ASTM D471-75. Components shall be stressed to simulate service conditions.

At the end of each test, visually inspect the components for signs of cracking, swelling, or other dimensional changes or loss of adhesion to adjoining components. 


\section{Section 11 - Test Methodology: Criterion 5.3.2}

Coupon specimens, or entire components, shall be immersed in the heat transfer fluid for a period of 1000 hours. During the test, the temperature of the fluid surrounding the specimens shall be cycled repetitively as follows: 20 hours at the maximum service temperature followed by cooling to minimum service temperature and reheating to the maximum service temperature over a four hour period. Appropriate modifications including flow rate and degree of fluid aeration shall be included in the test. Protective coatings shall form a part of the test specimen if they are used in the actual system. Testing shall be followed by visual inspection. Standard TM-01-71, Autoclave Corrosion Testing of Metal in High Temperature Water, of the National Association of Corrosion Engineers or ASTM D2570-73, Simulated Service Corrosion Testing of Engine Coolants, may be used in the evaluation of metals.

Following the test, the test specimens shall not show signs of pitting, crevices, erosion, or exhibit other signs of general corrosive deterioration with the exception of discoloration.

Section 12 - Test Methodology: Criterion 5.3.3

\section{Adjoining Dissimilar Materials Used in Contact with the Transfer Fluid}

Test specimens consisting of dissimilar materials in direct contact with one another shall be immersed in the heat transfer fluid for a period of 1000 hours at the maximum service temperature according to ASTM D1384-70 (1975). During the test, the heat transfer fluid shall be circulated to simulate $\mathrm{flow}$ rate and degree of fluid aeration. This shall be followed by visual observation. Protective coatings shall be used when they form a part of the component.

\section{Adjoining Dissimilar Materials Not Used in Contact with the Transfer Fluid}

Test specimens consisting of dissimilar materials in direct contract with one another shall be subjected to 100 cycles of heating and cooling in air containing 100 ppm sulfate. Each cycle shall consist of:

a. Heating to the maximum service temperature over a period of two hours.

b. Holding at the maximum service temperature and a relative humidity of $90 \%$ or greater for 18 hours.

c. Cooling to the minimum service temperature over a period of two hours.

d. Holding at the minimum service temperature for two hours.

Following the exposure, visually inspect the specimens for signs of corrosion.

At the completion of the above tests, specimens shall not show signs of pitting or exhibit other signs of corrosive deterioration with the exception of discoloration.

Section 13 - Test Methodology: Criterion 5.3.4

Expose components containing leachable substances and components that may be affected by the leachable substances in water or steam for a period of 500 hours at the maximum service temperature. At the end of the exposure, visually inspect the component that may have been affected by the leachable substance for signs of deterioration such as pitting, cracking, or dimensional changes. 
The evaluation shall consist of two stages. In the first stage, components shall be heated to their maximum service temperature for two hours and the composition of the decomposition products, if any, shall be determined. Analysis for organic materials could be by infrared spectroscopy or chromatography. Standard wet chemical techniques could be used for inorganic substances.

The second stage of the evaluation shall be performed if the amount and types of decomposition products are significant. The second stage shall consist of subjecting components, that would be exposed to the decomposition products in actual service, to the decomposition products in a test chamber for 100 hours at the maximum service temperature of the components being tested. The concentration of the decomposition products shall be the maximum concentration expected in actual service. During the exposure, moisture shall be added to the test chamber to maintain a relative humidity of $90 \%$ or greater.

After the exposure, test specimens shall be visually examined for signs of degradation such as cracking, corrosion, and swelling or other dimensional changes. 
6.1 Requirement Accessibility for maintenance and servicing. The H/C/HW systems shall be designed, constructed, and installed to provide sufficient access for general maintenance, convenient servicing, and monitoring of system performance.

6.1.1 Criterion Access for system maintenance. All individual items of equipment and components of the $\mathrm{H} / \mathrm{C} / \mathrm{HW}$ systems which may require periodic examination, adjusting, servicing and/or maintenance shall be accessible for inspection, service, repair, removal or replacement without dismantling of any adjoining major plece of equipment or subsystem. Individual collectors in an array shall be replaceable or repairable without disturbing non-adjacent collectors in the array.

Evaluation Review of drawings and specifications.

Commentary Accessibility as a function of component life is an important consideration. Some'manufactured collector systems and many individually designed systems are done in such a way that sequential installation is necessary. This can make it very difficult to replace an individual collector without disturbing the entire array.

Information on access provisions is provided in Reference [1].

6.1.2 Criterion Access for system monitoring. Appropriate access for sensors shall be provided for inspecting and checking essential system parameters, e.g. temperature, pressure, and critical voltages.

Evaluation Review of drawings and specifications for the location of test fittings and electrical contacts.

Commentary Adequately located test fittings will permit system monitoring and expedite the maintenance and repair of equipment.

$6.1 .3 \quad$ Criterion

Draining and filling of liquids. To facilitate system or subsystem maintenance and repair, subsystems employing liquids shall be capable of being conveniently filled and drained.

Evaluation Review of drawings and specifications.

6.1.4 Criterion

Flushing of liquid subsystems. Suitable connections shall be provided for the flushing (cleaning) of liquid energy transport subsystems.

Evaluation Review of drawings and specifications.

Commentary The recommendations of the system manufacturer for cleaning agents compatible with the materials of the system should be followed. 


\section{1 .5 \\ Criterion}

Evaluation

6.1.6 Criterion

Evaluation

6.1.7 Criterion

Evaluation

Commentary

6.2 Requirement

6.2.1 Criterion

Evaluation

Commentary
6.2 .2
Criterion

Filters. Filters shall be designed and located so that they can be cleaned or replaced with minimum disruption to the system and adjacent equipment. Cleaning frequencies shall be specified by the system manufacturer in the maintenance manual.

\section{Review of drawings and specifications.}

Water shut off. The HW system shall be valved to shut off from the cold water supply.

Review of drawings and specifications.

Impairment of operation. The functional capability of the H/C/HW systems shall not be impaired to a greater extent than conventional systems when system repairs or modifications are being made.

Engineering review of specifications and drawings.

Equipment that requires preventive maintenance shall be provided with complete instructions to maintain proper and efficient operation of component, subsystem, and system.

Installation, operation, and maintenance manual. A manual* shall be provided containing instructions for the installation, operation, and maintenance of the $\mathrm{H} / \mathrm{C} / \mathrm{HW}$ systems and/or subsystems and components.

Installation instructions. The instructions shall include physical, functional, and procedural requirements for $\mathrm{H} / \mathrm{C} / \mathrm{HW}$ subassembly and component installation.

These instructions shall describe the interconnection requirements of the various subsystems and components and their interface requirements with the building and site.

Review of installation instructions.

It is not the intent of this criterion to require the provision of complete, detailed system installation specifications. Such specifications would normally be project specific and part of the procurement process.

Maintenance and operation instructions. The manual shall completely describe the $\mathrm{H} / \mathrm{C} / \mathrm{HW}$ systems, their breakdown into subsystems, their relationship to external systems and elements, their performance characteristics, and their required parts and procedures for meeting specified capabilities.

The manual shall list all parts of the systems, by subsystem, describing as necessary for clear understanding of operation, maintenance, repair, and replacement, such characteristics as shapes, dimensions, materials, weights, functions, and performance characteristics. The manual shall include a tabulation of those specific performance requirements which are dependent upon specific maintenance procedures. The maintenance procedures,

* The manual may consist in whole or in part of a series of instruction sheets provided by the various subsystem and component manufacturers. 
Evaluation

Commentary

\section{2 .3 \\ Criterion}

Evaluation

\subsubsection{Criterion}

Evaluation

Cemmentary

$6.3 \quad$ Requirement

6.3.1 Criterion

Evaluation

Commentary including ordinary, preventive and minor repairs, shall be crossreferenced for all subsystems and organized into a maintenance cycle. The manual shall fully describe operation procedures for all parts of the system including those required for implementation of specified planned changes in mode of operation. The manual shall provide warning against hazards that could arise in the maintenance of the system and shall fully describe precautions that shall be taken to avoid these hazards.

The manual should specify temperature, pressure, and flow conditions which are expected to occur at the access points required in Criterion 6.1 .2 to facilitate operational checks and troubleshooting.

Review of maintenance and operating instructions.

One of the most common malfunctions in large systems is expected to be in the control system operation. These malfunctions are not always complete failures but more often a matter of adjustment. Control system malfunctions are not usually obvious unless testing at specified points is conducted.

Some systems contain toxic and/or flammable materials that could result in the poisoning of maintenance personnel or result in fires or explosions when repairs involving soldering or welding are involved. In addition, toxic fumes can be given off.

Maintenance plan. The manual shall include a comprehensive plan for maintaining the specified performance of the $\mathrm{H} / \mathrm{C} / \mathrm{HW}$ systems for their design service lives.

The plan shall include all the necessary ordinary maintenance, preventive maintenance and minor repair work, and projections for equipment replacement.

Review of maintenance plan.

Replacement parts. Parts, components, and equipment required for service, repair, or replacement shall be commercially available from the system or subsystem manufacturer or supplier.

Review of specifications for the availability of parts.

This criterion is intended to preclude long periods of system downtime due to the need for the repair or replacement of parts It would be desirable to have a minimum one-year's supply of consumable parts and potential early failure items, such as fan belts, bearings, etc., in hand for the system.

Repair and service personnel. The H/C/HW systems shall be designed in such a manner that they can be conveniently repaired by qualified service personnel.

Servicing of H, C, and HC systems. The H, C, and HC systems shall be capable of being serviced with a minimum amount of special equipment by a trained HVAC service technician using a service manual.

Review of drawings, specifications, and service instruction manuals.

The complexity and design of certain components may require their removal and replacement for repair of the system. 
6.3.2 Criterion Servicing HW system. The HW system shall be capable of being serviced with a minimum amount of special equipment by a qualified plumber using a service manual.

Evaluation Review of drawings, specifications, and service instruction manuals.

\section{$\underline{\text { Reference }}$}

1. Uniform Mechanical Code, International Conference of Building officials, 5360 South Workman Mill Road, Whittier, California 90601, 1973. 
7.1 Requirement

7.1.1 Criterion

Evaluation

Commentary

\subsubsection{Criterion}

Evaluation

Commentary

7.2 Requirement

\subsubsection{Criterion}

Evaluation

Commentary
Design. The buildings and sites shall utilize materlals, designs, and construction methods appropriate for their intended use.

Design-Habitable buildings. The design of habitable and publicly used buildings shall be done by registered Architects and/or Engineers. The design of these bulldings shall conform to state and local building codes and regulations.

Review of calculations, drawings, and specifications, and review of Architect and Englneer credentials.

A well designed solar energy system should include a building which is energy conserving. The codes and standards in most states do not completely address energy conservation; and upgrading in this particular way may be desirable.

There are several approaches that should be considered for the design of buildings that conserve energy. One approach considers the site where energy can be conserved by managing the microclimate and, therefore, modifying its effect on the building. A second approach considers the exterior envelope of the building where energy can be conserved by modifying factors such as: color, thermal conductivity, orientation, texture, surface area and weather tightness. A third approach considers the mass of the building and the objects around the building. Through careful selection of materials, the rate at which energy is stored and released can be managed, 'e.g., energy stored during the day and released at night can reduce the thermal load on the building in either a cooling cycle or a heating cycle depending on whether the energy is released inside or outside of the building. Which combination of options is chosen and how effecitve the selection will be is dependent on design conditions and design goals.

Passive use of solar energy. Consideration shall be given in the building and site design to the passive utilization of solar energy, wherever practical.

Review of calculations, drawings, and specifications.

Savings can be realized when normally provided components of the building and site can be given an additional use in the H/C/HW systems. Considering the building itself as a system for capturing, storing, and utilizing solar energy can provide opportunities for reductions in the building heating or cooling requirements.

Adequate space. The building site shall provide space to adequately accommodate the H/C/HW systems.

Collector. The building and site shall provide sufficient space for the installation of the solar collectors.

Review of site and building drawings showing the area provided for the solar collector and calculations showing the space needed for the collector.

This criterion does not require that the solar collector be separate from other solar components, but only intends to establish that adequate surface areas have to be provided if the 


\section{2 .2 \\ Criterion}

Evaluation

Commentary

7.3

7.3 .1

Criterion

Evaluation

Commentary

\section{3 .2}

Criterion

Evaluation collecting element is installed on the building or site. The slope and area of the collectors is a complicated problem and requires consideration of factors, such as the following: climatic region, collector orientation and tilt angles, collector exposure to wind, amount of energy to be supplied or released by collector, collector mounting (free-standing or integrated with the building), efficiency of the collector, and shading of the collector.

Storage. Where thermal storage is required, the building and/or site shall provide sufficient space for the installation of the storage subsystem.

Review of site and building drawings showing the space provided for thermal storage and calculations showing the volume required for storage.

This criterion does not mean that, where required, storage should be separate from other solar components, it is intended only to ensure that a sufficient volume is provided for storage. The amount of storage required will vary with such factors as: heat capacity, storage medium, climatic region, amount of energy to be supplied or released by the collector, efficiency of the collector, heat losses in the system, and design load of the $\mathrm{H} / \mathrm{C} / \mathrm{HW}$ systems.

Functioning of building and site. The use and habitability of the building and site shall not be substantially impaired by the $\mathrm{H} / \mathrm{C} / \mathrm{HW}$ systems.

Space use. A location shall be provided for solar subsystems that will not significantly impair the use of required exterfor or interior spaces.

Review of site and building drawings showing the location of solar subsystems.

The space provided for the solar subsystems should be in addition to that normally required. Solar subsystems should not reduce or increase humidity, temperature, or radiation beyond acceptable levels or interfere with required headroom or circulation space. Heat storage areas that are incorporated within the building should be properly insulated to prevent undesirable overheating of adjacent rooms. System subassemblies located on the site (e.g., collector or storage units) should not unduly interfere with trash removal, furniture moving, the servicing of mechanical equipment, or the normal movement of people and vehicles. The operation of solar equipment should not create noise levels which would impair the comfort levels of occupied spaces during the day or at night. Since a collector may reflect a large percentage of the incident solar radiation at high incidence angles, the possibility of reflecting solar rays onto areas where people congregate should be investigated. Solar subsystems such as storage should be used as positive design elements that add to rather than subtract from the aesthetic quality of a space.

Impact on environment. A site location shall be provided for the solar subsystems which will not significantly degrade the immediate natural environment and site.

Review of drawings and a report on the negative effects of the building and its solar subsystems on drainage, vegetation, microclimate, and wildlife. 
Commentary

7.3.3 Criterion

Evaluation

Commentary
This criterion does not require that existing conditions should be maintained but that environmental degradation of the site and the immediate area around the site should be prevented it if cannot be healed naturally without further deterioration. Several examples can be cited that could cause such conditions to exist: (1) runoff from a large collector is not collected and carried away in a drainage system it could, for certain soll conditions, cause excessive erosion, (2) if the reflected rays from a collector or the shade created by a collector killed existing vegetation and prevented the growth of new vegetation, large areas of soil might be exposed to excessive runoff, and (3) If the installation of solar equipment is poorly planned or implemented, it can result in the unnecessary cutting down of trees or in other conditions which would kill vegetation such as compaction, sunburn, drying, grade change, root pruning, or lack of support.

View. The location of solar components shall not unnecessarily block interior or exterior views of the site unless they are intended as an integrated part of that view.

Review of site and building drawings.

Even well-designed components can be undesirable obstructions to attractive views of the building or site, unless they are integrated into the view. 


\section{General References}

1. Aronin, Jeffrey F., Climate and Architecture, New York, N.Y., (1953).

2. Fitch, James Marston, American Building: The Environmental Forces that Shape It, Houghton Mifflin Co., Boston, Mass., (1972).

3. Fitch, James Marston, "Buildings Designed for Climate Control in the United States of America," Weather and the Building Industry, Research Conference Report No. 1, Building Research Advisory Board of National Research Council, Washington, D.C., (1950).

4. Givoni, B., Man, Climate and Architecture, E1sevier Publishing Co., New York, N.Y., (1969).

5. Knowles, Ralph L., Energy and Form, MIT Press, Cambridge, Mass., (1974).

6. Koenigsberger, Rugersō11, Mayhew, Szokolay, Manual of Tropical Housing and Building: Part 1 Climatic Design, Longman Group Limited, London, (1973).

7. Olgyay, Aladar, "Solar Control and Orientation to Meet Bioclimatic Requirements," Architectural Forum, (March 1954), pp. 38-46.

8. 0lgyay, Victor, Design with Climate, Princeton University Press, Princeton, N.J., (1963).

9. Robinette, Gary 0., Plants/People/and Environmental Quality, U.S. Department of Interior, National Park Service in Association with American Society of Landscape Architects Foundation, Government Printing Office, Washington, D.C. (1972).

10. AIA Research Corporation Solar Dwelling Design Concepts, prepared for U. S. Department of Housing and Urban Development, Office of Policy Development and Research, (June 1976). (Available from Superintendent of Documents, U. S. Government Printing Office, Washington, D. C., 20402, Stock No. 023-000-00334-1)

11. Steadman, Philip, Energy Environment and Building, Cambridge University Press, Cambridge, Mass., (1975).

12. The House Beautiful Climate Control Projects, Bulletin of the American Institute of Architects, September 1949 - January 1952.

13. Tota1 Environmental Action, Solar Energy Home Design in Four Climates, Tota1 Environmental Action, Harrisville, N.H., (1975).

14. United Nations, Climate and House Design, United Nations Publication, New York, N.Y., (1971). 
8.1 Requirement

8.1.1 Criterion

Evaluation

Commentary

\subsubsection{Criterion}

Evaluation

Commentary

\subsubsection{Criterion}

Evaluation

8.2 Requirement
Mechanical and electrical functioning of $\mathrm{H} / \mathrm{C} / \mathrm{HW}$ systems. The building and site elements shall not prevent the proper mechanical and electrical functioning of the $\mathrm{H} / \mathrm{C} / \mathrm{HW}$ systems.

Blockage of mechanical equipment. Buildings and planting arrangement shall be coordinated with the installation of solar components to avoid interference with their mechanical function.

Review of building and site drawings showing the location of solar system subassemblies, vegetation, fences, walls, and any other objects which might affect the operation of the $\mathrm{H} / \mathrm{C} / \mathrm{HW}$ systems.

Existing vegetation and future growth of that vegetation can become a problem in the functioning of mechanical equipment, air intakes and vents. For example, plants might block and, therefore, reduce the efficiency of a fan or a compressor-condenser unit. On the other hand, vegetation can also be used to advantage as a sunshade to reduce the cooling load.

Shading of collector. The location provided for the collector shall not be shaded more than the specified period allowed for in the design.

Review of calculations or drawings estimating the area of the collector shaded by objects such as mechanical equipment, chimneys, vents, snow, triees, and buildings. Consideration shall be given to the latitude of the site, the height of the object above the collector, the azimuth angle of the object relative to the collector and the cut-off angles at which solar energy can be efficiently collected throughout the year.

In locating trees in order to minimize the amount of shade falling on the collector, the designer may not be able to effectively use shade trees to improve the microclimate. Data are available for calculating shading angles as a function of the time of day and year $[1,2,3,4]$. Consideration should also be given to partial shading of collectors which could cause unusal stress concentrations and resulting glass breakage in an operating collector.

Sensor location. A location shall be provided for interior and exterior control sensors (if sensors are required by the solar technology being used) which will allow the detection of appropriate changes in the system and the environment without unnecessary interference from factors such as shade, drafts, thermal radiation, and vibrations.

Review of drawings showing the location and elevation of control sensing equipment. If sensing equipment is located on the exterior of a building, exterior elevations showing the location of control sensing equipment shall be provided.

Mechanical and electrical functioning of building and site. The mechanical and electrical operation of the building or site shall not be adversely affected by the $\mathrm{H} / \mathrm{C} / \mathrm{HW}$ systems. 


\subsubsection{Criterion}

Evaluation

Commentary

\subsubsection{Criterion}

Evaluation

Commentary

\subsubsection{Criterion}

Evaluation

Commentary

\subsubsection{Criterion}

Evaluation
Space for installation. Where portions of the solar subsystem and particularly the energy transport subsystem are installed within floors, walls, ceilings, or utility chases, adequate space shall be provided for installations.

Review of the drawings showing the layout of the energy transport subsystem and typical architectural sections for walls, floors, and roof.

A preferred location for piping and ducts in walls may be within interior walls rather than in exterior walls. This is particularly true for those pipes and ducts delivering hot water, heating or cooling to the building so that losses and gains, therefore, will be contained within the conditioned space. Provisions should be made when using solar heating/cooling systems (using lower working temperatures than conventional systems) for additional space to include the larger ductwork and piping required under these circumstances.

Exhaust and venting. The location provided for solar components shall not interfere aerodynamically or physically with the venting of the building plumbing systems or the exhaust of mechanical systems to the extent that their intended function is significantly impaired.

Review of drawings showing the location of solar components, plumbing vents, and mechanical exhausts.

The wind conditions created around chimneys, flues, plumbing vents, mechanical exhausts and condensers by the presence of solar components should be examined for possible interference with the mechanical operation of such elements. Flues and vents should be located elther far enough from higher elements (such as roof mounted solar equipment) or extended far enough above them to insure continuous outward flow from the flue or vent.

Utilities. The location and installation of solar components shall not interfere with the safe operation of existing or proposed utility systems.

Review of utility plan and site plan.

Underground potable water piping serving an array of solar collectors installed remote from the building if in proximity to sewers or sewage facilities, could allow contamination of the potable water system. A horizontal separation of at least 10 feet from a septic tank drainage field and 12 inches from a sewer line is common practice for pipes carrying potable water.

Mechanical and electrical functioning of connections. The connections between the $\mathrm{H} / \mathrm{C} / \mathrm{HW}$ systems and the building or site shall function mechanically or electrically as intended.

Plumbing connection. Plumbing connections between the solar components and water service or waste disposal systems shall be in accordance with applicable nationally recognized and local plumbing codes.

Review of drawings, details, and specifications related to plumbing connections. 
Commentary Particular attention should be given to making sure that plumbing connections are dimensionally coordinated, that pipe sizes and threads are compatible, and that changes in direction do not unduly restrict the flow of fluid.

8.3.2 Criterion Electrical connections. Electrical connections between the solar components and the electrical system of the building and site or electrical service to the building and site, shall be in accordance with applicable local and nationally recognized codes, as specified in Criterion 4.1.2.

Evaluation Review of drawings, details, and specifications related to electrical connections.

Commentary It is possible for improperly installed electrical connections to overload the electrical service and for electrical connections that are not mechanically secure to create a fire hazard.

8.3.3 Criterion

Duct connections. Duct connections between the solar components and the mechanical system shall be in accordance with ASHRAE and SMACNA standards.

Evaluation

Review of drawings, details, and specifications related to duct connections.

\section{References}

1. Aronin, Jeffery R , Climate and Architecture, New York, N.Y. (1953), p. $28-114$.

2. ASHRAE, Handbook of Fundamentals, American Society of Heating, Refrigerating and Air-Conditioning Engineers, Inc., New York, N.Y. (1972), p. 406.

3. Libbey-Owens-Ford Co., Sun Angle Calculator, Libbey-Owens-Ford Co., Toledo, Ohio (1975).

4. United Nations, Climate and House Design, United Nations Publication, New York, N.Y. (1971). 
$9.1 \quad$ Requirement

9.1.1 Criterion

Evaluation

Commentary

9.2

9.2 .1

Criterion

Evaluation

Commentary

\subsubsection{Criterion}

Evaluation

Commentary
Structural integrity of $\mathrm{H} / \mathrm{C} / \mathrm{HW}$ systems. The building or site shall not reduce the structural integrity of the $\mathrm{H} / \mathrm{C} / \mathrm{HW}$ systems below allowable design values.

Movement in adjacent structures. The locations provided for the installation of solar components shall take into account possible movements in adjacent structures which could impair the intended performance capability of the solar systems.

Review of site and building drawings.

The possibility of stresses being imposed by thermal expansion or contraction, wind movements, seismic loads, vibratory loads, or foundations settlement need to be considered. Solar components

- vary in their ability to withstand the effect on their performance of differential settlement. For example, a rock storage bin can probably settle a great deal without affecting its performance; however, a plumbing connection may be able to withstand very little differential settlement.

Structural integrity of building and site elements. The structural integrity of building and site elements shall not be impaired by the $\mathrm{H} / \mathrm{C} / \mathrm{HW}$ systems.

Loads. in addition to basic design loads, building and site elements shall be capable of carrying the increased loads imposed by solar components.

Review of structural drawings, specifications, and design calculations taking into consideration the loads set forth in Chapter 3, Structural (Systems and Components).

All possible loading conditions, such as those created by empty storage tanks exposed to wind, alternate or adjacent span loading of panels, or combinations of live loads along with dead loads should be checked. The addition of solar components to an existing structure may require detailed investigation of the existing structure and shall be based on the latest engineering practices and applicable codes.

Penetration of structural members. When penetrations are required in structural members to accommodate passage of solar components, the structural design should reflect such additional requirements. Structural members shall be designed so that compliance with state and local building codes and regulations is maintained.

Review of structural and mechanical drawings.

This criterion is intended to prevent holes which are cut for the installation of pipes, ducts, conduit wires, and other mechanical equipment from reducing the required strength of structural members. 


\subsection{Requirement}

9.3.1 Criterion

Evaluation

Commentary

\subsubsection{Criterion}

Evaluation
Structural connections. Structural connections between solar components and the bullding or site elements shall be capable of carrying imposed loads.

Structural connections. Structural connections between solar components and the building or site elements shall be capable of transmitting sustained loads as specified in the design.

Review of structural drawings, connection details, specifications, and design calculations.

This criterion deals not only with the connections of major structural elements but with brackets or other supports used for mounting solar components on a bullding. Allowable stresses and design criteria for solar components supporting structures shall be in conformity with accepted engineering practice and applicable codes. This criterion is intended to insure that the local area around the connection of a solar component is structurally designed. Criterion 9.2.1 is intended to insure that those loads are carrled by the building and site elements.

Brittle components. Where required, brittle elements of the solar components shall be attached by devices or other means capable of accommodating the maximum movement that would occur in normal use.

Review of structural connection details and specifications. 
10.1

Requirement

10.1 .1

Criterion

Evaluation

Commentary

10.1 .2

Criterion

Evaluation

Commentary

10.1 .3

Criterion

Evaluation

Cormentary

10.1 .4

Criterion

Evaluation

Comment ary
Safety of building and site. The safe operation of the building or site shall not be affected by the H/C/HW systems.

Fire. The location of solar components shall not be detrimental to the fire safety of the building or site.

Review of calculations, drawings, and specifications.

When solar components are located on the site, circulation paths should be checked to see that interference with the movement of fire fighting equipment or with the emergency evacuation of a building is not jeopardized. When system components are mounted on the building or made an integral part of the building, the fire safety of the building's occupants must be maintained. This will require that attention be given to the effects of "no flow" temperatures on adjacent parts of a building, use of roofs by fire fighters for gaining access, venting, and rescuing people from fires.

Protection against auto-ignition of combustibles. Combustible solids adjacent to solar equipment shall not be exposed to elevated temperatures which may cause ignition.

Review of calculations, drawings, and specifications. Testing to show compliance where necessary.

Heating of cellulosic materials as well as other combustible materials over an extended period of time may result in the material reaching and surpassing its auto-ignition temperature. The most commonly accepted ignition temperature of wood is $392^{\circ} \mathrm{F}$. However, studies have indicated that wood may ignite when exposed to a temperature of $212^{\circ} \mathrm{F}$ for prolonged periods of time. The ignition temperature of plastics may be above or below those of cellulosic materials. Clearances for HVAC equipment, ducting, and piping are discussed in NFPA No. 89M. Where applicable, clearances specified by a nationally recognized testing laboratory may be used.

Protection from thermal deterioration. Building materials adjacent to solar equipment shall not be exposed to elevated temperatures that can result in adverse physical, chemical, mechanical, or thermal changes.

Review of calculations, drawings, and specifications.

Buflding materials exposed to elevated temperatures may be subject to hardening, softening, melting, blistering, buckling, and other adverse changes which may reduce the structural and fire resistance ratings of the building elements.

Accidents. The location provided for solar components shall not increase the accident potential to a greater extent than would be expected for a conventional non-solar facility.

Review of calculations, drawings, and specifications.

Several examples can be given of how the presence of solar components might increase accident potential: (1) snow and ice accumulations on the collector could present a hazard to pedestrians 
below, (2) reflected rays from the collector could be distracting to drivers on adjacent highways or annoying to the occupants of nearby buildings, and (3) the ground around a storage unit might settle, creating a hazard because of the uneven ground.

10.1.5 Criterion Lightning protection. Lightning protection shall be provided in accordance with the NFPA No. 78 Lightning Protection Code [1].

Evaluation Review of calculations, drawings, and specifications.

Commentary There is some evidence to suggest that solar arrays, particularly solar arrays with plastic covers, increase the electrostatic potential between ground and air, and could induce increased lightning hazard in areas of high lightning incidence.

\section{Reference}

1. Lightning Protection Code, NFPA, No. 78, 1975, National Fire Protection Association (NFPA), 470 Atlantic Avenue, Boston, Mass. 02210. 
11.1

Requirement

11.1.1 Criterion

Evaluation

11.2

Requirement

11.2.1 Criterion

Evaluation

11.2.2 Criterion

Evaluation

Commentary

11.2.3 Criterion

Evaluation

$11.3 \quad$ Requirement

11.3.1 Criterion

Evaluation
Durability and reliability of $\mathrm{H} / \mathrm{C} / \mathrm{HW}$ systems. The building and site sha11 not reduce the durability or reliability of the $\mathrm{H} / \mathrm{C} / \mathrm{HW}$ systems to an extent that would significantly impair their intended function.

Vegetation. The location of plant materials shall consider the effects that their sap, roots, growth or decay could have on the durability and reliability of the $\mathrm{H} / \mathrm{C} / \mathrm{HW}$ systems.

Review of site plans showing the location and type of existing and proposed plant materials and the location of the solar components.

Durability and reliability of building and site. The durability and reliability of the building and site elements shall not be reduced by the $\mathrm{H} / \mathrm{C} / \mathrm{HW}$ systems to an extent that would significantly impair their intended function.

Chemical corrosion. Solar components shall not cause corrosion of the building or site elements to an extent that would significantly impair their intended performance.

See Evaluation: Criterion 5.3.4.

Heat and moisture. Roof mounted system components shall not cause a buildup of heat or moisture that would cause excessive deterioration of the roofing system or other components of the buildings.

Review of drawings, specifications, and calculations for potential temperature buildup caused by solar subsystems.

The presence of the collector can cause abnormal heat rises which could cause thermal degradation and the buildup of moisture which could cause rotting or the growth of mold and fungus. The provision of adequate ventilation may be required. Venting to interior mechanical areas or other genera11y unoccupied areas within the building may be acceptable in order to minimize heat loss caused by venting.

Exterior penetrations. Openings in the exterior enclosure of the building through which piping, ducting, and/or wiring are passed shall be made weather resistant and moisture proof.

Review of drawings and specifications.

Durability and reliability of connections. The connections between the $\mathrm{H} / \mathrm{C} / \mathrm{HW}$ systems and the building that are exposed to external environmental factors shall not undergo changes that will impair their expected performance.

Material compatibility. Connector materials between solar components and the building and site sha11 be chemically and physically compatible under in-use conditions.

See Evaluation: Criterion 5.3.2. 
12.1 Requirement

12.1.1 Criterion

Evaluation

Commentary

12.1.2 Criterion

Evaluation

Commentary

12.1.3 Criterion

Evaluation

12.2 Requirement
Maintalnability of $\mathrm{H} / \mathrm{C} / \mathrm{HW}$ systems. The building or site shall not prevent the practical maintainability of the $\mathrm{H} / \mathrm{C} / \mathrm{HW}$ systems, nor shall the systems prevent the practical maintainability of the building or site.

Accessibility. The design shall make adequate provision for accessible maintenance.

Review of site and building drawings.

Solar components should be accessible without trespassing on adjoining propérty and should not be located unnecessarily under buildings or roads, behind mechanical equipment or in other places which are inaccessible for maintenance without disassembling any major structural or mechanical elements. There should be sufficient room around components to permit their examination, adjusting, servicing, and/or maintenance. Accessibility for repair, maintenance and replacement should reflect the expected life of the component and frequency of routine maintenance required. An element with a shorter maintenance cycle or $11 \mathrm{fe}$ expectancy should be more accessible than one that has a longer maintenance cycle or life expectancy.

Misuse. Solar components shall be located where the potential for their misuse is minimized.

Review of site plans showing the location of recreational facilities, protective screening, roads, sidewalks, and solar subsystems.

The proximity of system components to playgrounds and sidewalks should be examined to minimize the potential misuse or vandalism. In addition, equipment which should only be adjusted by skilled personnel should not be located in areas subjected to normal pedestrian traffic.

Permanent maintenance accessories. Permanent maintenance accessorles such as hose bibs, drains, and ladder supports necessary for the maintenance of the $\mathrm{H} / \mathrm{C} / \mathrm{HW}$ systems shall be provided.

Review of maintenance plans and drawings and specifications showing type and the location of drains, ladder supports, safety belt clips, and other permanent maintenance accessories relative to the location of solar equipment.

Drains, hose bibs, and surfaces for supporting ladders or other equipment may be needed to service the solar eauipment.

Maintalnability of building and site. The practical maintainability of the building or site shall not be significantly impaired by the $\mathrm{H} / \mathrm{C} / \mathrm{HW}$ systems. 
12.2.1 Criterion Accessibility. The location of the solar components shall not impair accessibility needed to maintain the building or site.

Evaluation Review of maintenance plans, site plans, and building drawings.

Commentary The location of underground elements should be examined both to ensure that they can be maintained without trespassing on adjoining property and to ensure that they do not prevent digging, truck access, etc., necessary to maintain the facility or site.

12.2.2 Criterion Ice dams. The presence of a solar component shall not create the potential for significant ice damming which might cause roof leakage.

Evaluation Review of roof drawings and details for roof-installed solar components.

Commentary Ice sliding off a collector, for example, can create a dam behind which water could accumulate and cause roof leakage.

12.3 Requirement Maintainability of connections. The connections between the $\mathrm{H} / \mathrm{C} / \mathrm{HW}$ systems and building or site shall be maintainable.

12.3.1 Criterion Accessibility. Connections which require maintenance sha11 be accessible without disassembling major portions of the solar components, the building or the site elements.

Evaluation Review of maintenance plans and building drawings and specifications. 
Visual characteristics of building and site. Consideration shall be given to the effects on the visual characteristics of the existing and proposed environment caused by the installation of a solar energy system.

13.1.1 Criterion

Building. The effects of the solar subsystems on the mass, scale, grid pattern, texture, and color of the building shall be considered.

Evaluation Review of site and building drawings, models, and renderings.

13.1.2 Criterion

Neighborhood. Consideration shall be given to the relationship between the solar energy system and its building and site with the surrounding neighborhood.

Evaluation

Review of site plans, elevations, photographs of neighboring buildings, models, and renderings of the solar energy system installed on the building and site, and the surrounding neighborhood. 
Absorptance - The ratio of the amount of radiation absorbed by a surface to the amount of radiation incident upon it.

Absorptivity - The capacity of a material to absorb radiant energy.

Air chamber - A closed section of pipe or a container filled with air entrapped at atmospheric pressure which when mounted in a water supply line absorbs the pressure surges caused by the rapid opening and closing of valves.

Air gap separation - The unobstructed vertical distance through the free atmosphere between the lowest opening from any pipe or faucet supplying water to a tank, plumbing fixture, or other device and the flood level rim of the receptacle.

Auxiliary energy subsystem - Equipment utilizing conventional energy sources to supplement the output provided by the solar energy system. It may be integrated directly into the solar energy system, or it may be completely separate from it, and contain its own means for delivery of heating, cooling and/or hot water to the building.

Back pressure - A form of backflow caused by a pump, elevated tank, boiler, or other means that could create pressure within the system greater than the supply pressure of a fluid.

Backflow - The reverse flow of liquids, gases, or substances into the distributing pipe lines of a potable supply of water. Backflow may occur under two conditions - pressure greater than atmospheric (see "Back pressure"), and pressure that is subatmospheric (see "Backsiphonage").

Backsiphonage - A form of backflow due to a negative or subatmospheric pressure.

Cathodic protection - The process of providing corrosion protection against electrolytic reactions that could be deleterious to the performance of the protected material or component.

Chemical compatibility - The ability of materials and components in contact with each other to resist mutual chemical degradation, such as that caused by electrolytic action or plasticizer migration.

Climate - The prevailing or average weather conditions of a geographic area or region as shown by temperature and meteorological changes over a period of years.

Collector efficiency (instantaneous) - The amount of energy removed by the transfer fluid per unit of aperature (entrance window area) over a 15-minute period by the total incident solar radiation onto the collector for the 15-minute period.

Collector subsystem - The assembly used for absorbing solar radiation, converting it into useful thermal energy, and transferring the thermal energy to a heat transfer fluid.

Control subsystem - The assembly of devices and their electrical, pneumatic or hydraulic auxiliaries used to regulate the processes of collecting, transporting, storing and utilizing energy in response to the thermal, safety, and health requirements of the building occupants.

Cooling (C) system - The complete assembly of subsystems and components necessary to convert solar energy into thermal energy and use this energy in combination with auxillary energy, where required, for space cooling purposes.

Cooling degree days - The number of degrees that the daily mean temperature is above 65 degrees F. 
Combustible solids - This term as used herein means cellulosic materials, such as wood, paper and many fibrous materials (except asbestos and some of the synthetic fibers) as defined in Section 5 of the NFPA Fire Protection Handbook, 13th Edition.

Component - An individually distinguishable product that forms part of a more complex product (i.e. subsystem or system)

Creep - A time-dependent deformation caused by sustained loads. (See "Sustained 1oad.")

Cross-connection - Any connection between a potable water system and non-potable source or system through which backflow can occur. (See "Backflow.")

Cyclic load - A service load whose magnitude and/or direction are subject to time dependent variation.

Design life - The period of time during which an $\mathrm{H} / \mathrm{C} / \mathrm{HW}$ system is expected to perform its intended function without requiring major maintenance or replacement.

Dielectric fitting - An insulating or nonconducting fitting used to isolate electrochemically dissimilar materials.

Hot water (HW) system - The complete assembly of subsystems or components necessary to convert solar energy into thermal energy and use this energy in combination with auxiliary energy, where required, to provide hot water in the building.

Ease of ignition - The flame exposure time required to produce sustained flaming of a representative specimen of material from a controlled impinging flame source.

Electrical distribution subsystem - All electrical conductors and equipment installed in an $\mathrm{H} / \mathrm{C} / \mathrm{HW}$ system including supply conductors for operation of the systems.

Emittance - The ratio of the radiant energy emitted by a body to the energy emitted by a black body at the same temperature.

Energy transport subsystem - That portion of an $\mathrm{H} / \mathrm{C} / \mathrm{HW}$ system which contains heat transfer fluids and transports energy throughout the system.

Environmental impact statement - A report of any effects that the system or its building could have on the site and its surroundings.

Expansive soil - A soil which exhibits an increase in volume with an increase in moisture content.

Failure (structural) - Failure of a structure or any structural element is defined as one of the following:

(a) Sudden, locally-increased curvature, major spalling, or structural collapse.

(b) The inability of the structure to resist a further increase in load.

(c) An increase in deflection of no less than the maximum allowable deflection under service load conditions, occurring during any 10-minute period after application of the superimposed load without increase in the applied load.

Fluid requiring special handling - Fluid having a degree of toxicity such that it is categorized as a "highly toxic substance" or a "toxic substance" as defined by paragraphs 191.1 (e) and (f) of the Hazardous Substances Act, Regulations, Part 191, Chapter 1, Tile 21 (A); fluid having a degree of flammability such that it is categorized as a "flammable substance" or an "extremely flammable substance" as defined by the application of the Tagliabue Open-Cup Flash Point Test (stated in the Act). 
Heat actuated cooling - The use of thermal energy to initiate a thermodynamic cycle which results in lowering the temperature of a heat transfer fluid, which in turn is used to lower the indoor air temperature.

Heat capacity - The amount of heat necessary to raise the temperature of a given mass one degree.

Heat transfer medium - A fluid used in the transport of thermal energy.

Heating degree days - The number of degrees that the daily mean temperature is below 65 degrees $\mathrm{F}$.

Heating (H) system - The complete assembly of subsystems and components necessary to convert solar energy into thermal energy and use this energy in combination with auxiliary energy, where required, for heating purposes.

Heating and cooling (HC) system - The complete assembly of subsystems and components necessary to convert solar energy into thermal energy and use this energy in combination with auxiliary energy, where required, for combined heating and cooling purposes.

Humidity, relative - The ratio of the actual partial pressure of water vapor present to the pressure of saturated water vapor at the same temperature and barometric pressure.

In-service conditions - The conditions to which a solar $\mathrm{H} / \mathrm{C} / \mathrm{HW}$ system and its components will be exposed during their operational lifetimes.

Load factors - Multipliers by which design loads are increased in order to obtain the loads to be used in ultimate strength design of structural elements.

Maximum "flow" temperature - The maximum temperature that will be obtained in a component when the heat transfer fluid is flowing through the system.

Maximum "no-flow" temperature - The maximum temperature that will be obtained in a component when the heat transfer fluid is not flowing through the system.

Maximum service temperature - The maximum temperature to which a component will be exposed in actual service, either with or without the flow of heat transfer fluid.

Metastable precipitation - The precipitation of solid matter from a solution under conditions where such precipitation is marginally stable.

Minimum service temperature - The minimum temperature to which a component will be exposed in actual service, either with or without the flow of heat transfer fluid.

Outgassing - The process by which materials and components expel gases.

Passive solar energy system - An assembly of collectors, thermal storage device(s) and transfer media which converts solar energy into thermal energy and in which no energy in addition to solar is used to accomplish the transfer of thermal energy. The prime elements in a passive system are usually some form of thermal capacitance and solar energy control.

Pipe friction - Pipe wall roughness or duct wall roughness. Such roughness causes the loss of energy in the form of heat.

Pitting - The process by which localized wear is caused in materials or components by erosion or chemical decomposition. 
Plasticizer migration - The process by which plasticizers used in plastics migrate within the specimen and either concentrate in a narrow boundary area or migrate to another material in connection with the specimen.

Ponding - The retention of water due to deflection of horizontal surfaces.

Potential heat - The difference between the heat of combustion of a representative specimen of material and the heat of combustion of any residue remaining after exposure to a simulated standard fire, determined by combustion calorimetric techniques.

pphm - Parts per hundred million.

Rate of heat release - A method of measuring the relative combustibility of materials by determining the rate at which heat is released by the material, determined by calorimetric techniques.

Residual deflection - The portion of the displacement of an element in a structure which is not recovered after the removal of the action causing that displacement.

Resultant velocity of hail - The velocity resulting from a hailstone falling at its terminal velocity and acted on by a wind force.

Sensors - Devices (such as pressure transducers, thermocouples, flowmeters, etc.) used to sense individual parameters.

Service loads - Loads which are expected during the service life of a structure and upon which the design of the structure is based.

Shading angles - Angles that the sun makes in both elevation and azimuth that cause shadows.

Significant (deterioration, loss, etc.) - Deterioration that either results in a decrease in performance greater than that allowed for in the design or in the creation of a hazard.

Solar degradation - The process by which exposure to sunlight deteriorates the properties of materials and components.

Solar energy - The photon energy originating from the sun's radiation in the wave-length region from 0.3 to 2.7 micrometers.

Solar time - The hours of the day as reckoned by the apparent position of the sun. Solar noon is that instant on any day at which the sun reaches its maximum altitude for that day. Solar time is very rarely the same as local standard time in any locality.

Storage subsystem - The assembly used for storing thermal energy so that it can be used when required.

Subsystem - A major, separable, functional assembly of a system.

Sustained load - A load that is sustained over a period of time.

Tap temperature - The temperature at which potable hot water is discharged from an outlet at the point of use.

Temperature, dry-bulb - The temperature of a gas or mixture of gases indicated by an accurate thermometer after correction for radiation.

Temperature, wet bulb - The temperature at which liquid or solid water, by evaporating into air, can bring the air to saturation adiabatically at the same temperature. 
Terminal velocity of hail - The maximum vertical velocity reached by a hailstone occurring when the drag force on the hailstone is equal to the force exerted by gravity on its mass.

Toxic fluids - Gases or liquids which are poisonous, irritating and/or suffocating, are classified in the Hazardous Substances Act, Part 191, Chapter I, Title 21.

Transmittance - The ratio of the radiant flux transmitted through and emerging from a body to the total flux incident on it.

Ultimate strength design - A method of proportioning structures or members for failure at a specified multiple of working loads, and assuming nonlinear distribution of flexural stresses.

Utility plan - A drawing showing location of electrical lines, gas lines, water, etc.

Vertical penetrations - The-vertical passage of a utility chase, pipe, duct, etc., through a fire-rated structural assembly.

Water hammer - A term used to indicate that destructive forces, exemplified by the pressure surges and attendant pounding noises and vibration which develop in a pipe system when a column of noncompressible liquid flowing through a pipe line at a given pressure and velocity is stopped abruptly.

Water hammer arrester - A manufactured device, other than an air chamber, containing a permanently sealed cushion of gas or air, designed to provide protection against excessive shock pressure without maintenance.

Working stress design - A method of proportioning structures or members for prescribed working loads at stresses well below the ultimate, and assuming linear distribution of flexural stresses.

Zero hardness - A property of softened water such that no calcium or magnesium can be found in it by ordinary analytical methods.

$21 / 2$ percent design summer temperature - The outdoor air temperature will be higher than the stated value not more than 88 hours per year ( $21 / 2 \%$ of the 2,928 hours in June through September).

$971 / 2$ percent winter design temperature - The outdoor air temperature will be lower than the stated values for not more than 65 hours per year $(21 / 2 \%$ of the 2,160 hours in December, January and February). 
ABBREVIATIONs
(Code Groups, Associations, and Gov't. Agencies)

AASHTO

AGA

ANSI

ARI

ASHRAE

ASME

ASTM

ERDA

FM

HUD

NACE

NASA

NBBPVI

NBC of Canada

NBS

NESCA

NEMA

NFPA

OSHA

SAE

SMACNA

UBC

UL
American Association of State Highway and Transportation officials

American Gas Association

American National Standards Institute

Air-Conditioning and Refrigeration Institute

American Society of Heating; Refrigerating, and

Air-Conditioning Engineers

American Society of Mechanical Engineers

American Society for Testing and Materials

Energy Research and Development Administration

Factory Mutual

Department of Housing and Urban Development

National Association of Corrosion Engineers

National Aeronautics and Space Administration

National Board of Boiler and Pressure Vessel Inspectors

National Building Code of Canada

National Bureau of Standards

National Environmental Systems Contractor's Association

National Electrical Manufacturer's Association

National Fire Protection Assoctations

Occupational Safety and Health Administration

Society of Automotive Engineers

Sheet Metal and Air-Conditioning Contractor's National Association

Uniform Building Code

Underwriter's Laboratories, Inc. 
NBS-114A (REV. $7-73$ )

\begin{tabular}{|c|c|c|}
\hline $\begin{array}{l}\text { 1. PUIBLICAATION OR RI:PORT NO. } \\
\text { NBSIR 76-1187 }\end{array}$ & $\begin{array}{l}\text { 2. Gov't Accession } \\
\text { No. }\end{array}$ & 3. Recipient's Accession No. \\
\hline \multirow{2}{*}{\multicolumn{2}{|c|}{$\begin{array}{l}\text { 4. TITLE AND SUBTITLE } \\
\text { Interim Performance Criteria for Solar Heating } \\
\text { and Cooling Systems in Commercial Buildings }\end{array}$}} & $\begin{array}{l}\text { 5. Publication Iatc } \\
\text { November } 1976\end{array}$ \\
\hline & & $\begin{array}{l}\text { 6. Performing Organization Code } \\
465.00\end{array}$ \\
\hline \multicolumn{2}{|c|}{ 7. AUTHOR(S) } & 8. Performing Organ. Report No. \\
\hline \multirow{2}{*}{\multicolumn{2}{|c|}{$\begin{array}{l}\text { 9. PERFORMING ORGANIZATION NAME AND ADDRESS } \\
\text { NATIONAL BUREAU OF STANDARDS } \\
\text { DEPARTMENT OF COMMERCE } \\
\text { WASHINGTON, D.C. } 20234\end{array}$}} & $\begin{array}{l}\text { 10. Project/Task/Work Unit No. } \\
4656505 \text {, Task } 2\end{array}$ \\
\hline & & $\begin{array}{l}\text { 11. Contract/Grant No. } \\
\text { E }(49-1)-3800\end{array}$ \\
\hline \multirow{2}{*}{\multicolumn{2}{|c|}{$\begin{array}{l}\text { 12. Sponsoring Organization Name and Complete Address (Street, City, State, ZIP) } \\
\text { Energy Research and Development Administration } \\
20 \text { Massachusetts Avenue, N.W. } \\
\text { Washington, D.C. } 20545\end{array}$}} & $\begin{array}{l}\text { 13. Type of Report \& Period } \\
\text { Covered } \\
\text { Interim }\end{array}$ \\
\hline & & 14. Sponsoring Agency Code \\
\hline
\end{tabular}

16. ABSTRACT (A 200-word or less factual summary of most significant information. If document includes a significant bibliography or literature survey, mention it here.)

Public Law 93-409, the Solar Heating and Cooling Demonstration Act of 1974, provides for "demonstration within a three-year period of the practical use of solar heating technology, and . . . the development and demonstration within a five-year period of the practical use of combined heating and cooling technology." Under the provisions of the Act, in February 1975, the NASA developed a first edition of this document containing interim performance criteria for the design and evaluation of solar heating and cooling systems to be demonstrated in commercial buildings. Since that time, responsibility for further development of the document has been assumed by the NBS. This second edition of the "commercial criteria" represents the first revision to the NASA document. It is expected that this document will be updated periodically as data and information are gained from the demonstration program.

17. KEY WORDS (six to twelve entries; alphabetical order; capitalize only the first letter of the first key word unless a proper name; separated by semicolons)

Buildings; cooling; heating; hot water; performance criteria; solar energy; standards.

\begin{tabular}{|c|c|c|}
\hline $\begin{array}{l}\text { 18. AVAILABHLITY } \bar{X} \text { Unlimited } \\
\square \neg \text { For Official Distribution. Do Not Release to NTIS }\end{array}$ & $\begin{array}{l}\text { 19. SECURITY CLASS } \\
\text { (THIS REPURT) } \\
\text { UNCL ASSIFIED }\end{array}$ & 21. NO. OF PAGES \\
\hline $\begin{array}{l}{[\text { Order From Sup. of Doc., U.S. Government Printing Office }} \\
\text { Washington, D.C. 20402, SD Cat. No.C.13 }\end{array}$ & $\begin{array}{l}\text { 20. SHCURITY CLASS } \\
\text { (THS PAGE) }\end{array}$ & 22. Price \\
\hline $\begin{array}{l}\text { Order From National Technical Information Service (NTIS) } \\
\text { Springfield, Virginia } 22151\end{array}$ & UNCLASSIFIED & $\$ 5.00$ \\
\hline
\end{tabular}


